\title{
ARetusa Cardoso
}

\section{"Exposição à poluição de origem veicular, exercício físico e efeitos na proteína CC16 e na função renal em adultos jovens"}

Tese apresentada à Faculdade de Medicina da Universidade de São Paulo para obtenção do título de Doutora em Ciências

Programa: Pneumologia

Orientador: Dr. Ubiratan de Paula Santos

SÃO PAULO

2016 
Exposição à poluição de origem veicular, exercício físico e efeitos na proteína $\mathrm{CC16}$ e na função renal em adultos jovens.

Tese apresentada à Faculdade de Medicina da Universidade de São Paulo para obtenção de título de Doutora em Ciências.

Programa de: Pneumologia.

Orientador: Dr. Ubiratan de Paula Santos

São Paulo 
Dados Internacionais de Catalogação na Publicação (CIP)

Preparada pela Biblioteca da

Faculdade de Medicina da Universidade de São Paulo

Creprodução autorizada pelo autor

\section{Cardoso, Aretusa}

Exposição à poluição de origem veicular, exercício físico e efeitos na proteína CC16 e na função renal em adultos jovens / Aretusa Cardoso. -- São Paulo, 2016.

Tese(doutorado)--Faculdade de Medicina da Universidade de São Paulo. Programa de Pneumologia.

Orientador: Ubiratan de Paula dos Santos.

Descritores: 1.Exercício 2.Poluição do ar 3.Material particulado 4.Proteina CC16 5.Função renal 6.KIM-1 7.Ngal 8.Marcadores inflamatórios sistêmicos

USP/FM/DBD-418/16 
Projeto: Exposição à poluição de origem veicular, exercício físico e efeitos na proteína CC16 e na função renal em adultos jovens.

Aluna: Aretusa Cardoso no USP: 6014330

Orientador: Dr. Ubiratan de Paula Santos

Comissão Científica InCor: 3847/12/103 (SDC)

№ FAPESP: 2012/23141-6

Colaboração

- Lab. de Toxicologia Forense do Dep. de Medicina Legal da FMUSP.

- LIM 3 e DLC-HCFMUSP.

- Laboratório de Pleura - Pneumologia Incor.

- Departamento de Otorrinolaringologia da EPM/UNIFESP.

- Laboratório de Poluição Atmosférica Experimental - Departamento de Patologia da FMUSP. 


\section{DEDICATÓRIA}

Em memória daquele que tudo fez para que isso fosse possível, dono do sorriso mais sincero, da alma mais pura, pai daquele que é meu melhor amigo e companheiro, grande provedor e exemplo de minha família, meu avô, Anibal Cardoso. 


\section{AGRADECIMENTOS}

Agradeço a meus pais Ailton e Magali pela vida dedicada aos filhos, por serem responsáveis diretos pelo meu constante evoluir pessoal e profissional. Por todo o sacrifício, por todos os acertos e erros que nos tornaram o que somos: uma família incrível! Por terem me dado à vida e feito de mim uma pessoa íntegra e responsável desde sempre.

A meus irmãos Aline e Ícaro, os melhores companheiros de infância e de vida. Agradeço pelo apoio e compreensão nos meus muitos momentos de ausência. Vocês são e serão, eternamente, meus pequenos irmãos e minha motivação para ser um bom exemplo. Vocês são o que terei no futuro: a certeza de que nunca vou estar sozinha.

A minha avó Marli pelo amor incondicional, colo e incentivo em todos os momentos.

A aquela que é responsável pelo meu melhor sorriso, e é a tradução do que é o amor em nossas vidas, minha pequena Isis.

Ao meu orientador, Ubiratan de Paula Santos pela paciência e conhecimentos compartilhados durante essa jornada e parceria.

Ao professor Paulo Hilário Nascimento Saldiva pelo incentivo inicial, palavras de entusiasmo e motivação no começo de tudo.

Ao Dr. Mario Terra Filho pela ajuda essencial na conclusão deste trabalho. 
À aquela que, de secretária se tornou amiga de todas as horas e que estará para sempre na minha vida, Alessandra Torquato, meu imenso obrigada por tudo! Por todas as conversas, risadas, ajuda e principalmente, amizade e lealdade em todos os momentos.

Ao companheiro de coletas, dia-a-dia, de trabalho e de vida, Renato Batista Paceli, meu muito obrigada.

Aos colegas de trabalho que são (e sempre serão!) os amigos feitos nessa jornada e que trouxeram leveza e alegria nesse período: André Luiz, Lusinete, Luciana Vitale, Jéssica, Juliana Puka e Solange. As coisas teriam sido muito mais difíceis sem vocês!

Aos amigos e companheiros de coleta e vida na minha incrível jornada dentro do Centro de Preparação de Oficiais da Reserva do Exército Brasileiro, Capitão Matheus Cavalcante Sá, Soldado Rafael Machado (R Machado!), ao doce e amigo enfermeiro Cícero, e ao amigo e incentivador, Tenente Fernando Passarelli.

A aquela que, de parceira nas análises virou amiga, Lia Junqueira Marçal. Sem você e a querida Alcione esse trabalho não teria sido viável.

Aos amigos de vida (são muitos, por sorte!) que acreditaram em mim e foram minha razão para insistir e fazer o meu melhor. Agradeço em especial aos que, nos meus piores momentos, foram ombro, torcida e apoio fundamental para que eu não desistisse: Dennysson Maicon Peressin Mazzini (cuja ajuda na reta final foi importantíssima), Priscila Cristina João, Bianca Tenório, Josiane Abrantes, Jean Cleiton Fonseca, Vitor Augusto Urashima, Fábio Calegari, Alessandro 
Menezes, Rafael Moura, Elizangela Peixoto Fernandes. Aos queridos Enderson Marinho Ribeiro e Rodrigo Jundi Maenoçono (in memorian), minha saudade e agradecimento por toda torcida e apoio até nossos últimos momentos juntos por aqui.

Aos que foram inspiração, da primeira Graduação até o momento, professores e amigos queridos, inspiração acadêmica e pessoal: Amouni Mohmoud Mourad, Roberto Rodrigues Ribeiro, Paulo Roberto Santos-Silva, José Carlos Petorossi Imparato, Marcelo Cecchetti.

À Dra. Dirce Trevisan Zanetta pelo apoio e fundamental ajuda no tratamento estatístico dos dados.

À professora Naomi Kondo Nakagawa por organizar e viabilizar a construção desse enorme e incrível projeto.

À professora Vilma Leyton e à querida Ana Cristina Mielli pela ajuda fundamental nas análises iniciais e pela recepção no Lab. de Toxicologia Forense do Departamento de Medicina Legal da FMUSP.

E finalmente, agradeço à Faculdade de Medicina da Universidade de São Paulo por ser minha casa desde 2002. Eu não poderia ter sido abraçada por uma instituição melhor, e não poderia ter caminhado desde a Especialização em solo mais fértil. Agradeço também ao Instituto do Coração (Incor) por ter sido o berço e provedor desse projeto que mudou minha vida em todos os sentidos. 
"Não importa o quanto a vida possa ser ruim, sempre existe algo que você pode fazer e triunfar.

Enquanto há vida, há esperança" 
Esta tese está de acordo com:

Referência: adaptado de International Committee of Medical Journals Editors (Vancouver).

Universidade de São Paulo. Faculdade de Medicina. Serviço de Biblioteca e Documentação. Guia de apresentação de dissertações, teses e monografias. Elaborado por Annelise Carneiro da Cunha, Maria Julia de A. L. Freddi, Maria F. Crestana, Marinalva de Souza Aragão, Suely Campos Cardoso, Valéria Vilhena. 2ํㅡ. Ed. São Paulo: Serviço de Biblioteca e documentação; 2005.

Abreviatura dos títulos dos periódicos: de acordo com Listo f Journals Indexed in Index Medicus. 


\section{SUMÁRIO}

Lista de Siglas

Lista de Abreviaturas e Símbolos

Lista de Figuras

Lista de Tabelas

Lista de Gráficos

Resumo

Abstract

O que sabemos

O que queremos saber

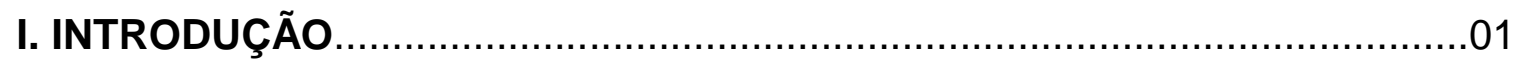

I.1 - Poluição do ar............................................................... 01

I.1.2 - Tipos e Fontes de Poluentes........................................01

I.1.3 - Efeitos da Exposição à Poluição do ar...............................03

I.2 - O papel da atividade física................................................04

I.3 - Poluição e Exercício..............................................................05

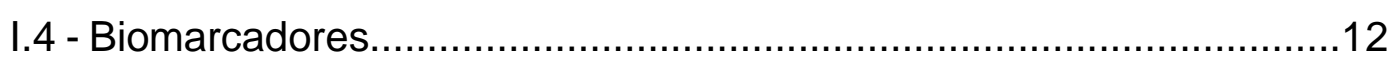

I.4.1 - Marcadores sanguíneos............................................12

I.4.2 - Marcador de Toxicidade Pulmonar - Proteína CC16............12

I.4.3 - Marcadores de Função Renal........................................15

I.4.3.a - Cistatina C......................................................15

I.4.3.b - Microalbuminúria.............................................16

I.4.3.C - Ngal......................................................... 16

I.4.3.d - KIM-1 ....................................................... 17

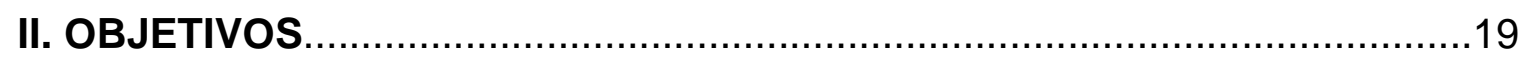

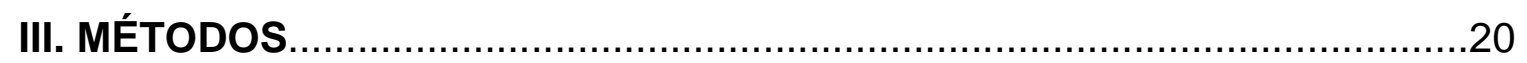

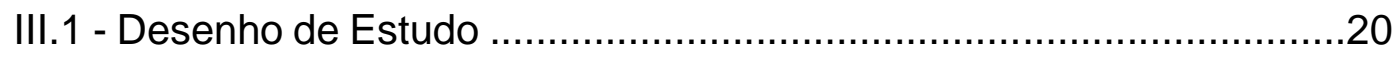

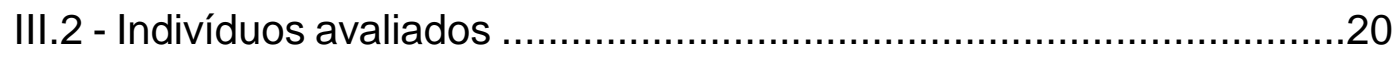

III.3 - Protocolo do Estudo .......................................................

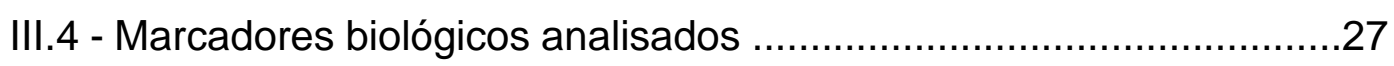


III.4.1 - Marcadores sanguíneos

III.4.1.a - Dosagem de carboxihemoglobina........................27

III.4.1.b - Análises bioquímicas e hematológicas..................27

III.4.2 - Marcador de Toxicidade Pulmonar.....................................28

III.4.3 - Marcadores de Função Renal.............................................28

III.4.3.a - Microalbuminúria...............................................28

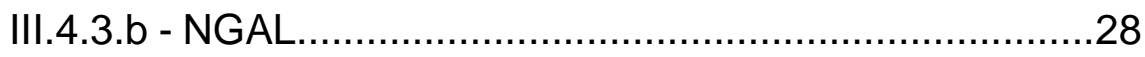

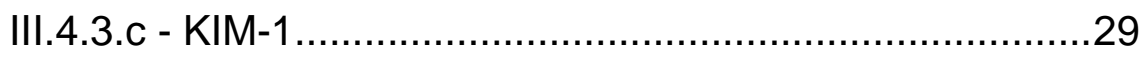

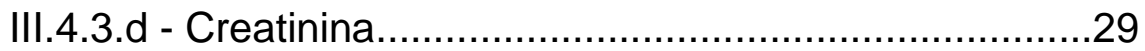

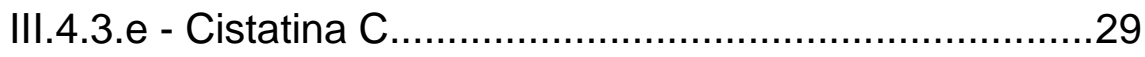

III.4.4 - Estimativas da função renal............................................29

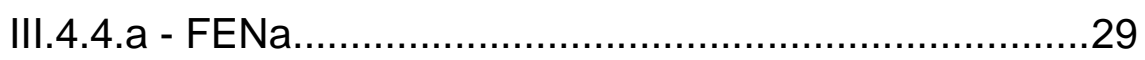

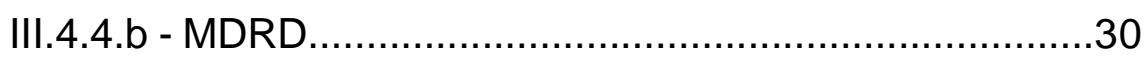

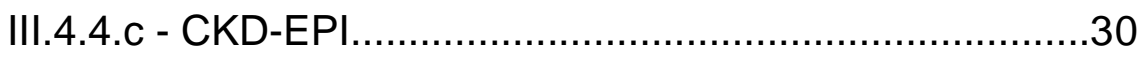

III.5 - Medidas de poluentes e de variáveis climáticas...............................31

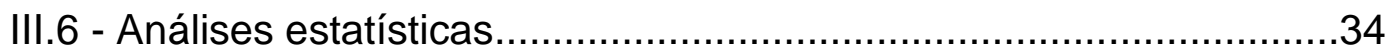

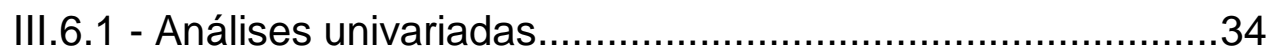

III.6.2 - Análises de regressão linear..............................................34

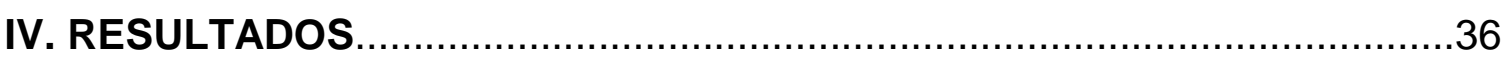

IV.1 - Resultados das variáveis ambientais e antropométricas...................36

IV.2 - Resultados dos marcadores sanguíneos nos circuitos......................38

IV.3 - Resultados da análise da Proteína CC16 nos circuitos......................44

IV.4 - Resultados dos marcadores de Função Renal nos circuitos..............47

V. DISCUSSÃO

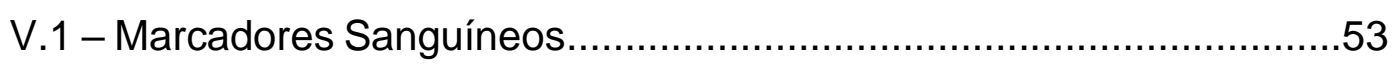

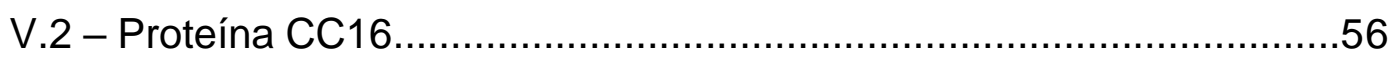

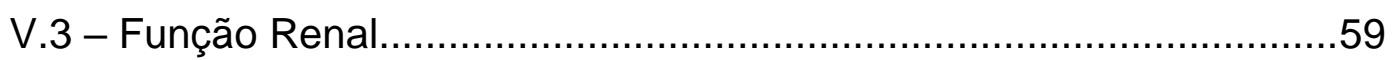

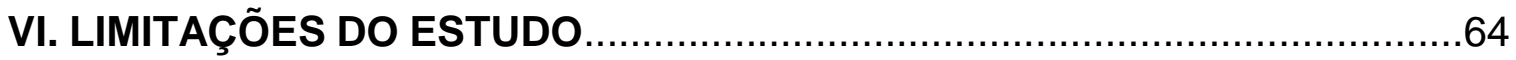

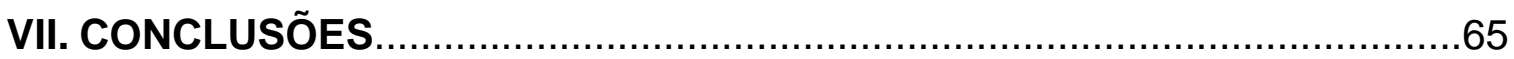

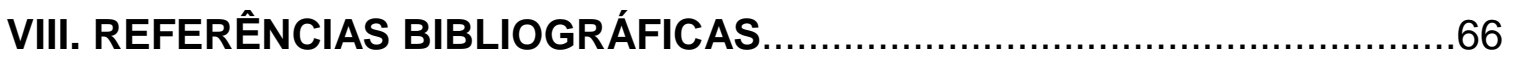

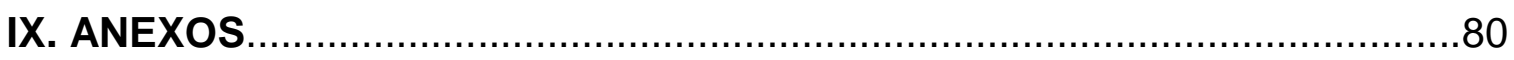




\section{Lista de Siglas}

BIE: Broncoconstrição induzida pelo exercício

CAPPesq: Comissão de Ética para Análise de Projetos de Pesquisa

CC16: Proteína secretada pelas células Clara pulmonares

CO: Monóxido de Carbono

$\mathrm{CO}_{2}$ : Dióxido de Carbono

COex: Monóxido de Carbono no ar exalado

$\mathrm{COHb}$ : Carboxihemoglobina

CKD-epi: Chronic Kidney Disease Epidemiology Collaboration

CPOR: Centro de Preparação de Oficiais da Reserva

CPK: Creatina fosfoquinase

DALYs: Disability Adjusted Life Years

DHL: Desidrogenase Lática

DNA: Ácido desoxirribonucleico

DP: Desvio Padrão

DPOC: Doença pulmonar obstrutiva crônica

FENa: Fração de excreção de sódio

FC: Frequência cardíaca

FR: Frequência respiratória

HC-FMUSP: Hospital das Clínicas da Faculdade de Medicina da Universidade de

São Paulo

IAM: Infarto Agudo do Miocárdio

IMC: Índice de massa corporal 
IIQ: Intervalo interquartil

KIM-1: Kidney Injury Molecule-1

MDRD: Modification of Diet in Renal Disease

MET: Equivalente Metabólico

Ngal: Neutrophil gelatinase-associated lipocalin

OMS: Organização Mundial da Saúde

PA: Pressão Arterial

PM: Particulate Matter (Material Particulado)

$P Q:$ Parque

$\mathrm{SpO}_{2}$ : Saturação periférica de oxigênio

TCLE: Termo de Consentimento Livre Esclarecido

TFG: Taxa de Filtração Glomerular

TTPA: Tempo de Tromboplastina Parcial Ativada

URar: Umidade Relativa do $\mathrm{Ar}$

VEF1: Volume expiratório forçado no primeiro segundo

$\mathrm{VO}_{2 m a x}$ : Consumo Máximo de Oxigênio

VP: Vias Públicas 


\section{Lista de Abreviaturas e Símbolos}

bpm: batimentos por minuto

d: decilitro

g: grama

g/L: gramas por litro

g/dL: gramas por decilitro

INR: razão normalizada internacional

$\mathrm{kg}$ : quilograma

$\mathrm{kg} / \mathrm{m}^{2}$ : quilo por metro quadrado

km: quilômetro

km/h: quilômetro por hora

$\mathrm{L}$ : litros

L/min: litros por minuto

m: metros

mcg: microgramas

$\mathrm{mEq} / \mathrm{d}$ : Miliequivalente por decilitro

$\mathrm{mEq} / \mathrm{L}$ : Miliequivalente por litro

mg: miligrama

$\mathrm{mil} / \mathrm{mm}^{3}$ : Mil por milímetro cúbico

milhões/mm³: Milhões por milímetro cúbico

min: minutos

$\mathrm{mL}$ : mililitros

$\mathrm{mL} / \mathrm{bat} / \mathrm{min}$ : mililitros por batimento por minuto 
$\mathrm{mL} / \mathrm{kg} / \mathrm{min}$ : mililitros por quilo por minuto

$\mathrm{mL} / \mathrm{min}$ : mililitros por minuto

$\mathrm{mL} / \mathrm{min} / 1,73 \mathrm{~m}^{2}$ : mililitros por minuto por área de 1,73 metros quadrados

mm: milímetros

mmHg: milímetros de mercúrio

$\mathrm{ng} / \mathrm{ml}$ : nanogramas por mililitro

$\mathrm{Ng} / \mathrm{g}$ : nanogramas por grama

ppm: partes por milhão

$\mathrm{U} / \mathrm{L}$ : Unidades por litro

ug/l: micrograma por litro

$\%:$ porcentagem

ㄷ: Graus Celsius

$\mu \mathrm{m}$ : micrômetro

$\mu \mathrm{g} / \mathrm{m}^{3}:$ micrograma por metro cúbico

>: maior

$<:$ menor

\pm : mais ou menos 


\section{Lista de Figuras}

Figura 1 - Tamanhos, fontes e composição do Material Particulado e poluição do $\operatorname{ar}$

Figura 2 - \% de DALYs para diversos fatores de risco......................................

Figura 3 - Incidência de doenças relacionadas à inatividade física....................05

Figura 4 - Taxa de Filtração Glomerular média da população avaliada e distância da Rodovia principal.

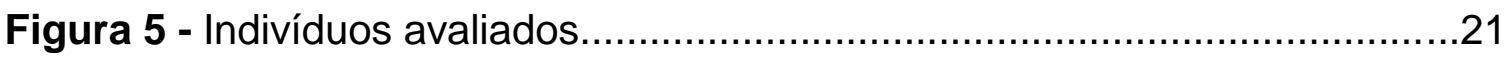

Figura 6 - Sistema de avaliação durante o período de estudo. .22

Figura 7 - Pista de corrida dentro do Parque do Horto Florestal, a 1010 metros de altitude (Circuito PQ).

Figura 8 - Pista de corrida de rua, a 720 metros de altitude (Circuito VP)............23

Figura 9 - Foto de satélite mostrando os dois circuitos (PQ e VP). .24

Figura 10 - Cidade de São Paulo vista do ponto mais alto do Parque do Horto Florestal. .25

Figura 11 - Vista aproximada da imagem 11, evidenciando a poluição do ar sobre a cidade .25

Figura 12 - Monitor de massa de aerossóis por espectrofotometria, MP DUSTTRAK Aerossol Monitor. 32

Figura 13 - Termo higrômetro Data Logger DHT .32

Figura 14 - Monitor MP DUSTTRAK, em detalhe, na mochila que era levada pelo líder da equipe de corrida de cada um dos grupos .33 


\section{Lista de Tabelas}

Tabela 1 - Concentração de Material Particulado, Temperatura e Umidade Relativa do Ar durante o período de estudo .36

Tabela 2 - Características dos indivíduos avaliados, dados basais, précorrida. .37

Tabela 3 - Resultado dos marcadores sanguíneos (Circuito em Parque), Pré e Pós-corrida às segundas-feiras $(\mathrm{N}=39)$ .38

Tabela 4 - Resultado dos marcadores sanguíneos (Circuito em Parque), Pré e Pós-corrida às sextas-feiras $(\mathrm{N}=34)$ .39

Tabela 5 - Resultado dos marcadores sanguíneos (Circuito Vias Públicas), Pré e Pós-corrida às segundas-feiras $(\mathrm{N}=39)$ .40

Tabela 6 - Resultado dos marcadores sanguíneos (Circuito Vias Públicas), Pré e Pós-corrida às sextas-feiras $(N=34)$

Tabela 7 - Efeito da realização de exercício e do local em marcadores sanguíneos. Modelo de regressão linear com efeito misto $(\mathrm{N}=39)$

Tabela 8 - Resultado das análises da proteína CC16 corrigida pela creatinina urinária $(\mu \mathrm{g} / \mathrm{g})(\mathrm{N}=39)$ .44

Tabela 9 - Avaliação do efeito* da realização de exercício e do local (Parque x Via Pública) no marcador pulmonar- proteína CC16 corrigida pela creatinina urinária $(\mathrm{N}=39)$ .45

Tabela 10 - Resultado dos marcadores renais (Circuito Parque), Pré e Pós-corrida às segundas-feiras $(\mathrm{N}=39)$

Tabela 11 - Resultado dos marcadores renais (Circuito Parque), Pré e Pós-corrida às sextas-feiras $(\mathrm{N}=34)$ 
Tabela 12 - Resultado dos marcadores renais (Circuito Via Pública), Pré e Póscorrida às segundas-feiras $(\mathrm{N}=39)$ .49 Tabela 13 - Resultado dos marcadores renais (Circuito Via Pública), Pré e Póscorrida às sextas-feiras $(\mathrm{N}=34)$ .50 Tabela 14 - Efeito* da realização de exercício e em diferentes ambientes (Parque x Via Pública) em marcadores da função renal .52 


\section{Lista de Gráficos}

Gráfico 1 - Gráfico de perfil individual e perfil do grupo no aumento da proteína CC16 corrigida pela Creatinina nos indivíduos em ambos os circuitos..................46 Gráfico 2 - Box plot dos valores da proteína CC16 corrigida pela creatinina antes e após a corrida nos circuitos .46 


\section{RESUMO}

Cardoso A. Exposição à poluição de origem veicular, exercício físico e efeitos na proteína CC16 e na função renal em adultos jovens. [Tese]. São Paulo: Faculdade de Medicina, Universidade de São Paulo; 2016.

Introdução: A Poluição do ar e a inatividade física são dois importantes fatores de risco para saúde. Ainda não são bem conhecidos o balanço sobre os efeitos na saúde da realização de exercícios em ambientes poluídos. Objetivos: Avaliar o impacto da realização de exercício físico em ambientes com diferentes concentrações de poluentes sobre a toxicidade pulmonar, em marcadores sanguíneos e na função renal. Métodos: 40 soldados do exército brasileiro, nãofumantes, saudáveis, do sexo masculino e praticantes de corrida de rua regulares foram avaliados. Participaram de corridas de $7,5 \mathrm{~km}$ todas as manhãs, a uma velocidade de $10 \mathrm{~km} / \mathrm{h}$, por uma semana em um circuito dentro de um Parque Florestal (PQ) e uma semana em um circuito em Vias Públicas (VP). Foram coletadas amostras de sangue e urina antes e depois da corrida em dois dias de cada semana, sendo determinados marcadores sanguíneos, de toxicidade pulmonar e da função renal. Os níveis de $\mathrm{MP}_{2,5}$ foram registrados durante todos os dias das semanas no período em que foram feitas as avaliações. Resultados: A concentração de $\mathrm{MP}_{2,5}$ no circuito $\mathrm{PQ}$ foi de $24 \mu \mathrm{g} / \mathrm{m}^{3}$ (IQR: 8-39) e no circuito VP de $62 \mu \mathrm{g} / \mathrm{m}^{3}$ (IQR: 37-103), $\mathrm{P}<0,001$. Trinta e nove participantes concluíram. Idade: $19 \pm 1$ anos, Índice de Massa Corpórea: $23,5 \pm 2,38 \mathrm{~kg} / \mathrm{m}^{2}$, Frequência

cardíaca repouso: 69,1 \pm 10,4bpm. A concentração de proteína CC16 urinária aumentou após as corridas em ambos circuitos, mas de forma mais acentuada no 
circuito PQ. Marcadores sanguíneos e de função renal se alteraram após a corrida, sem diferenças significativas entre os circuitos. Conclusão: A realização de atividade física esteve relacionada à inflamação sistêmica e alteração da função renal, sem diferença entre os circuitos em diferentes ambientes. A proteína CC16, marcador de toxicidade e alteração de permeabilidade pulmonar foi o único que se elevou, com maior magnitude, no circuito localizado no interior de um parque.

Descritores: exercício; poluição do ar; material particulado; Proteína CC16, função renal, KIM-1, Ngal, marcadores inflamatórios sistêmicos. 


\section{ABSTRACT}

Cardoso A. Exposure to air pollution of vehicular origin, physical exercise and effects on CC16 protein and renal function in young adults. [Thesis]. São Paulo: Faculdade de Medicina, Universidade de São Paulo; 2016.

Introduction: The Air pollution and physical inactivity are two important risk factors for health. The assessment of the health effects of exercising in polluted environments are still not well known. To assess the impact of performing physical exercise in environments with different concentrations of pollutants on lung toxicity in blood markers and renal function. Methods: 40 soldiers from the Brazilian army, non-smoking, healthy male and regular street runners were evaluated. Participated in races of $7.5 \mathrm{~km}$ every morning at a speed of $10 \mathrm{~km} / \mathrm{h}$, for a week in a circuit within a Forest Park (PK) and a week in a circuit in Public Ways (PS). Blood and urine samples were collected before and after running over two days each week, with certain blood markers, pulmonary toxicity and renal function. The levels of PM2.5 were recorded during every day of the week in the period they were made evaluations. Results: The concentration of the PM2.5 circuit PK was $24 \mu \mathrm{g} / \mathrm{m}^{3}$ (IQR: 8-39) and PS circuit $62 \mu \mathrm{g} / \mathrm{m}^{3}$ (IQR: 37-103), $\mathrm{P}<0.001$. Thirty-nine participants completed. Age: $19 \pm 1$ years, body mass index: $23.5 \pm 2.38 \mathrm{~kg} / \mathrm{m}^{2}$, resting heart rate: $69.1 \pm 10.4 \mathrm{bpm}$. The concentration of urinary protein CC16 increased after the races on both circuits, but more sharply in the PK circuit. Blood markers and markers of renal function are altered after the run, with no significant differences between the circuits. Conclusion: Physical activity was related to the variation of the markers indicating inflammation and changes in renal function, with no 
difference between the environments except for the marker of pulmonary toxicity that increased with greater magnitude in the PK circuit.

Descriptors: exercise, air pollution, particulate matter, CC16 protein, renal function, KIM-1, Ngal, systemic inflammatory markers. 


\section{O que sabemos}

A exposição à poluição do ar está associada a efeitos cardiovasculares, respiratórios, metabólicos e à maior risco de câncer de pulmão, sendo um dos principais fatores de risco de óbitos global conhecidos.

Fazer exercícios físicos regularmente melhora a sobrevida e reduz ricos de morbimortalidade. A realização do exercício desencadeia a produção de uma série de mediadores químicos que diminuem a inflamação sistêmica e a produção de substâncias oxidativas que agridem os tecidos e o DNA.

Fazer exercícios físicos em ambientes poluídos, pelo aumento da ventilação-minuto, implica em uma maior carga inalada de poluentes.

Pessoas com comorbidades crônicas cardiovasculares, respiratórias e metabólicas, ao se exercitarem em ambientes poluídos, tem maior risco de exacerbação ou agravamento destas doenças. Indivíduos hígidos que realizam exercícios regularmente, mesmo em ambientes poluídos, parecem se beneficiar do efeito protetivo do exercício com relação aos efeitos adversos da exposição à poluição do ar, mas os estudos ainda não são conclusivos.

Por outro lado, são escassos e pouco conhecidos os efeitos combinados do exercício físico e da poluição do ar sobre o sistema renal, motivo de maior preocupação em anos recentes, com a epidemia de insuficiência renal em trabalhadores cortadores de cana-de-açúcar, em diversos países da América Central, que no trabalho realizam exercícios físicos em sobrecarga física e térmica e se expõem à risco de inalação de poluentes. 


\section{0 que queremos saber}

Se existe diferença em marcador de toxicidade pulmonar, em marcadores sanguíneos e na função renal de indivíduos hígidos associados à realização de exercício físico em ambientes com diferentes concentrações de poluente $\left(\mathrm{MP}_{2,5}\right)$. 
"Existem muitas hipóteses em ciência que estão erradas. Isso é perfeitamente aceitável. Elas são a abertura para achar as que estão certas."

Carl Sagan 


\section{INTRODUÇÃO}

\section{I.1 - Poluição do ar}

A poluição do ar é um tema que vem ganhando crescente destaque na literatura científica, com estudos demonstrando-a como um dos principais riscos globais para a saúde. A exposição aguda ou crônica à poluição tem um relevante impacto sobre a saúde, sendo um importante fator de risco de mortalidade (1-3).

Cerca de 3,7 milhões de óbitos estão associados aos efeitos da poluição do ar por exposição ao material particulado (MP). Do total de óbitos estimados, cerca de $40 \%$ foram em decorrência de doença cardíaca isquêmica, $40 \%$ por doença cerebrovascular, $11 \%$ por doença pulmonar obstrutiva crônica (DPOC), 6\% para o câncer do pulmão, e 3\% atribuídas a infecções do trato respiratório inferior (4).

\section{I.1.2 - Tipos e Fontes de Poluentes}

A queima de combustíveis ou de biomassa são as principais fontes emissoras de poluentes do ar. Os principais poluentes emitidos são o material particulado (MP), monóxido de carbono (CO), dióxido de enxofre $\left(\mathrm{SO}_{2}\right)$, óxidos nitrosos (NO) e compostos orgânicos voláteis (5). Por reação fotoquímica induzida pelas radiações ultravioletas do sol, compostos orgânicos voláteis e óxidos nitrosos dão origem ao ozônio. Estes poluentes exercem efeitos sobre a saúde, diretamente, enquanto os gases de efeito estufa exercem seus efeitos em grande parte através da mudança do clima (6). 


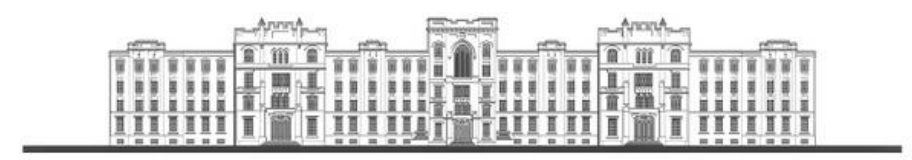

O MP é uma mistura de partículas sólidas e líquidas em suspensão, de variados diâmetros aerodinâmicos, sendo de maior interesse as partículas menores do que $10 \mu \mathrm{m}$, pois ao serem inaladas (principalmente as menores do que $2,5 \mu \mathrm{m}$ ) atingem as vias aéreas terminais (5). Na Figura 1 podemos visualizar as dimensões comparativas entre as partículas.

As principais fontes geradoras de MP têm origem na queima de combustíveis por veículos automotivos, em processos industriais, na queima de biomassa e na ressuspensão de partículas do solo. O MP pode também ser formado secundariamente na atmosfera, a partir de reações de gases, como o dióxido de enxofre $\left(\mathrm{SO}_{2}\right)$ e óxidos de nitrogênio $\left(\mathrm{NO}_{x}\right)$, que são emitidos principalmente em atividades de combustão (7). O MP tem um núcleo de carbono com várias substâncias adsorvidas, motivo pelo qual seus efeitos tendem a ser mais variados e tóxicos do que os poluentes gasosos (8).
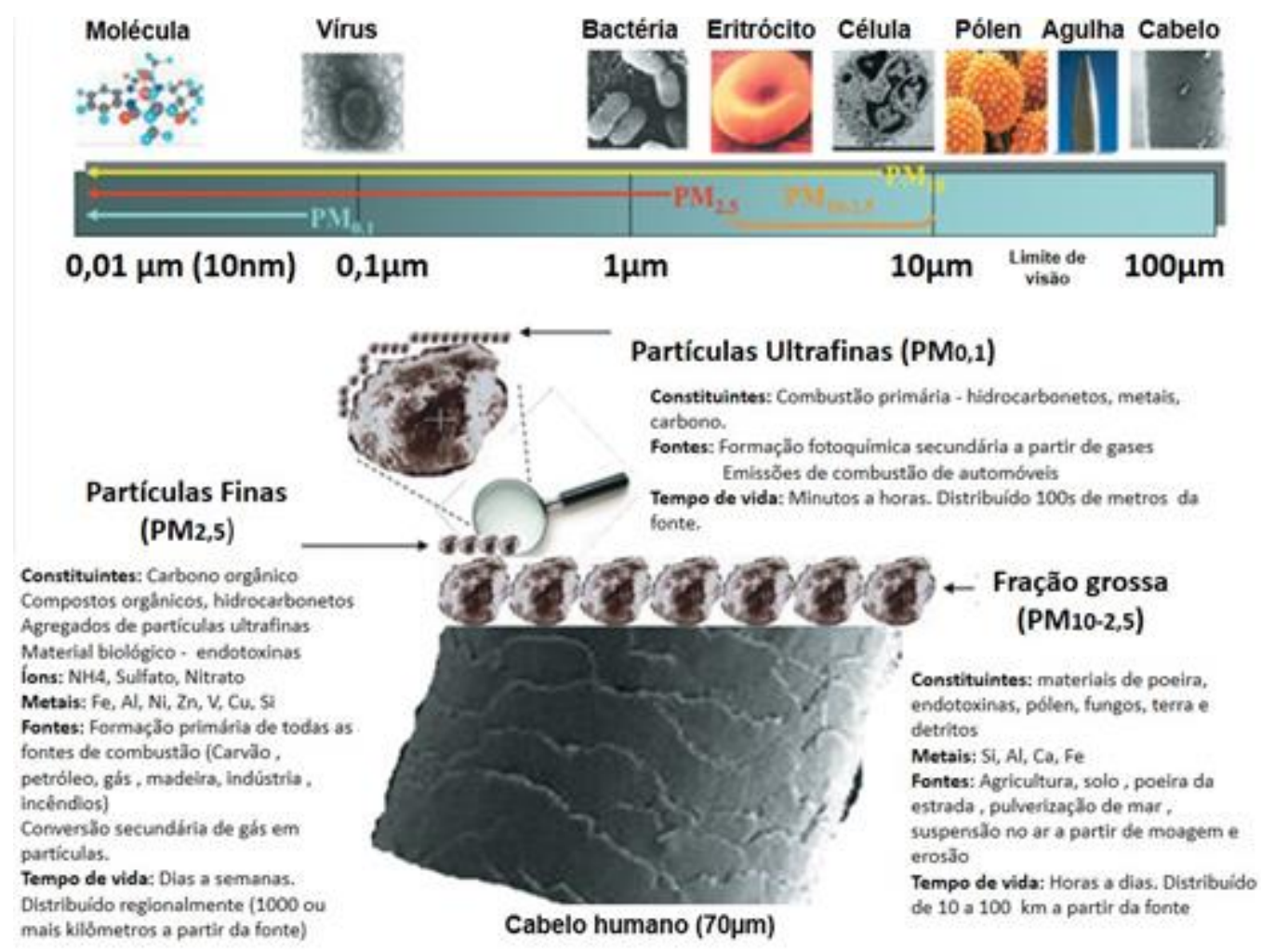

Figura 1 - Tamanhos, fontes e composição do Material Particulado e poluição do ar (Adaptado de Brook RD, Clinical Science 2008; 115:175-8). 


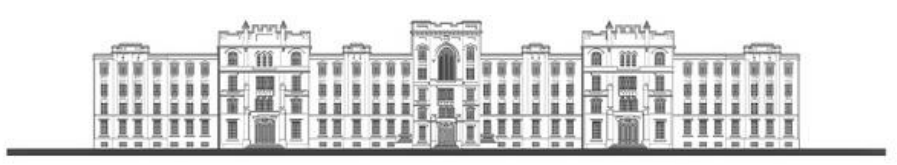

O tamanho das partículas está diretamente associado ao seu potencial nocivo para causar problemas à saúde. Diversos estudos sugerem que, quanto menores, mais nocivas essas partículas e maiores são os efeitos decorrentes da inalação das mesmas (9-12). Abaixo as medidas para cada tipo de partícula de MP:

$$
\mathrm{MP}_{10}=<10 \mu \mathrm{m}, \mathrm{MP}_{2,5}=<2,5 \mu \mathrm{m}, \mathrm{MP}_{1}=<1 \mu \mathrm{m}, \mathrm{e} \mathrm{MP}_{0,1}=<1 \mu \mathrm{m}
$$

\section{l.1.3 - Efeitos da Exposição a Poluição do ar}

Inúmeros estudos têm comprovado a relação entre a poluição do ar e a exacerbação e aumento da incidência de doenças, especialmente as cardiopulmonares (13-17). A poluição do ar está associada à efeitos agudos e crônicos da exposição. Os efeitos agudos ocorrem horas ou dias após a exposição, enquanto que os efeitos crônicos aparecem de meses a anos após a exposição.

Diversos estudos revelam que a exposição à poluição do ar está associada com a elevação das taxas de internação por doenças respiratórias (14, 17-20).

Estudo realizado na cidade de São Paulo (17) encontrou associação entre aumento nos níveis de poluentes $\left(\mathrm{MP}_{10}, \mathrm{SO}_{2}\right.$ e $\left.\mathrm{CO}\right)$ e aumento do número de admissões hospitalares de pacientes com DPOC, e que mulheres parecem ser mais susceptíveis a elevações dos níveis de CO.

Estudos sugerem que os efeitos da poluição decorrem de estresse oxidativo e inflamação pulmonar e sistêmica, ambos induzidos pelos poluentes, em particular pelo material particulado $(1-3,7,21)$. 


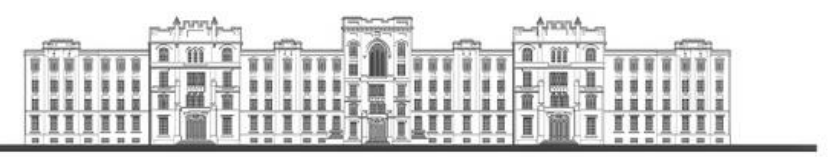

\section{I.2 - O papel da atividade física}

Ao lado da poluição do ar, a baixa atividade ou a inatividade física é outro importante fator de risco para morbimortalidade global (22). Dados globais estimaram para 2010, que aproximadamente três milhões de óbitos e cerca de $3,2 \%$ do total de DALYs (Disability-adjusted life-years) sejam atribuídos à baixa atividade ou à inatividade física (22) (Figura 2).

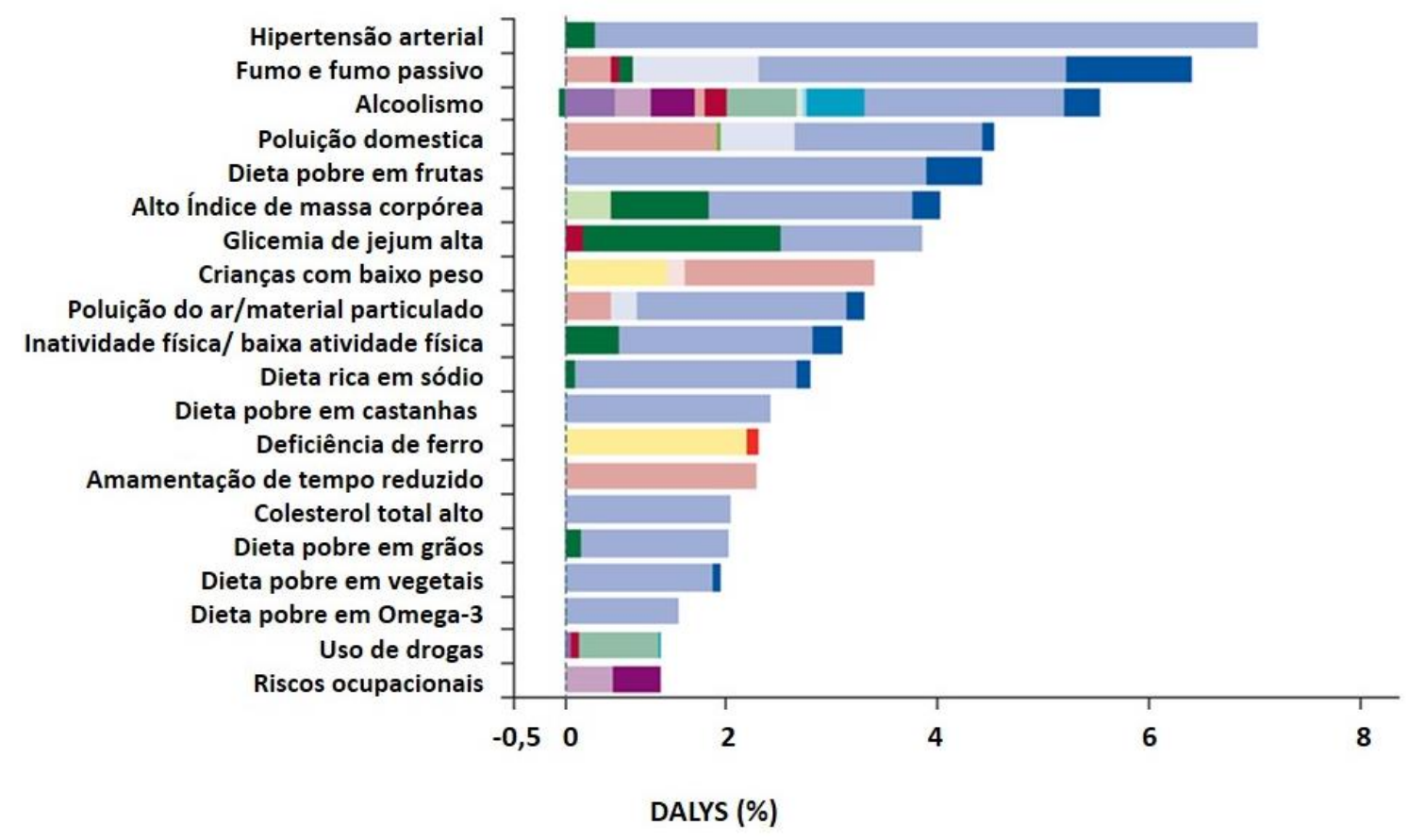

Figura 2 - \% de DALYs (soma dos anos vividos com incapacidade + anos de vida perdidos, vividos a menos da expectativa de vida para cada população)

Por outro lado, fazer exercícios regularmente está associado ao aumento da sobrevida. Segundo Handschin (23), (Figura 3) inatividade e obesidade são fatores de risco independentes na etiologia de doenças crônicas e determinam a incidência de doença e de mortalidade com maior precocidade. Fazer exercícios físicos regularmente diminui a inflamação sistêmica e a produção de 
substâncias oxidativas agressoras dos tecidos corporais e do DNA, diminuindo assim a incidência de doenças crônicas $(23,24)$.

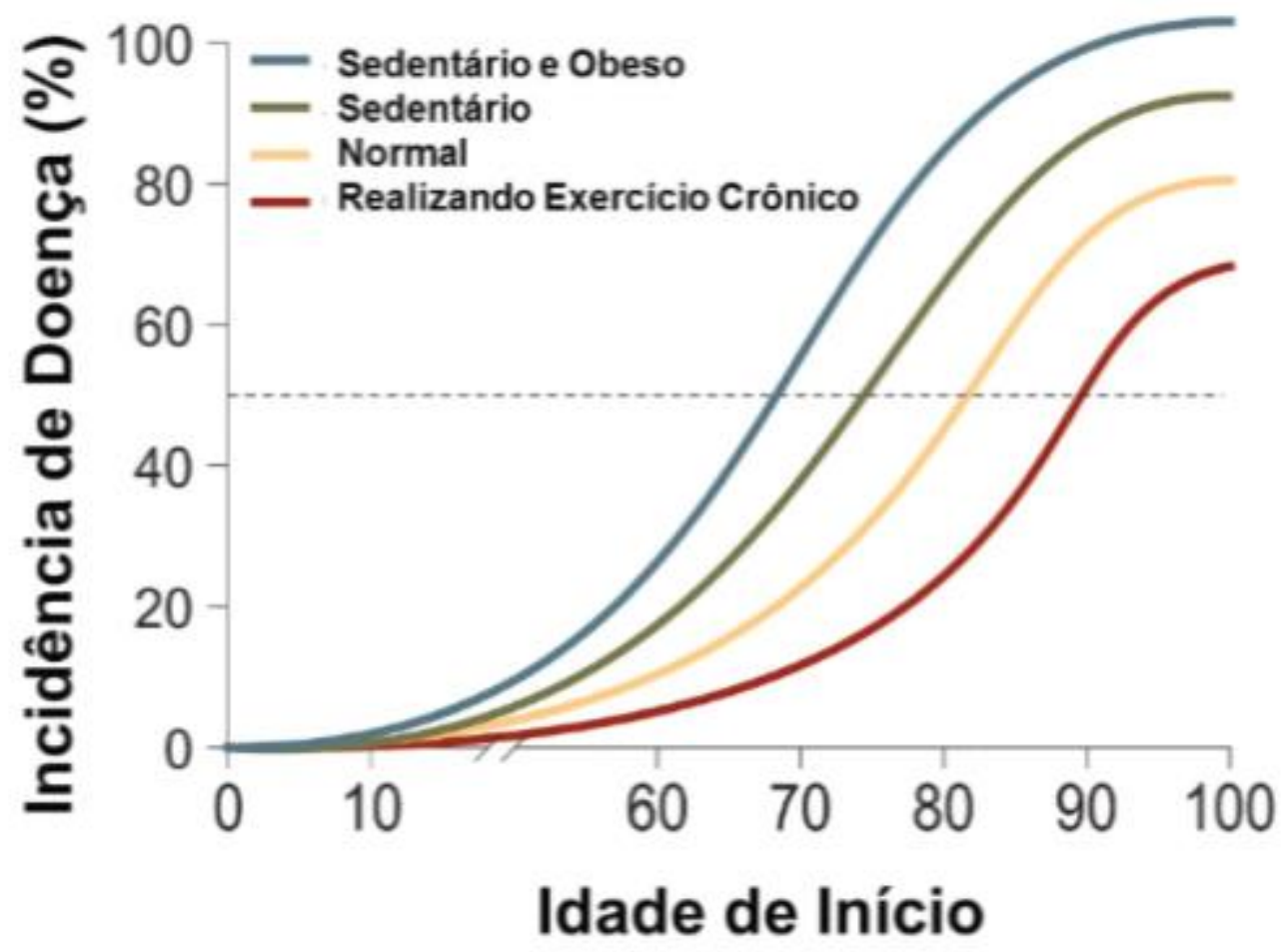

Figura 3 - Inatividade, obesidade e exercício físico influenciam na incidência de doenças crônicas (Adaptado de Handschin C, Nature. 2008) 


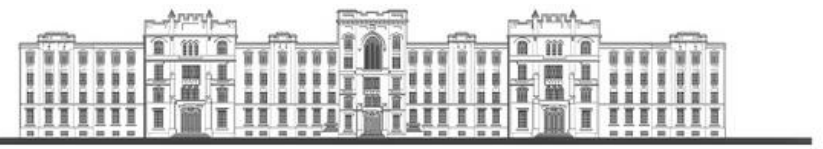

\section{I.3 - Poluição e Exercício}

Vários estudos têm abordado a relação entre exercício físico e poluição do ar, e possíveis efeitos em diversos órgãos e sistemas (8, 9, 25). O exercício físico realizado em ambientes com altos níveis de poluentes, particularmente em indivíduos com comorbidades, está associado com efeitos deletérios sobre o sistema cardiorrespiratório $(9,10,21,26)$.

Em indivíduos saudáveis, o impacto do exercício realizado em ambientes poluídos, como ocorre em muitas cidades médias e grandes, não está bem estabelecido $(26,27)$, mas os dados existentes sugerem que o exercício regular proporciona um efeito protetivo que supera o impacto negativo da inalação de maior quantidade de poluentes durante a atividade, devido ao aumento da ventilação-minuto durante o exercício (28-30). No entanto, as estimativas são baseadas em estudos em ambientes com concentrações de poluentes inferiores à aquelas encontradas em grande parte das cidades médias e grandes de todo o mundo, como é o caso de São Paulo, onde a concentração média anual de $\mathrm{MP}_{2.5}$ é estimada em cerca de $25 \mu \mathrm{g} / \mathrm{m}^{3}$ (31), 2,5 vezes superior ao limite recomendado pela OMS (12).

Embora a prática regular de exercícios físicos seja recomendada por contribuir para reduzir ou postergar a incidência e melhor controlar morbidades crônicas respiratórias, metabólicas e cardiovasculares (23), não existe conhecimento suficiente sobre o balanço entre os riscos e benefícios da sua realização em ambientes poluídos, mesmo em indivíduos hígidos.

Estudo realizado com o uso de modelos matemáticos conduzido na Holanda (30), estimou o impacto na sobrevida de indivíduos se eles mudassem seu meio de transporte de carro para bicicleta. As estimativas sugeriram que os 


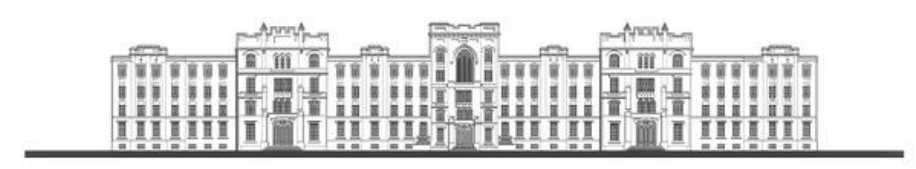

efeitos benéficos do aumento da atividade física são substancialmente maiores, acarretando aumento na sobrevida de 3 a 14 meses, comparado com a estimativa da redução da vida em 0,8 a 40 dias em decorrência da inalação da poluição, e de mais 5 a 9 dias por acidentes de trânsito. Porém, estes resultados são estimativas indiretas, ou seja, através de uma modelagem matemática, feita com uma população de 500 mil pessoas onde as concentrações de $\mathrm{MP}_{2,5}$ eram inferiores às observadas em grandes cidades, como referido nos recentes dados da OMS 2014 (12).

Corroborando com estes resultados, outro estudo recentemente publicado (32), relata o benefício do exercício físico (ciclismo), mesmo em ambientes poluídos. Neste estudo conduzido por Tainio et al., baseado em estimativas de impacto da poluição na morbidade em diversos cenários de exposição com variação de 5 a $200 \mu \mathrm{g} / \mathrm{m}^{3}$ na concentração de $\mathrm{MP}_{2,5}$, e riscos estimados durante caminhada e ciclismo, os autores concluíram que em ambientes com até 22 $\mu \mathrm{g} / \mathrm{m}^{3}$ de $\mathrm{MP}_{2,5}$, os benefícios do exercício aumentam após 7 horas/dia de uso de bicicleta e a partir de 16 horas/dia para caminhadas. Já em ambientes com concentrações de $160 \mu \mathrm{g} / \mathrm{m}^{3}$, os efeitos da exposição passariam a exceder os benefícios após $1 \mathrm{~h} 30$ min de bicicleta. Para caminhada, os riscos superariam os benefícios após 1 h e 30 min em ambientes com $200 \mu \mathrm{g} / \mathrm{m}^{3}$ de $\mathrm{MP}_{2,5}$.

Estudo realizado em Ausburg (Alemanha) (9) com 1300 pacientes, avaliou o risco de IAM desencadeado por esforço físico moderado $(M E T=5)$ e intenso (MET $\geq 6$ ) e verificou que o risco de IAM foi significativamente maior quando os exercícios foram realizados ao ar livre em comparação ao mesmo esforço realizado em ambiente interno. $O$ efeito também foi maior entre indivíduos sedentários comparado com os que praticavam atividade física regular. 


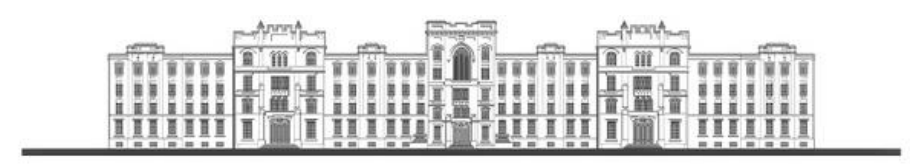

Estudo realizado por McCreanor et al. (10), avaliou 60 indivíduos asmáticos submetendo-os à caminhada de duas horas em um circuito no interior de um parque (Hyde Park, $\mathrm{MP}_{2,5}=11,9 \mu \mathrm{g} / \mathrm{m}^{3}$ ) e em um circuito em via pública (Oxford Street, $\mathrm{MP}_{2,5}=28,3 \mu \mathrm{g} / \mathrm{m}^{3}$ ) em Londres. Foram observados queda na função pulmonar e maior concentração de mieloperoxidase no escarro, um marcador inflamatório de vias aéreas $(24,5 \mathrm{ng} / \mathrm{ml}$ em Oxford Street contra 4,24 $\mathrm{ng} / \mathrm{ml}$ ) após caminhada em via pública quando comparada à realizada no circuito parque.

Ao realizar exercícios, os indivíduos inalam maior volume de ar, e por consequência, maior quantidade de poluentes. Durante o exercício, também ocorre um aumento da respiração bucal, e 60 a $80 \%$ das partículas inaladas entre 1 e $10 \mu$ m são depositadas nos brônquios e bronquíolos e 40 a 60\% das partículas entre 1 e $5 \mu \mathrm{m}$ são depositadas à nível alveolar $(26,27)$.

Um estudo em laboratório (33) avaliou 19 indivíduos jovens hígidos (idade média de 22 anos, IMC $=22,25 \mathrm{~kg} / \mathrm{m}^{2}$ ) divididos em dois grupos (atletas treinados e atletas destreinados). Todos os participantes realizaram teste de shuttle multi-estágio em dois dias diferentes, um dia em ambiente mais poluído $\left(\mathrm{CO}=37,4 \mathrm{ppm}\right.$ e $\left.\mathrm{MP}_{10}=250 \mu \mathrm{g} / \mathrm{m}^{3}\right)$, e outro menos poluído $(\mathrm{CO}=2,5 \mathrm{ppm}$ e $\left.M P_{10}=19 \mu \mathrm{g} / \mathrm{m}^{3}\right)$. Os resultados mostraram que, após o exercício em circuito com maior concentração de poluentes, quando comparado com circuito com menor concentração de poluentes, os indivíduos atingiram menor $\mathrm{VO}_{2 \max }$, apresentaram redução do número de hemácias e do hematócrito, aumento dos glóbulos brancos e das plaquetas, em ambos os grupos (treinados e destreinados). A conclusão do estudo mostrou que os parâmetros fisiológicos e de sangue em 


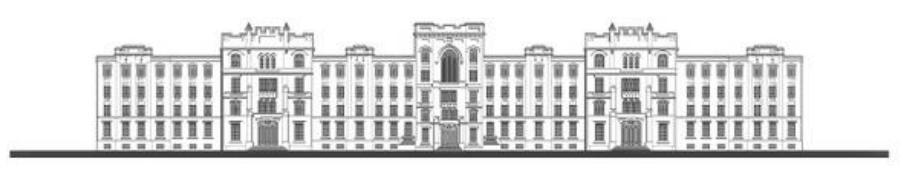

ambos os grupos sofreram influência negativa após realização de atividade física no ambiente poluído.

Vários métodos e marcadores têm sido utilizados para avaliar os possíveis efeitos da exposição a poluentes na saúde, entre eles a variabilidade da frequência cardíaca, a pressão arterial, o endotélio vascular e a função pulmonar $(10,34,35)$. Entre os marcadores inflamatórios ou de toxicidade mais empregados na atualidade está a dosagem de proteína CC16, que é produzida pelas células claras do pulmão, e estudos mostram que essa proteína está implicada nas defesa pulmonares.

Além dos efeitos cardiopulmonares, que são mais amplamente estudados, são escassos os estudos que avaliaram os efeitos da poluição do ar, associados ou não à realização de exercícios, na função renal. O surgimento de métodos e novos marcadores, ainda de pouco uso na pratica clínica (36-43), mas promissores na avaliação de alterações renais precoces, que podem permitir uma melhor avaliação de possíveis efeitos do exercício e da exposição ambiental no rim. Dentre os biomarcadores emergentes mais estudados estão: NGAL e a KIM-1. Destes biomarcadores, NGAL é o mais utilizado em estudos clínicos e o mais precoce para detecção de $\operatorname{IRA}(36,44,45)$, sendo KIM-1 detectado tardiamente por ser um marcador de regeneração tecidual pós lesão $(42,44)$

Estudo realizado por Lue et al. (46) evidenciou que moradores próximos à via com intenso tráfego de veículos e altas concentrações de $\mathrm{MP}_{2,5}$ apresentavam menor taxa de filtração glomerular quando comparadas às pessoas que viviam às distâncias maiores (Figura 4). 

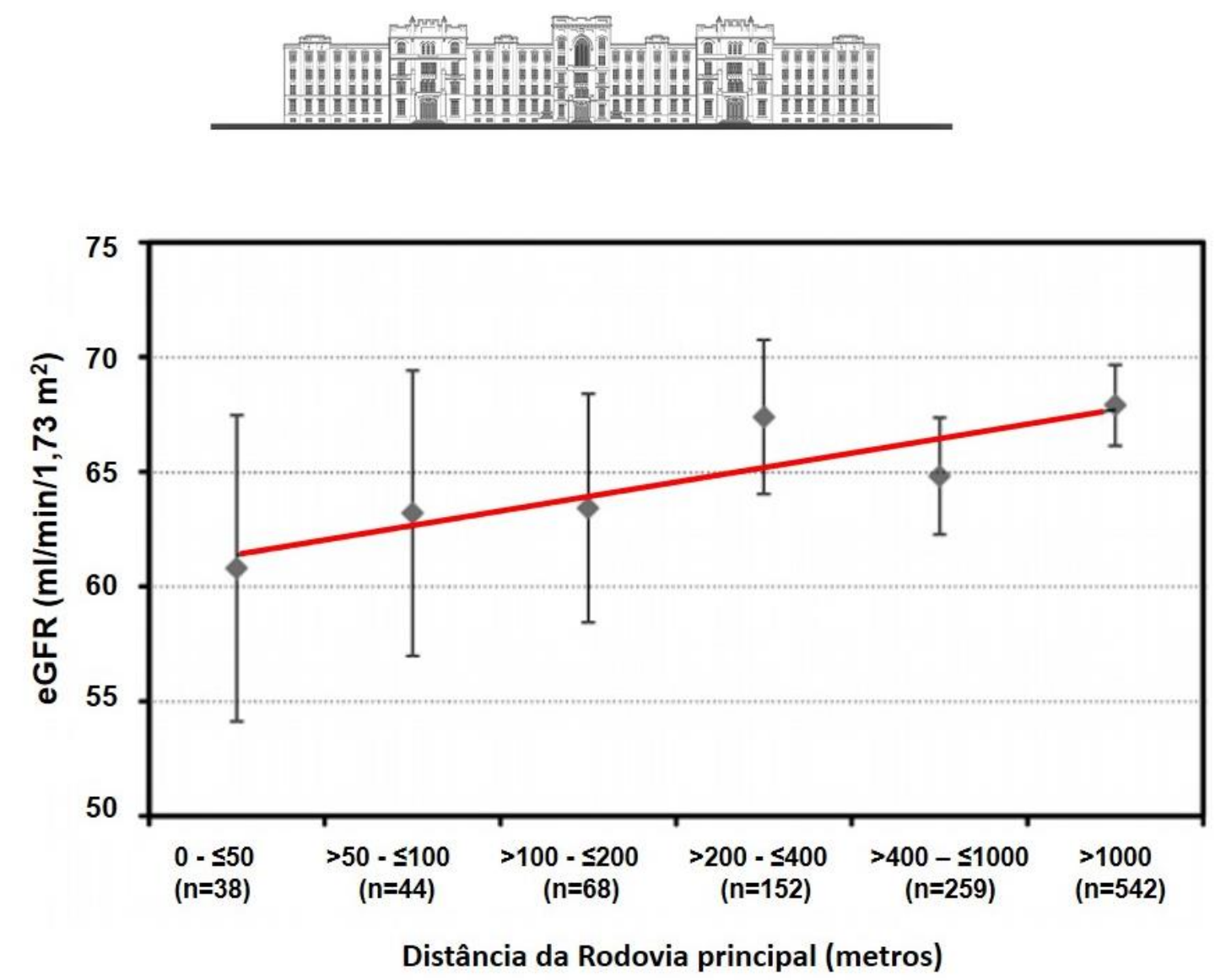

Figura 4 - Taxa de Filtração Glomerular média da população avaliada e distância da Rodovia principal. (Adaptado de Lue et al., J Epidemiol Community Health. 2013).

Pesquisa conduzida por Wesseling (47) avaliou biomarcadores renais em um grupo de cortadores de cana do sexo masculino na Nicarágua, antes e depois do turno de trabalho, no primeiro dia no início da colheita, no sexto dia durante a aclimatização, em seguida, e 9 semanas depois da colheita. Foi encontrado aumento da creatinina sérica, diminuição da taxa de filtração glomerular, e um aumento de 4 vezes na Ngal urinária após 9 semanas de trabalho no grupo de cortadores.

Outro estudo (48) encontrou resultados semelhantes numa população ainda maior de cortadores de cana (284, $88 \%$ homens). Foi relatado aumento significativo da Ngal e queda da função renal e da taxa de filtração, corroborando com o estudo anterior que encontrou diminuição da função renal. 


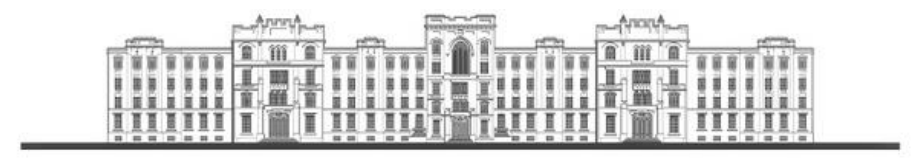

Outro estudo realizado com cortadores de cana brasileiros (49) mostrou que todos os avaliados (28 homens) tiveram diminuição média de $20 \%$ da taxa de filtração glomerular no fim do turno de trabalho, e 18,5\% apresentaram resultados aumentados na dosagem de creatinina sérica, compatíveis com lesão renal aguda.

Apesar de existirem evidências clínicas e experimentais de que o tabagismo e a exposição a poeiras podem provocar alterações renais funcionais e estruturais, inclusive proteinúria (50-52), a exposição à poluição associada ou não à realização de exercícios, como fator de risco para ocorrência de alterações renais é um tema pouco explorado. 


\section{I.4. Biomarcadores}

\section{I.4.1 - Marcadores Sanguíneos}

A utilização potencial de marcadores fisiológicos, bioquímicos e hematológicos tem recebido muita atenção recentemente. Sobretudo, são marcadores de fácil e rotineira mensuração laboratorial. Diversos estudos tem abordado a dosagem de marcadores sanguíneos a fim de mensurar as alterações decorrentes do esforço durante o exercício e suas demandas metabólicas (53). Alguns estudos relatam alterações nesses marcadores também após exposição à poluição, mostrando que essas alterações podem estar associadas à doenças cardiovasculares (54) e de coagulação (55), além de outros efeitos agudos $(56,57)$.

\section{I.4.2 - Marcador de toxicidade pulmonar - Proteína CC16}

A Proteína de Célula Clara (CC16) é uma proteína de baixo peso molecular (16 kDa) secretada pelas células Clara no fluido de revestimento brônquico pulmonar, a partir de onde se difunde passivamente ao sangue sendo posteriormente eliminada pelos rins. Também chamada de CC10, uteroglobina ou proteína urinária $1(58,59)$, é uma proteína produzida pelas células Clara pulmonares, presente predominantemente nos bronquíolos terminais, e secretada para o fluído de revestimento do epitélio pulmonar, de onde se difunde passivamente para o sangue. Sua ação ainda não é totalmente esclarecida, mas a principal hipótese é a de que ela realiza a proteção do trato respiratório contra agentes tóxicos inalados (59). A excreção urinária da proteína tem sido estudada por ser um marcador de exposição aos poluentes, além da excreção urinária de 


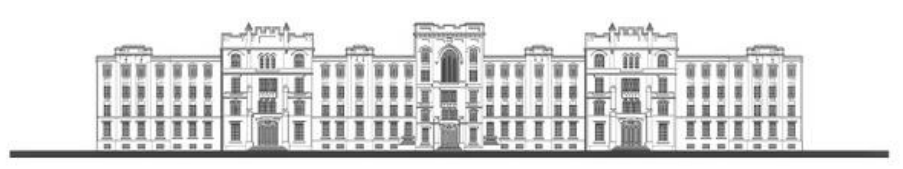

CC16 pode resultar de sobrecarga do processo de reabsorção tubular $(58,60$, 61).

A proteína CC16 é um marcador sensível para a detecção de dano ou disfunção das células epiteliais do pulmão e suas variações refletem variação na sua síntese e/ou da integridade da barreira epitelial (62). Tem sido utilizada como um marcador periférico potencial de lesão epitelial respiratória, e é um marcador que tem sido sugerido na abordagem para avaliação da integridade do epitélio respiratório em amostras de sangue e urina (59).

Estudo com desenho duplo-cego randomizado com 10 atletas do sexo masculino, mostrou que a proteína CC16 se altera em ambiente quente e úmido e poluído por ozônio (0,1 ppm), dois fatores que, combinados, seriam suficientes para provocar dano epitelial e ativação do processo de proteção antioxidante precoce nas vias aéreas respiratórias superiores desses atletas imediatamente após o exercício (63). Diminuição dos níveis séricos de CC16 são encontrados após a ressecção pulmonar, em trabalhadores expostos à sílica, em fumantes e em pacientes asmáticos (58).

Fatores que podem interferir na dosagem de CC16 em urina são a secreção prostática (a próstata também secreta CC16), gravidez e a diminuição da função renal. Por essa razão, em indivíduos do sexo masculino, em gestantes ou em pacientes com alterações da função renal, a coleta de urina deve ter seus primeiros $100 \mathrm{ml}$ descartados, sendo coletada a urina em outro coletor para armazenamento e análise (58).

A proteína CC16 tem sido proposta como um marcador de fácil determinação, e seu papel para avaliação de respostas à toxicidade pulmonar 
tem sido preconizado por vários estudos uma vez que sua dosagem em urina é um método não invasivo.

Em 2004, Timonen et al. (62), coletaram amostras de urina quinzenalmente durante 6 meses ( $n=1249$ ) em indivíduos portadores de doença cardíaca em três cidades europeias (Amsterdã, Erfurt e Helsinki) para análise das concentrações da Proteína CC16. A poluição do ar foi monitorada em um monitor central em cada cidade, onde as concentrações de $\mathrm{MP}_{2,5}$ encontradas foram, respectivamente, 20, 23 e $13 \mu \mathrm{g} / \mathrm{m}^{3}$. Os resultados mostraram que a concentração de CC16 aumentou junto com os níveis crescentes de $\mathrm{MP}_{2,5}$ em Helsínque, especialmente entre indivíduos com doenças pulmonares. Nas outras cidades, não houve aumento significativo nas concentrações de CC16 quando ocorria aumento na concentração de $\mathrm{MP}_{2,5}$. Esse resultado sugere que a exposição à poluição do ar por partículas pode levar ao aumento da permeabilidade epitelial nos pulmões ou da produção aumentada da proteína.

Por outro lado, Brauner et al. (64), também avaliaram o efeito da exposição à poluição do ar sobre a produção de proteína CC16. Em estudo conduzido em 2008, seu grupo avaliou um grupo de adultos saudáveis e não fumantes (20 homens com idade média de 27 anos, e nove mulheres com idade média de 26 anos) com exame prévio de função pulmonar normal. Os indivíduos foram submetidos ao exercício submáximo com bicicleta, em câmara fechada, com e sem exposição ao ar poluído. As concentrações de $\mathrm{MP}_{2,5}$ nos momentos em que não houve filtração do ar para o interior da câmara foram em média 9,7 $\mu \mathrm{g} / \mathrm{m}^{3}$ (mínimo de $\left(7,0\right.$ e máximo de $\left.11,6 \mu \mathrm{g} / \mathrm{m}^{3}\right)$. Nenhuma associação significativa com a exposição, exercício e tempo de exposição foi observada para aumento da CC16, com os autores sugerindo que possa existir um limiar de concentração 


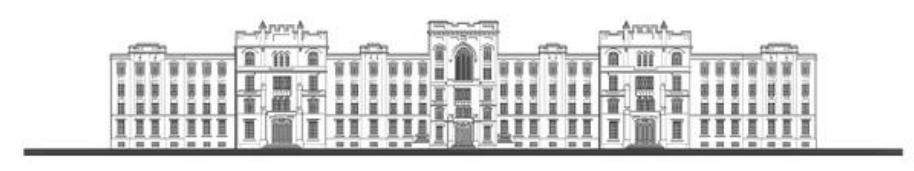

de material particulado para a estimulação de produção e liberação da proteína CC16 (64).

\section{I.4.3 - Marcadores de Função Renal}

A importância crescente do impacto da morbimortalidade por doenças renais (65) e com diversos estudos evidenciando papel ambiental associado a possíveis efeitos renais (47-49) motivaram a realização do presente estudo. Além da creatinina, Cistatina $\mathrm{C}$ e microalbuminúria, outros novos marcadores que tem sido propostos para avaliar a função renal, como por exemplo, Ngal e KIM-1 serão objeto de avaliação.

\section{I.4.3.a - Cistatina C}

A Cistatina C é um marcador de taxa de filtração glomerular mais preciso do que a creatinina sérica, e pode apresentar aumento dos seus níveis muito rapidamente em casos de injúria renal aguda. Habitualmente é dosada em sangue (66), mas no presente estudo foi dosada em urina junto com outros marcadores de função renal.

É uma proteína de baixo peso molecular produzida regularmente por todas as células nucleadas e sua presença já foi demonstrada no interior de células, assim como sua secreção em diversos fluxos extracelulares. A concentração urinária de Cistatina C é baixa, e a sua concentração em indivíduos normais é de cerca de $100 \mathrm{ug} / \mathrm{L}$. Foi demonstrado que a concentração de Cistatina $C$ na urina de pacientes com distúrbios tubulares renais pode ser 200 vezes maior $(37,61,67,68)$. 


\section{I.4.3.b - Microalbuminúria}

Chama-se de microalbuminúria a presença de quantidades mínimas de proteínas (albumina) na urina. Em uma pessoa saudável, essa quantidade é muito pequena e não ultrapassa, em circunstâncias normais, 30 miligramas por dia ou 20 microgramas por minuto (69). É um indicador precoce de alteração renal. Mede pequenas quantidades de albumina eliminada na urina, antes de uma lesão renal se tornar evidente. Como a molécula de albumina é pequena, é uma das primeiras proteínas detectadas na urina quando há lesão renal. Indivíduos com níveis consistentes de albumina na urina (microalbuminúria) têm um risco maior de desenvolvimento de insuficiência renal $(69,70)$.

\section{I.4.3.c - Ngal (Neutrophil gelatinase-associated lipocalin)}

NGAL (Lipocaína Associada à Gelatinase Neutrofílica), também conhecida como lipocalina-2, siderocalin, uterocalin, e $24 \mathrm{p} 3$, pertence à família das lipocalinas (40, 41, 43, 45). Esta proteína de 25 kDa é segregada por vários tipos de tecidos humanos, incluindo os tratos gastrointestinal, respiratório e renal.

A NGAL é uma proteína de fase aguda, com propriedades antimicrobianas, secretada por neutrófilos, mas também por outras células como as epiteliais respiratórias e por células tubulares renais. Os níveis de NGAL estão aumentados, especialmente na urina, em menos de 2 horas após dano renal, o que torna o NGAL um marcador diagnóstico em potencial tanto para lesão aguda renal quanto para o início do processo de reparação renal. Sua eficácia para diagnóstico de insuficiência renal aguda está acima de $90 \%$ (36, 39, 71-74).

Devido ao seu pequeno tamanho molecular, a NGAL é livremente filtrada e pode ser facilmente detectada na urina. NGAL urinária (NgalU) é um 


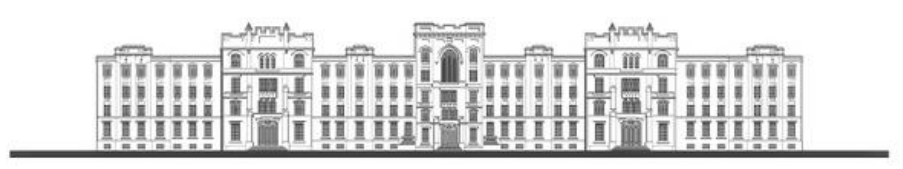

biomarcador muito precoce e sensível da lesão renal, e vários estudos demonstraram que os níveis urinários dela estão marcadamente aumentados em lesão renal aguda, nefropatia diabética, síndrome nefrótica, nefrite tubulointersticial, e nefropatia com envolvimento da imunoglobulina A $(\lg A)$ (IgAN) $(36,39,71-74)$.

\section{I.4.3.d - KIM-1 (Kidney Injury Molecule-1)}

KIM-1, ou Molécula de Injúria Renal 1, é um marcador de lesão tubular proximal, e recebe o número $1 \mathrm{em}$ seu nome pois é uma glicoproteína transmembranar de tipo I. É uma glicoproteína da família das imunoglobulinas, expressa no túbulo proximal, após lesão renal aguda isquêmica ou tóxica (42, 74-76).

Foi descoberta em células epiteliais tubulares renais em uma tela de moléculas envolvidas na patogênese da lesão renal aguda. Em rins saudáveis, KIM-1 é indetectável. No entanto, o aumento da expressão desta proteína foi encontrado em níveis muito elevados na membrana apical de células do túbulo proximal, após lesão isquêmica e nefrotóxica. A expressão de KIM-1 está ausente nos glomérulos, nas células intersticiais peritubulares, ou nas células medulares internas. Seus níveis na urina aumentam dentro de 12 horas após início da injúria renal, durante processo de reparação das células tubulares proximais, após evento isquêmico, precedendo a elevação sérica de creatinina $(42,61,76,77)$.

Os níveis de KIM-1 têm sido documentados como sendo o diagnóstico de sinais de danos de tecido renal e sua tentativa de regeneração. Estudos clínicos documentaram que a KIM-1 é regulada positivamente nos túbulos de pacientes 


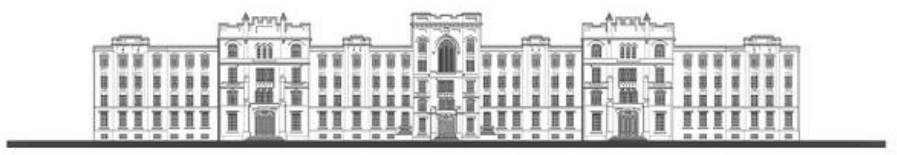

com esclerose glomerular focal, nefropatia por IgA, glomerulonefrite membrano proliferativa, e está associada com proteinúria, lesão tubular e fibrose intersticial. Estes resultados conduziram à sugestão de que KIM-1urinária pode ser um biomarcador promissor e não-invasivo de danos túbulo intersticiais crônicos (40, 41, 43-45). 


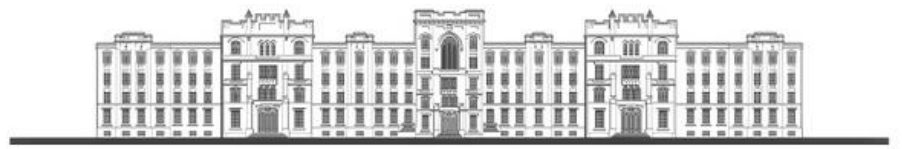

\section{OBJETIVOS}

\section{II.1 - Principal}

Avaliar o efeito da realização de exercícios físicos em ambientes com diferentes concentrações de poluentes, na toxicidade pulmonar, em marcadores sanguíneos e na função renal em indivíduos jovens.

\section{II.2 - Secundário}

Avaliar efeitos da realização de exercícios físicos, em ambientes com diferentes concentrações de material particulado fino:

1 - Em marcadores sanguíneos;

2 - Em marcador de toxicidade pulmonar (Proteína CC16);

3 - Em marcadores da função renal. 


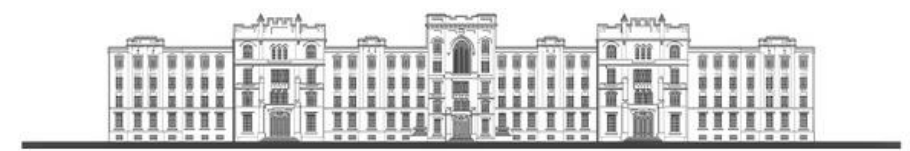

\section{MÉTODOS}

\section{III.1- Desenho do estudo}

Este estudo seguiu um delineamento experimental, do tipo transversal prospectivo não randomizado. Os indivíduos foram avaliados em dois diferentes dias em dois momentos, pré-treino e pós-treino. Todos os participantes completaram um programa de corrida de alta intensidade e os participantes serviram como seu próprio controle. As variáveis de desfecho foram medidas antes e depois do período de intervenção.

\section{III.2 - Indivíduos avaliados}

Foram selecionados 40 voluntários do sexo masculino (Figura 5) entre 200 alunos da escola de Especialistas do Exército Brasileiro (CPOR), nunca fumantes, hígidos, com negativa para uso de drogas anabolizantes, sem antecedentes de patologias e/ou cirurgia renais ou pulmonares, e praticantes de atividade física regular (todos os indivíduos, como parte do treinamento Militar realizavam corridas em circuito de rua, de quatro a cinco vezes por semana, desde seis meses antes do estudo, quando ingressam na Corporação). A seleção foi realizada por meio de triagem após a inscrição de interessados que concordaram em assinar o TCLE (Anexo 3) e que atendiam aos critérios antes expostos (Figura 6). 


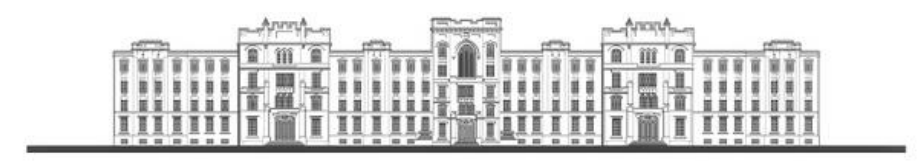

Após a primeira semana de avaliações, um participante foi excluído em decorrência de acidente ocorrido durante treinamento, restando 39 voluntários participantes.

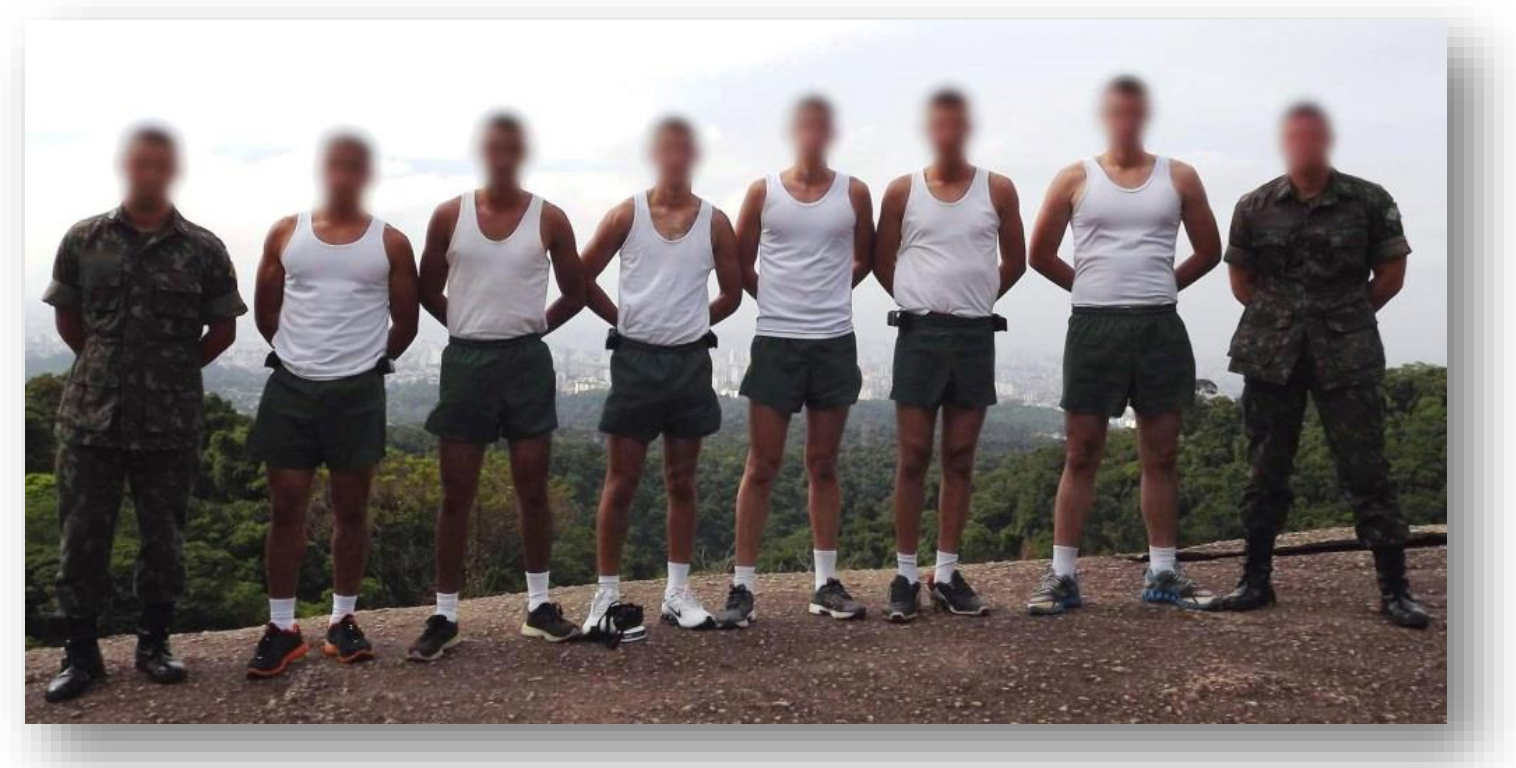

Figura 5 - Indivíduos avaliados.

\section{III.3 - Protocolo do Estudo}

Os 39 participantes foram aleatoriamente distribuídos em cronograma de corridas entre os meses de setembro a novembro de 2012, sendo que em cada semana cinco indivíduos correram em um circuito em Via Pública (circuito VP) e cinco em um circuito no interior de um Parque (circuito PQ). No circuito VP as corridas foram realizadas em avenidas e ruas com elevado tráfego de veículos, com predomínio de automóveis, e no Circuito $P Q$ foram realizadas no interior do Horto Florestal de São Paulo, ambos os circuitos localizados na zona norte da Cidade de São Paulo. Na semana seguinte, observando um intervalo de mudanças entre os circuitos de 72 horas, os participantes alternavam o circuito das corridas. 


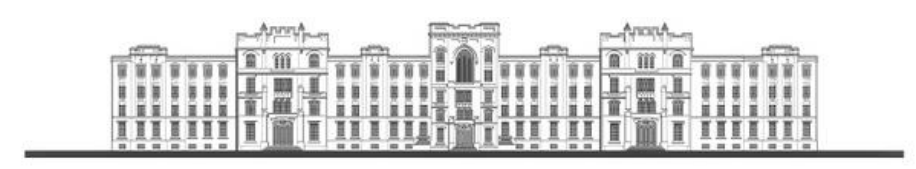

Todos eram orientados a não ingerir bebidas alcoólicas e informar uso de medicamentos e ocorrência de acidentes fora do trabalho em ficha de avaliação individual e de controle de coletas (Anexo 4).

Os indivíduos foram avaliados sempre nas segundas-feiras e nas sextasfeiras, em dois momentos: Tempo 1: antes da atividade física, e Tempo 2: de 15 a 30 minutos após a corrida. As corridas tiveram início entre 07 hrs 45 min e 08 hrs e 15 min e duravam, em média, 45 minutos (Figura 6).

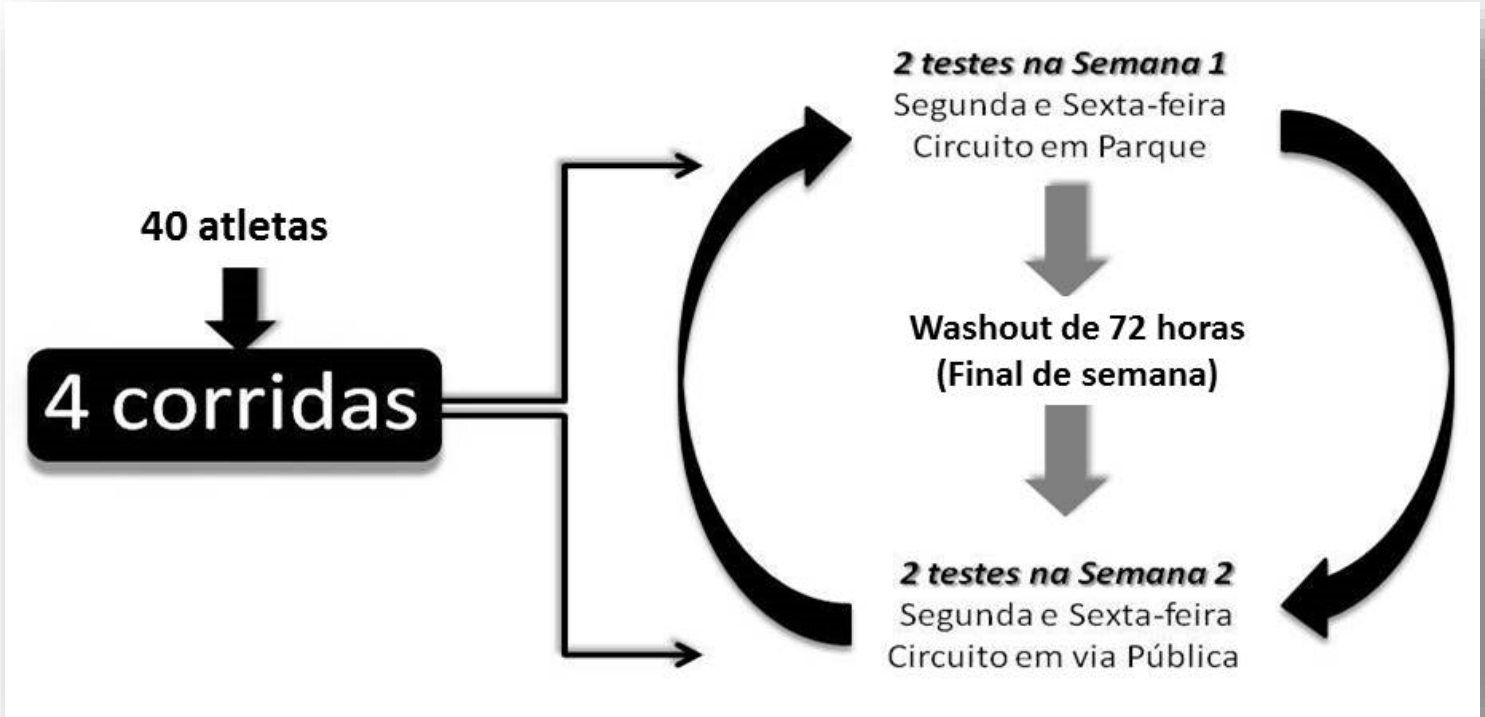

Figura 6 - Sistema de avaliação dos indivíduos durante o período de estudo.

Nos dias das avaliações os voluntários foram de casa até os circuitos Parque e Vias Públicas usando máscaras protetoras para material particulado fino.

Os circuitos tinham 7,5 km de extensão, que foram percorridos à uma média de velocidade de $10 \mathrm{~km} / \mathrm{h}$ (166 m/min) com duração de 45 minutos, aproximadamente. Visão integral dos circuitos pode ser visualizada nas figuras 8 e 9, a seguir: 


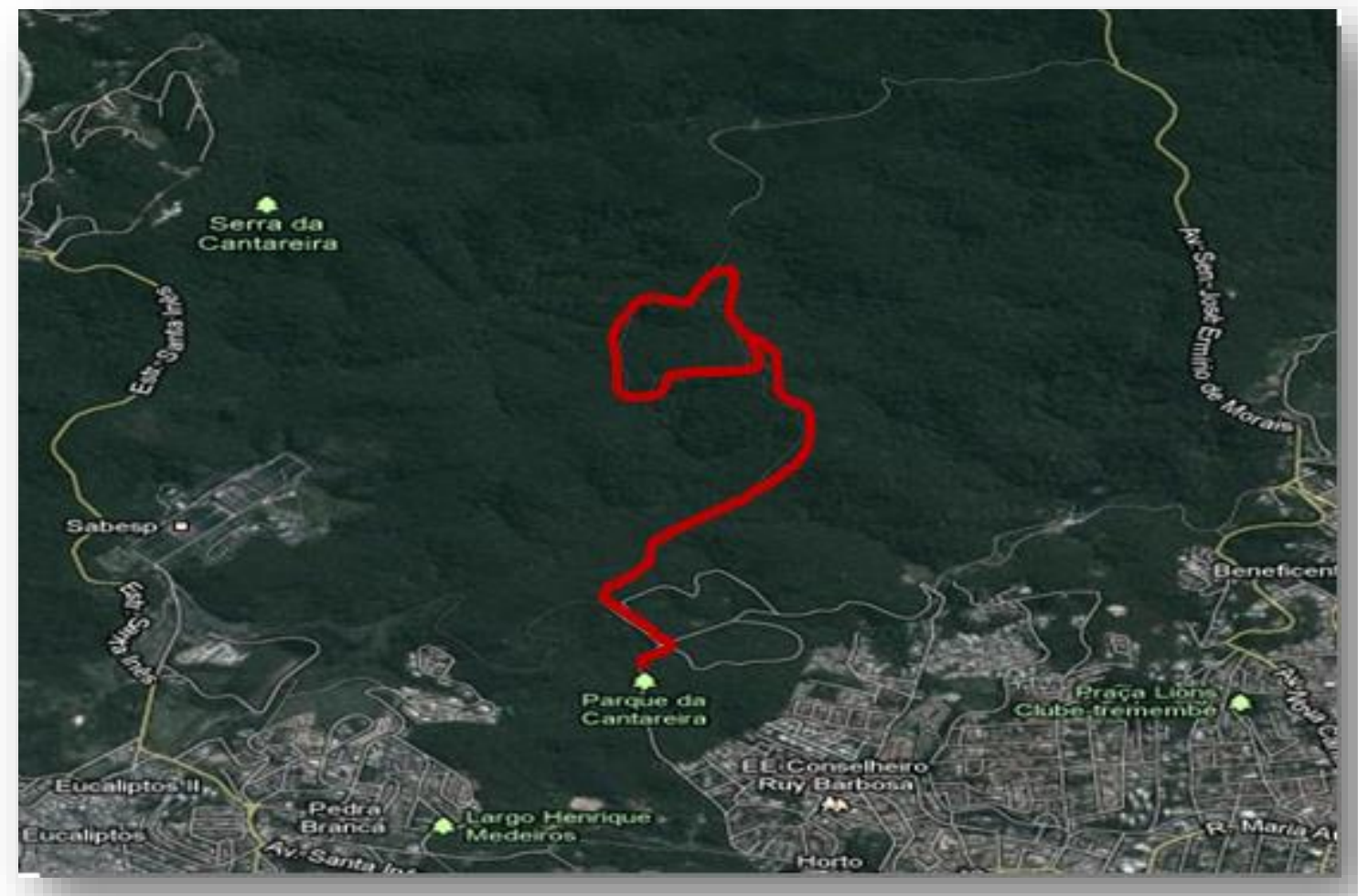

Figura 7 - Pista de corrida dentro do Parque do Horto Florestal, a 1010 metros de altitude (Circuito PQ).

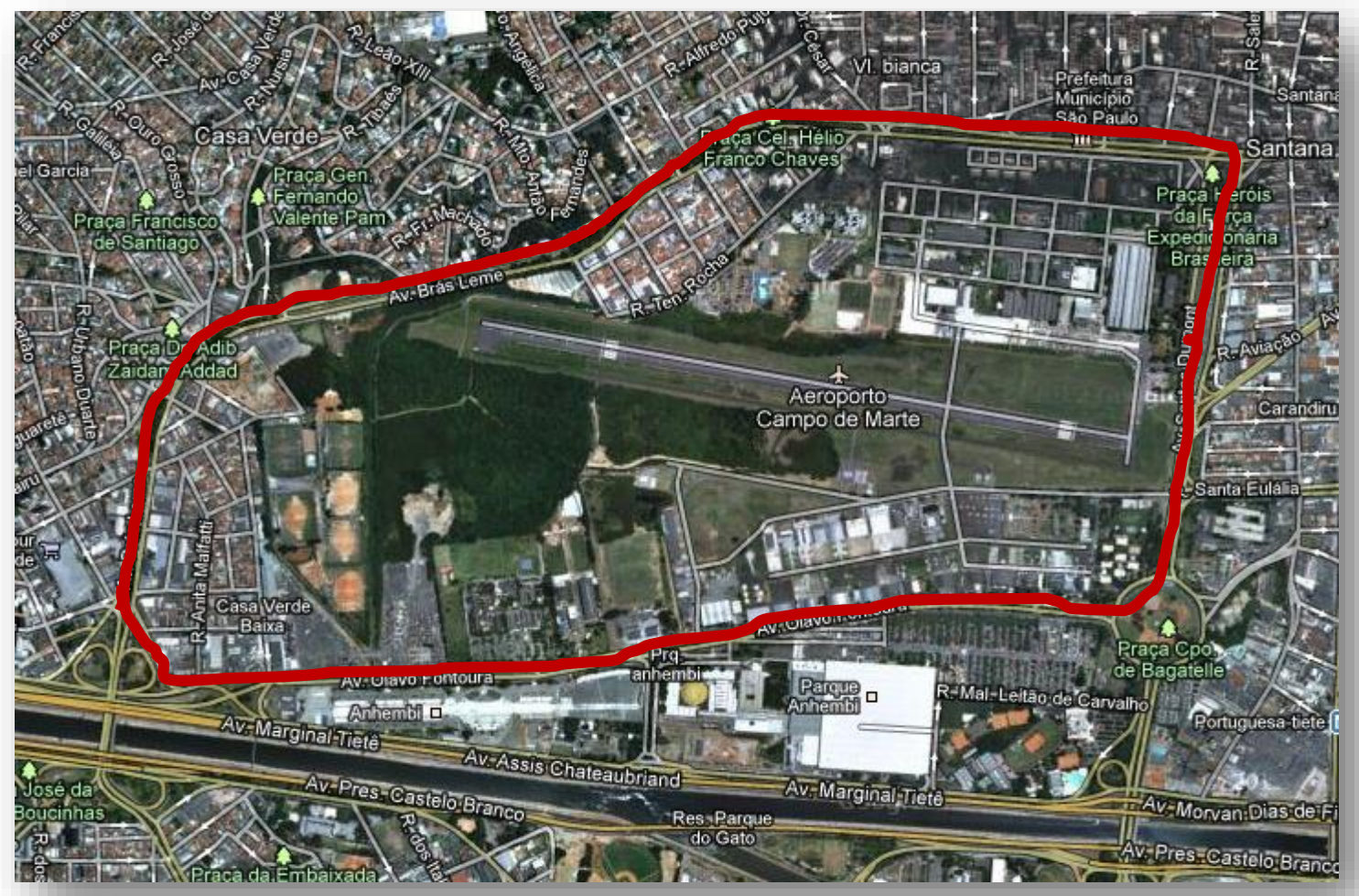

Figura 8 - Pista de corrida de rua, a 720 metros de altitude (Circuito VP). 


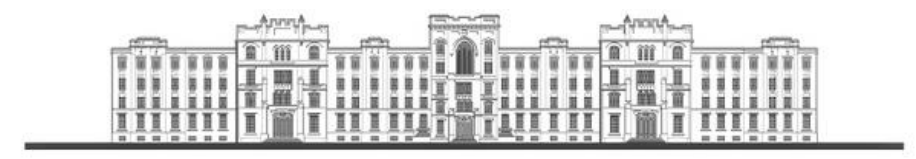

A Figura 9 mostra, através de uma imagem de satélite, a distância entre os dois circuitos $(5,23 \mathrm{~km})$ e a característica de cada um com relação à proximidade das vias de circulação de veículos.

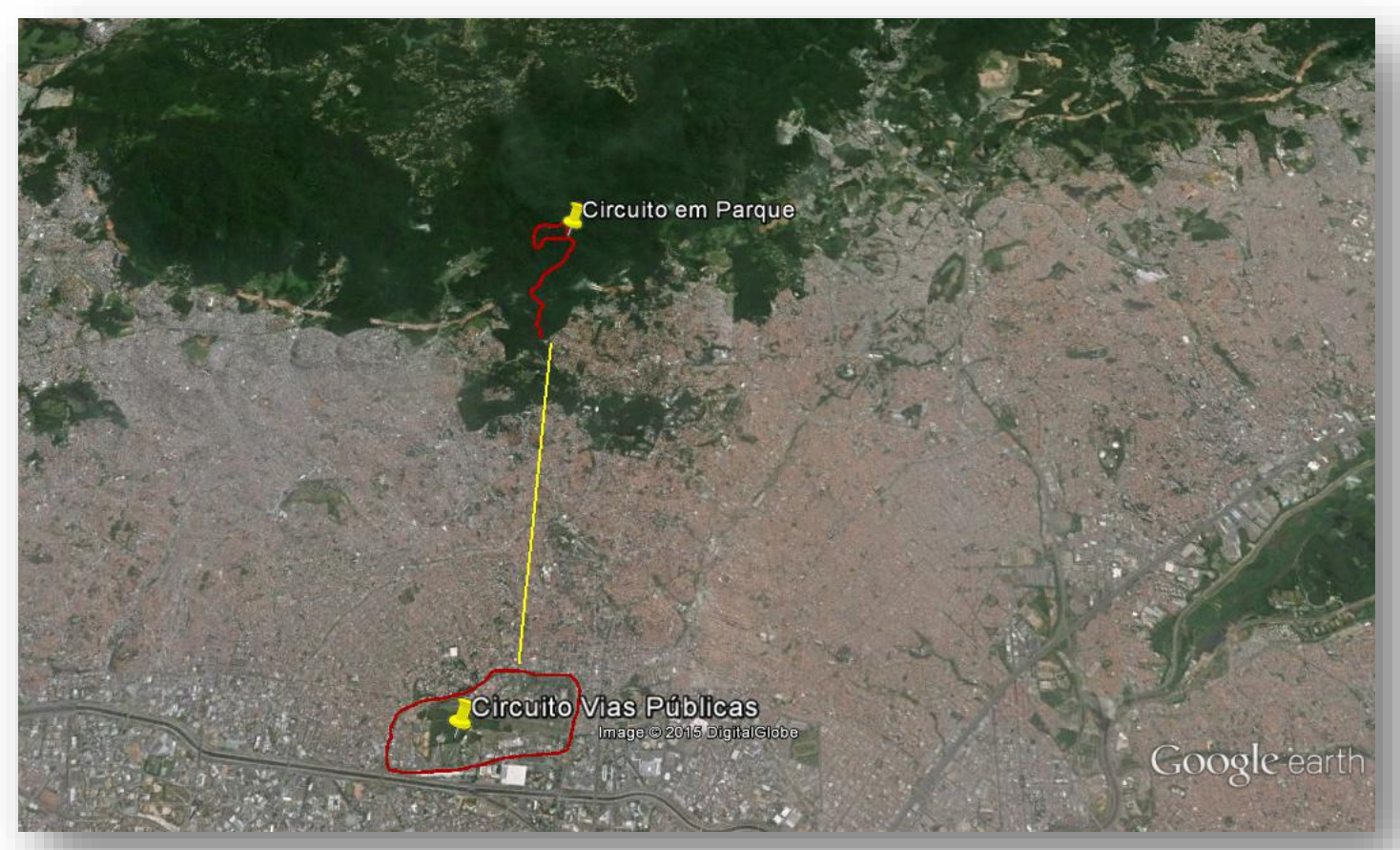

Figura 9 - Foto de satélite mostrando os dois circuitos (PQ e VP).

Nas figuras 10 e 11, as imagens do primeiro dia de coleta, onde é possível visualizar a cidade de São Paulo de cima da Pedra Grande, ponto mais alto do Parque do Horto Florestal. 


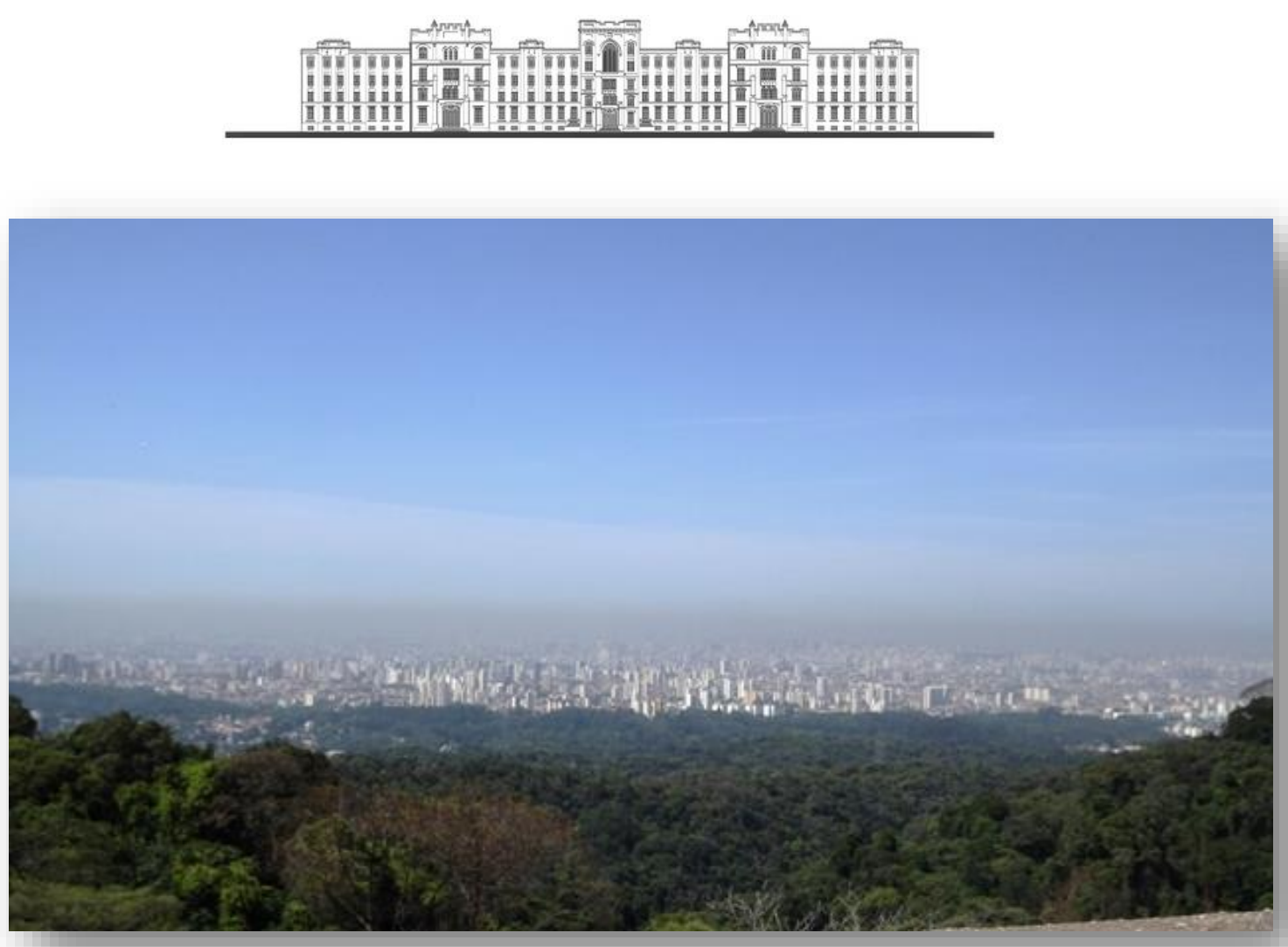

Figura 10 - Cidade de São Paulo vista do ponto mais alto do Parque do Horto Florestal.

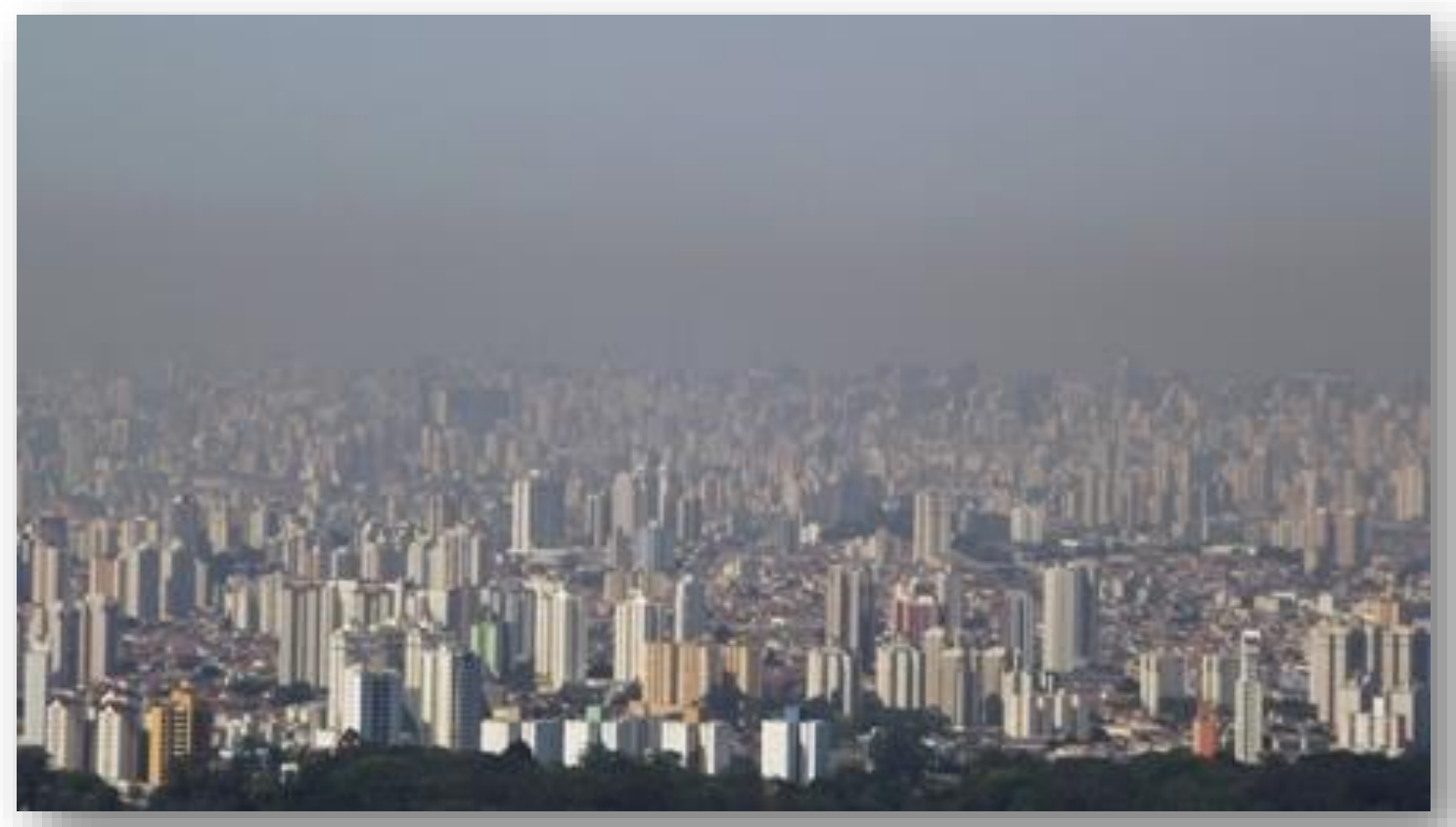

Figura 11 - Vista aproximada da Figura 10, evidenciando a poluição do ar sobre a cidade. 


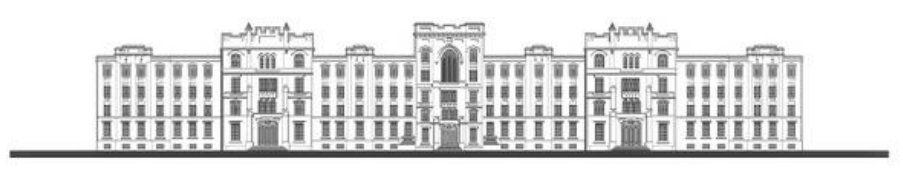

Nos dois circuitos, $\mathrm{PQ}$ e VP, os treinos seguiram o mesmo protocolo: aplicação de questionário breve para registro de intercorrências como consumo de bebidas alcoólicas, ocorrência de acidentes e uso de medicamentos, seguidos de registro da pressão arterial, frequência cardíaca (FC), medição do COex (monóxido de carbono no ar exalado) para confirmação de status não tabágico e coletas de amostras de sangue e urina. Após estes procedimentos, realizaram, com orientação de supervisor, cinco minutos de alongamento. Após o alongamento, o grupo que correu no circuito VP realizou corrida contínua, executada a uma média de velocidade de $10 \mathrm{~km} / \mathrm{h}$, percorrendo uma distância de aproximadamente $7,5 \mathrm{~km}$, em 45 minutos. Considerando a distância e o tempo o exercício realizado pelos indivíduos nesse estudo foi considerado intenso $(M E T=10,5)$ em ambos os circuitos. A quantificação do equivalente metabólico dessa atividade física foi obtida pela fórmula do Colégio Americano de Medicina do Esporte (ACSM) $(78,79)$, onde se calcula a média da velocidade desenvolvida, dividindo-se a distância em metros pelo tempo de corrida, ou seja, $7500 \mathrm{~m} / 45 \mathrm{~min}$ de corrida $=166,66 \mathrm{~m} / \mathrm{min}$. Com esse valor, calculamos $\circ \mathrm{VO}_{2}$ estimado para corrida através da equação $\mathrm{m} / \mathrm{min} \times 0,2 \mathrm{mlO}$.m.min+3,5 $\mathrm{ml} / \mathrm{kg} / \mathrm{min}$. Logo, $166,66 \times 0,2+3,5=36,8 \mathrm{ml} / \mathrm{kg} / \mathrm{min} / 3,5=10,5 \mathrm{METs}$. Portanto, o indivíduo consumiu nos 7500 metros de corrida que realizou em 45 minutos o equivalente a 10,5 METs, o que caracteriza uma atividade física de intensidade vigorosa (21).

O grupo que correu no circuito $P Q$ foi levado por veículo motorizado até o local, utilizando máscaras respiratórias até chegar ao parque no interior do Horto Florestal, onde realizou corrida contínua na mesma velocidade e em trajeto com a mesma distância e duração média do realizado no circuito de via pública. Não 


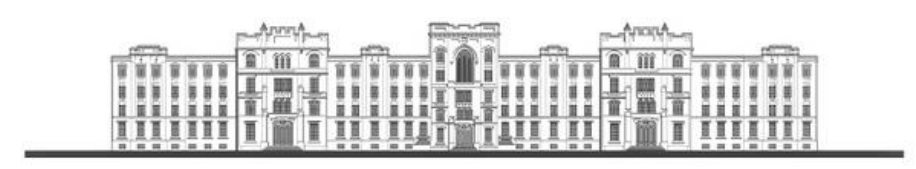

houve ingestão de líquidos ou alimentos durante a corrida e, após as mesmas, os indivíduos foram submetidos à nova coleta de amostras de urina e de sangue.

\section{III.4. Marcadores biológicos avaliados}

As amostras de sangue e urina foram armazenadas em caixa de isopor, em estante sobre gelo conforme o recomendado pela Divisão de Laboratório Central do Hospital das Clínicas de São Paulo. As amostras foram processadas no Laboratório de Investigação Médica 3, do Departamento de Patologia e enviadas aos diversos laboratórios para análises (Laboratório de Investigação Médica Medicina Laboratorial 3: determinação dos marcadores de função e alterações renais e da proteína CC16; Divisão de Laboratório Central do Hospital das Clínicas de São Paulo: análises laboratoriais gerais; Laboratório de Investigação Médica do Departamento de Medicina Legal, Ética Médica e Medicina Social e do Trabalho da FMUSP: dosagem de carboxihemoglobina).

\section{III.4.1. Marcadores sanguíneos}

III.4.1.a - Dosagem de carboxihemoglobina ( $\mathrm{COHb})$ : dosada por método de Espectrofotometria UV-VIS (Modelo 1650PC Shimadzu, Japão) em amostras de sangue venoso.

III.4.1.b - Análises bioquímicas e hematológicas: Hemograma completo com contagem de plaquetas: determinado através de contagem automatizada, em equipamento XT2000 da Roche (Suiça); Creatina fosfoquinase (CPK), Desidrogenase Lática (DHL), Aspartato aminotransferase (AST) e Alanina 


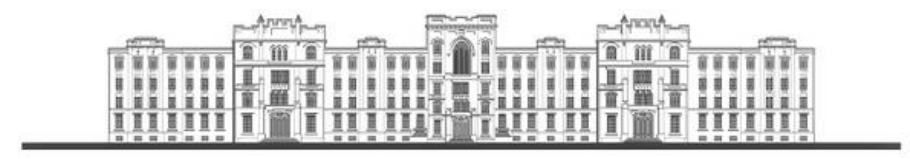

aminotransferase (ALT): pelo método da Cinética UV, em equipamento automatizado Cobas C111 da Roche (Suiça); Sódio (Na) e Potássio (K): determinados em equipamento ABL800 flex da Radiometer (Dinamarca) com a técnica ISE (Eletrodo íon Seletivo) em sangue e urina; TP e TTPA: realizado em sangue venoso coletado e conservado em tubo com citrato de sódio a 3,2\% $(3,5 \mathrm{ml})$ determinados pelos métodos de Quick e de ProctorRapaport modificado, respectivamente, em equipamento Star - Evolution da Stago (França).

\section{III.4.2. Marcador de toxicidade Pulmonar}

Proteína CC16 (Proteína de Células Claras): A determinação da CC16 na urina foi realizada com técnica de ELISA, com kits da Biovendor e leitura em equipamento Power wave X da Bio-tek (EUA). As amostras foram incubadas com um anticorpo policlonal anti-humano de células Claras de coelhos em poços de microtitulação revestidos.

\section{IIl.4.3. Marcadores de Função Renal}

III.4.3.a - Microalbuminúria: Expressa a fase inicial de injúria renal e está presente quando a excreção urinária de albumina supera $30 \mathrm{mg} / 24 \mathrm{~h}$. Foi analisada pelo método de imunoturbidimetria no equipamento Cobas C111 da Roche (Suiça).

III.4.3.b - NGAL (Neutrophil Gelatinase Associated Lipocalin): dosada no plasma e urina por método Multiplex/ Luminex, com kit da Millipore (EUA), com leitura realizada no aparelho Blo-plex da Bio-rad (EUA). 


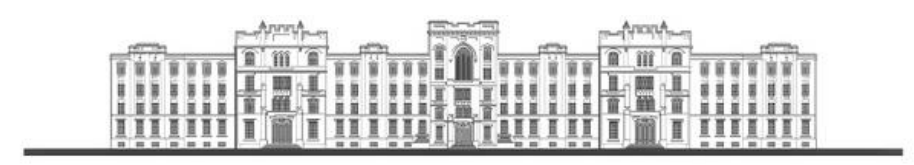

III.4.3.C - KIM-1 (Kidney Injury Molecule-1): dosada por método Multiplex/ Luminex com kits da Millipore (EUA) e leitura realizada no aparelho Blo-plex produzido pela Bio-rad (EUA).

III.4.3.d - Creatinina: dosada em amostra de soro através do método Jaffé, no equipamento Cobas C111 da Roche (Suiça). Em urina, foi dosada em equipamento automatizado Cobas C111 da Roche (Suiça).

III.4.3.e - Cistatina C (CysC): dosada em urina por método Multiplex/ Luminex com kits da Millipore (EUA) e a leitura realizada no aparelho Blo-plex produzido pela Bio-rad (EUA).

\section{III.4.4 - Estimativas da funcão renal:}

III.4.4.a - FENa: É a porcentagem do sódio filtrado que é excretado na urina. Na presença de oligúria uma $\mathrm{FENa}<1 \%$ sugere hipoperfusão, enquanto valores superiores a $1 \%$ sugerem doença renal intrínseca. Existe perda deste valor se diuréticos ou expansão volêmica significativa forem realizados antes da coleta, razão pela qual nossos indivíduos não fizeram ingestão de líquidos durante e após a corrida, até o momento da coleta. A fração de excreção de sódio é calculada obtendo-se as dosagens de Sódio e Creatinina em amostra isolada de urina e no plasma e fazendo-se a relação:

\section{$(\mathrm{FENa})=\left[\left(\mathrm{U}_{\mathrm{Na}} \times \mathrm{P}_{\mathrm{Cr}}\right) /\left(\mathrm{P}_{\mathrm{Na}} \times \mathrm{U}_{\mathrm{Cr}}\right)\right] \times 100$}

sendo o valor normal entre 1 e $3 \%$. Valores menores que $1 \%$ indicam insuficiência renal pré-renal e maiores que 3\%, comprometimento renal. 


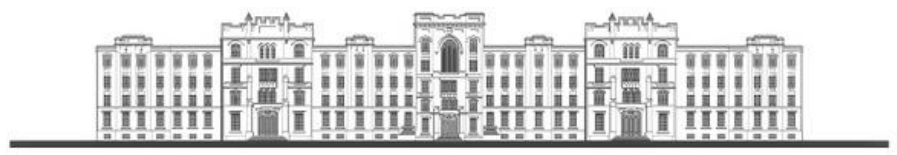

III.4.4.b - MDRD: A equação do MDRD para estimativa da Taxa de Filtração Glomerular (TFG) foi originalmente desenvolvida com base nos dados do estudo Modification of Diet in Renal Disease (MDRD) em pacientes com doença renal crônica e não incluiu indivíduos saudáveis. O padrão-ouro usado no desenvolvimento da equação MDRD foi o clearance de iotalamato-I e, portanto, ela estima a TFG (em $\mathrm{mL} / \mathrm{min} / 1,73 \mathrm{~m}^{2}$ ) e não a depuração de creatinina. $\mathrm{Na}$ versão original da equação MDRD, foram incluídas determinações de albumina e ureia nitrogenada séricas. Atualmente, a fórmula do MDRD abreviada com quatro variáveis tem sido recomendada, pois seu desempenho é tão bom quanto o da equação inicial. TFG calculada pela equação do MDRD e a TFG real são muito próximas para resultados $<60 \mathrm{~mL} / \mathrm{min} / 1,73 \mathrm{~m}^{2}$, enquanto a TFG excede a taxa estimada por um valor pequeno quando a TFG é $>60 \mathrm{~mL} / \mathrm{min} / 1,73 \mathrm{~m}^{2}$.

III.4.4.c - CKD-EPI: O grupo Chronic Kidney Disease Epidemiology Colaboration (CKD-EPI) desenvolveu, a partir de coorte que incluiu indivíduos com e sem doença renal crônica, uma nova equação, que é uma variação da fórmula do MDRD. A equação, denominada de CKD-EPI, usa as mesmas quatro variáveis que a equação do MDRD, mas, comparativamente, apresenta melhor desempenho e previsão de desfechos adversos. As observações de menor viés e maior acurácia da equação CKD-EPI em comparação à equação do estudo MDRD, particularmente nas faixas de TFG> $60 \mathrm{ml} / \mathrm{min} / 1,73 \mathrm{~m}^{2}$, constituem o racional para preconizar o seu uso clínico em substituição às equações de estimativa da TFG até então utilizadas. 


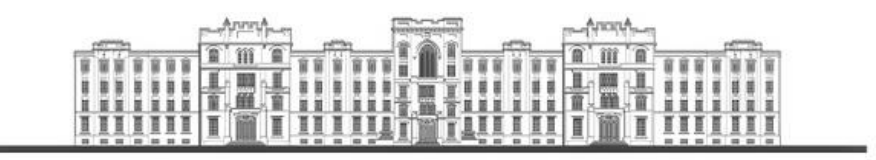

\section{III.5 - Medidas de poluentes e de variáveis climáticas}

Durante as corridas foram realizadas medições contínuas de material particulado fino $\left(\mathrm{MP}_{2,5}\right)$, da Temperatura $\left({ }^{\circ} \mathrm{C}\right)$ e da Umidade Relativa do ar $(\%)$. A concentração de partículas com diâmetro aerodinâmico menor do que $2,5 \mu \mathrm{m}$ $\left(\mathrm{MP}_{2,5}\right)$ foi medida com um monitor de massa de aerossóis por espectrofotometria, MP DUSTTRAK Aerosol Monitor (Modelo 8520, TSI Inc., Mn, EUA), que mede a dispersão de um feixe de laser de comprimento de onda de 780 nanômetros causada pela passagem do ar direcionado por um circuito de fluxo ativo; a dispersão da luz é diretamente proporcional à massa das partículas que atravessam o feixe. Com a integração desse sinal fotoelétrico ao fluxo de ar calibrado no dispositivo (1,7L/min) gera-se um valor instantâneo e contínuo de concentração de material particulado expresso em $\mu \mathrm{g} / \mathrm{m}^{3}$ (Figura 12). Para que existisse uma medida fidedigna de cada indivíduo, um líder em cada grupo carregou durante a corrida uma mochila com o equipamento acondicionado adequadamente em seu interior, com uma mangueira coletora do ar colocada externamente em uma das alças da mochila, captando assim a amostra do mesmo ar que era inalado pelo corredor (Figura 14).

A temperatura e umidade do ar foram registradas através de um aparelho do tipo termo higrômetro digital (Figura 13) da marca Data Logger, modelo 30.3015 (TFA,GmbH). Os registros foram reportados para microcomputador para análises dos dados. 

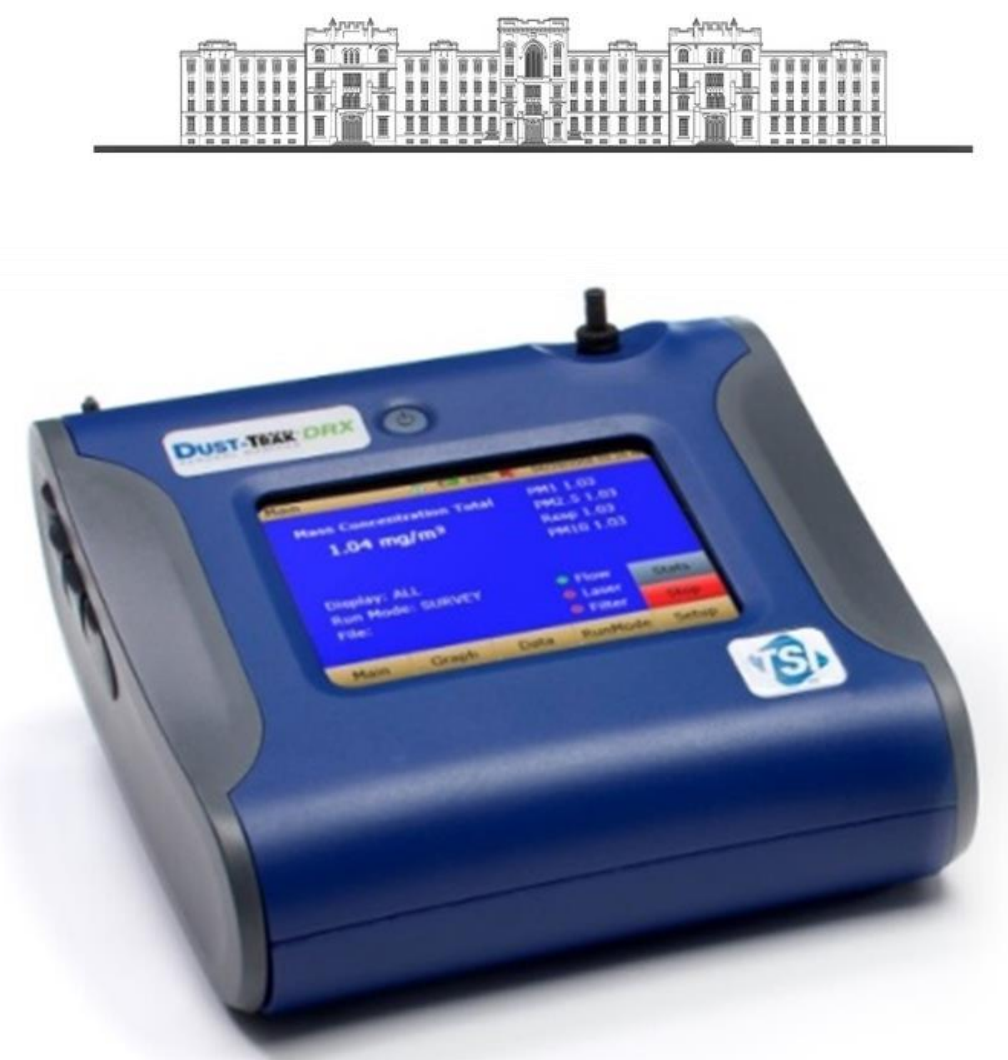

Figura 12 - Monitor de massa de aerossóis por espectrofotometria, MP DUSTTRAK Aerossol Monitor (Modelo 8520, TSI Inc., Mn, EUA).

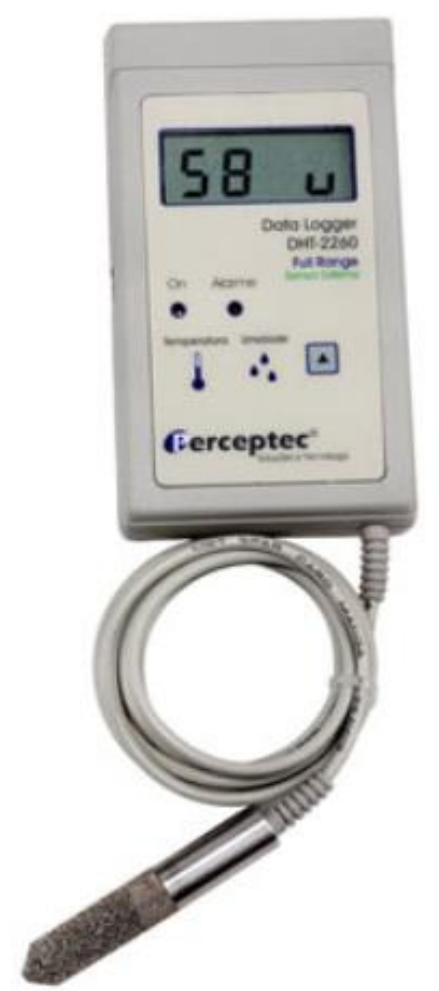

Figura 13 - Termo higrômetro Data Logger DHT (Modelo 2260 Full Range Perceptec). 

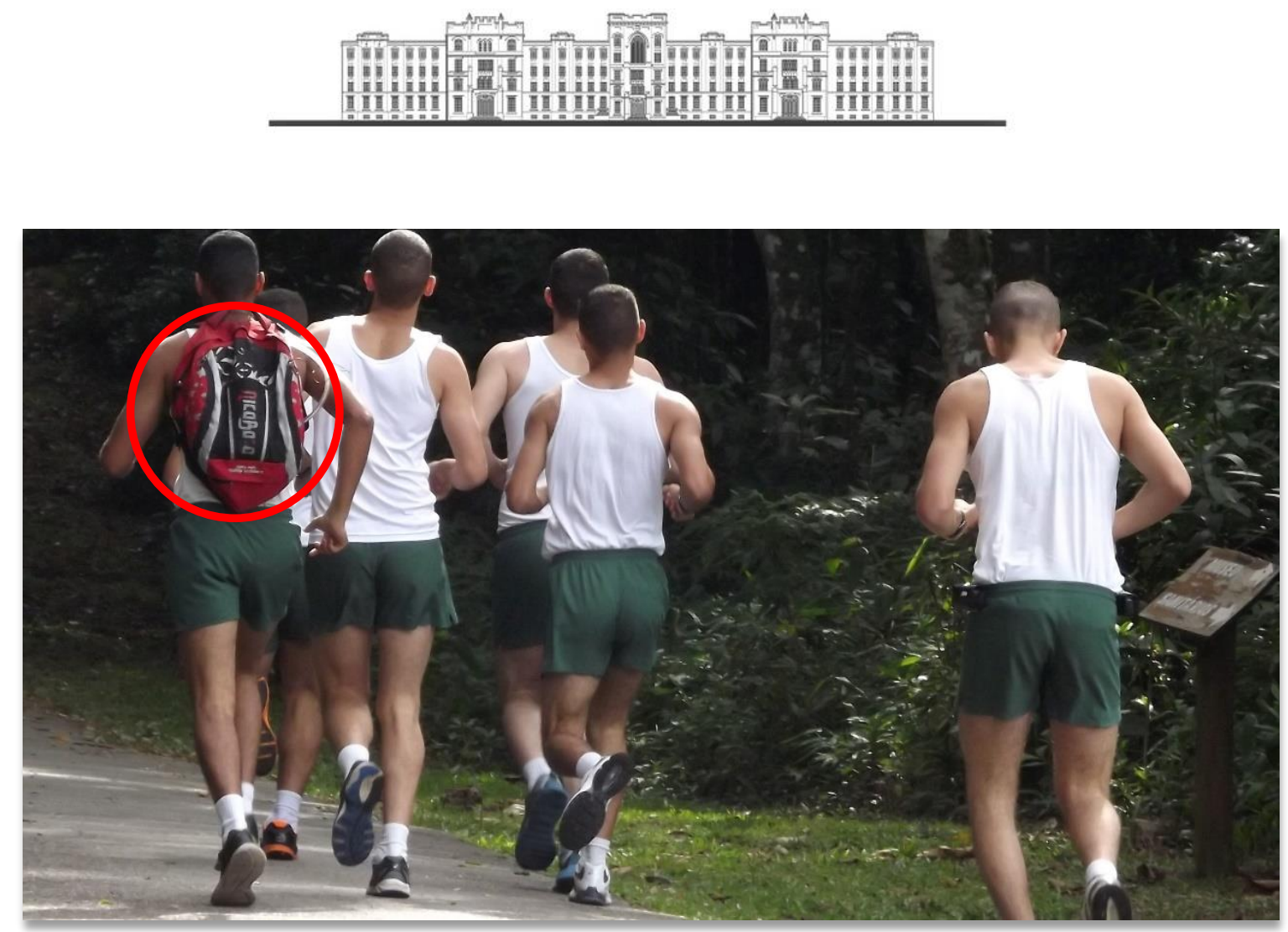

Figura 14 - Monitor MP DUSTTRAK, em detalhe, na mochila que era levada pelo líder da equipe de corrida de cada um dos grupos. No detalhe, como exemplo, uma das corridas realizadas no Parque do Horto Florestal. 


\section{III.6. Análises estatísticas}

\section{III.6.1 - Análises univariadas}

Para comparação das variáveis associadas à poluição e clima foi utilizado teste de Mann-Whitney. Para os indicadores biológicos foram realizadas análises descritivas e univariadas com uso de Teste t pareado ou Wilcoxon Signed Rank test, conforme apropriado, sendo adotado o nível de significância de 0,05. Optamos por deixar os dados de média e desvio padrão e mediana e intervalo interquartil nas tabelas para permitir leitura mais abrangente da distribuição dos dados.

\section{III.6.2 - Análises de regressão linear com modelo de efeitos mistos}

Os efeitos da corrida (referência medidas realizadas antes da corrida) e do local da corrida (Circuito Vias Públicas versus Circuito no Parque Horto Florestal, como referência) sobre as variáveis dependentes foram avaliados de forma conjunta em análise múltipla, usando modelos lineares mistos. Para cada modelo avaliado, foi testada a interação entre essas variáveis independentes no efeito fixo e o ajuste com intercepto ou com intercepto e angulação, como efeitos aleatórios. O modelo misto trata as respostas de cada indivíduo como medidas repetidas, considerando as correlações dessas medidas. As variáveis dependentes que não tinham distribuição normal foram transformadas com logaritmo natural ou raiz quadrada, conforme apropriado. Todos os modelos foram ajustados para índice de massa corpórea. A significância dos efeitos da parte fixa do modelo foi avaliada pelo teste Wald. Os modelos foram avaliados por distribuição normal dos resíduos e dos efeitos aleatórios, bem como pela avaliação dos intervalos de confiança dos parâmetros estimados. Para cada 


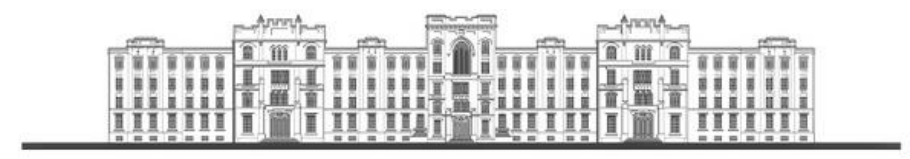

variável dependente avaliada, a seleção do melhor modelo foi feita pelo Critério de Informação Akaike. As análises foram feitas com o pacote R (versão 2.15.3) e para os modelos mistos, utilizou-se a biblioteca computacional NLME (Linear and Non linear Mixed Effects Models) (80). Como análise exploratória, também foram avaliados modelos que incluíram o dia da semana, se $2^{\underline{a}}$ feira ou $6^{\underline{a}}$ feira, em que o exercício/corrida foi realizado em cada circuito (referência $2^{\underline{a}}$ feira). 


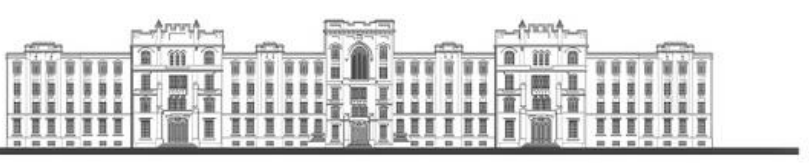

\section{RESULTADOS}

Todos os resultados foram expressos em valores Pré e Pós-corrida, em cada um dos circuitos.

\section{IV.1 - Resultados das variáveis ambientais e antropométricas}

Na Tabela 1 são descritas as características dos poluentes e variáveis climáticas. A concentração de $\mathrm{MP}_{2,5}$ medida durante o período de estudo, especificamente nos dias de corrida foi 3 vezes maior no Circuito em Via Pública com relação ao Circuito Parque. Não houve variação significativa nas variáveis climáticas.

Tabela 1 - Concentração de Material Particulado, Temperatura e Umidade Relativa do Ar durante o período de estudo.

\begin{tabular}{|c|c|c|c|}
\hline & $\begin{array}{c}\text { Circuito PQ } \\
\text { Média ( } \pm \text { DP) } \\
\text { Mediana (IIQ) }\end{array}$ & $\begin{array}{c}\text { Circuito VP } \\
\text { Média ( } \pm \text { DP) } \\
\text { Mediana (IIQ) }\end{array}$ & Valor de $p$ \\
\hline $\mathrm{MP}_{2,5}\left(\mu \mathrm{g} / \mathrm{m}^{3}\right)$ & $\begin{array}{c}23,90(15,40) \\
23,50(8,00-39,00)\end{array}$ & $\begin{array}{c}71,80(43,00) \\
62,00(37,50-103,00)\end{array}$ & $<0,001$ \\
\hline Temperatura $\left({ }^{\circ} \mathrm{C}\right)$ & $\begin{array}{c}22,35(1,96) \\
22,60(21,70-23,50)\end{array}$ & $\begin{array}{c}22,10(1,88) \\
22,20(20,90-23,50)\end{array}$ & 0,187 \\
\hline URar (\%) & $\begin{array}{c}58,34(6,69) \\
59,00(54,00-61,00)\end{array}$ & $\begin{array}{c}58,58(6,77) \\
59,00(54,25-61,00)\end{array}$ & 0,884 \\
\hline
\end{tabular}

Nota: $\mathrm{MP}_{2,5}$ : material particulado com diâmetro $<2,5 \mu \mathrm{m}$; URar\%: umidade relativa do ar em \%. Dados monitorados durante as corridas de $2^{\mathrm{a}}$ a $6^{\mathrm{a}}$ feira durante 0 período de estudo (de 10/09/2012 à 30/11/2012). 


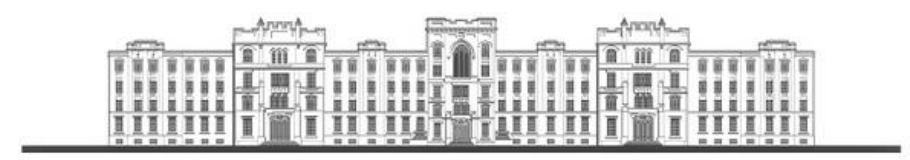

Na Tabela 2 são descritos os dados basais (valores pré-corrida registrados nas segundas-feiras) dos indivíduos avaliados. A frequência cardíaca média registrada com Polar durante as corridas foi 160,2 ( $\pm 10,22$ bpm) no Circuito PQ e 154,7 ( $\pm 10,3$ bpm) no Circuito VP, diferença não significativa $(p=0,178)$.

Tabela 2 - Características dos indivíduos avaliados, dados basais, pré-corrida $(\mathrm{N}=39)$.

\begin{tabular}{lc}
\hline & Média $( \pm$ DP) \\
\hline Idade $(\mathrm{anos})$ & $19,08(0,95)$ \\
IMC $\left(\mathrm{kg} / \mathrm{m}^{2}\right)$ & $23,5(2,38)$ \\
PAS $(\mathrm{mmHg})$ & $126,43(11,5)$ \\
PAD $(\mathrm{mmHg})$ & $70,10(7,82)$ \\
$\mathrm{FC}(\mathrm{bpm})$ & $69,1(10,4)$ \\
$\mathrm{CO}$ exalado $(\mathrm{ppm})$ & $1,37(2,04)$ \\
& $0,00(0-2,25)^{\star}$ \\
$\mathrm{SpO}_{2}(\%)$ & $97,5(0,95)$ \\
\hline
\end{tabular}

Nota: $\mathrm{N}$ = número de indivíduos avaliados; IMC = Índice de Massa Corpórea; PAS = Pressão Arterial Sistólica; PAD = Pressão Arterial Diastólica; FC = Frequência Cardíaca; $C O=$ Monóxido de Carbono em partes por milhão; $\mathrm{SpO}_{2}=$ Saturação de oxigênio. Valores expressos em Média \pm Desvio Padrão e *Mediana e Intervalo Interquartil.

Devido à ocorrência de chuvas em um dos dias de avaliação, impossibilitando a corrida, as análises pareadas dos dados dos circuitos nas 6as feiras contaram com 34 em vez de 39 participantes. 


\section{IV.2 - Resultados dos marcadores sanguíneos nos circuitos}

Nas Tabelas 3 a 6 são apresentados os resultados das determinações dos marcadores analisados sanguíneos pré e pós-corridas, por circuito, por dia da semana ( $2^{\mathrm{a}}$ feira e $6^{\mathrm{a}}$ feira).

Tabela 3 - Resultado dos marcadores sanguíneos (Circuito em Parque), Pré e Pós-corrida às segundas-feiras $(\mathrm{N}=39)$.

\begin{tabular}{|c|c|c|c|}
\hline Variáveis & $\begin{array}{c}\text { PQ pré, } 2^{\text {a }} \text { feira } \\
\text { Media ( } \pm \text { DP) } \\
\text { Mediana (IIQ) }\end{array}$ & $\begin{array}{c}\text { PQ pós, } 2^{\text {a }} \text { feira } \\
\text { Media ( } \pm \text { DP) } \\
\text { Mediana (IIQ) }\end{array}$ & Valor $p$ \\
\hline $\begin{array}{l}\text { COHb } \\
(\%)\end{array}$ & $\begin{array}{c}0,14(0,52) \\
0,05(0,05-0,05)\end{array}$ & $\begin{array}{c}0,05(0,00) \\
0,05(0,05-0,05)\end{array}$ & $0,250^{\star \star}$ \\
\hline $\begin{array}{l}\text { CPK } \\
(\mathrm{U} / \mathrm{L})\end{array}$ & $\begin{array}{c}239,78(232,92) \\
159(102,5-280,5)\end{array}$ & $\begin{array}{c}297,52(264,53) \\
202,50(139,50-354,50)\end{array}$ & $<0,001^{\star *}$ \\
\hline $\begin{array}{l}\mathrm{DHL} \\
(\mathrm{U} / \mathrm{L})\end{array}$ & $\begin{array}{c}180,41(39,32) \\
184,00(167,00-203,00)\end{array}$ & $\begin{array}{c}201,26(44,04) \\
197,00(174,00-233,00)\end{array}$ & $<0,001^{* *}$ \\
\hline $\begin{array}{l}\text { Eritrócitos } \\
\text { (milhões } / \mathrm{mm}^{3} \text { ) }\end{array}$ & $\begin{array}{c}5,36(0,31) \\
5,33(5,13-5,63)\end{array}$ & $\begin{array}{c}5,40(0,35) \\
5,37(5,13-5,77)\end{array}$ & $0,057^{*}$ \\
\hline $\begin{array}{l}\text { Hemoglobina } \\
(g / d L)\end{array}$ & $\begin{array}{c}15,44(0,74) \\
15,50(14,70-15,90)\end{array}$ & $\begin{array}{c}15,53(0,80) \\
15,30(14,90-16,20)\end{array}$ & $0,139^{*}$ \\
\hline $\begin{array}{l}\text { Hematócrito } \\
(\%)\end{array}$ & $\begin{array}{c}46,21(2,14) \\
46,00(44,30-48,10)\end{array}$ & $\begin{array}{c}45,83(2,24) \\
45,70(43,80-47,40)\end{array}$ & $0,029^{*}$ \\
\hline $\begin{array}{l}\text { Leucócitos } \\
\left(\mathrm{mil}^{\prime} / \mathrm{mm}^{3}\right)\end{array}$ & $\begin{array}{c}6,84(1,89) \\
6,41(5,99-7,05)\end{array}$ & $\begin{array}{c}7,21(2,00) \\
6,75(5,08-8,00)\end{array}$ & $0,053^{*}$ \\
\hline $\begin{array}{l}\text { Neutrófilos } \\
\left(\mathrm{mil}^{\mathrm{m}} \mathrm{mm}^{3}\right)\end{array}$ & $\begin{array}{c}3,65(1,70) \\
3,20(2,70-4,04)\end{array}$ & $\begin{array}{c}4,33(1,67) \\
4,12(3,40-4,93) \\
\end{array}$ & $<0,001^{*}$ \\
\hline $\begin{array}{l}\text { Linfócitos } \\
\left(\mathrm{mil} / \mathrm{mm}^{3}\right)\end{array}$ & $\begin{array}{c}2,16(0,53) \\
2,06(1,74-2,50)\end{array}$ & $\begin{array}{c}1,98(0,70) \\
1,87(1,57-2,31)\end{array}$ & $0,106^{*}$ \\
\hline $\begin{array}{l}\text { Monócitos } \\
\left(\mathrm{mil} / \mathrm{mm}^{3}\right)\end{array}$ & $\begin{array}{c}0,68(0,23) \\
0,66(0,60-0,73)\end{array}$ & $\begin{array}{c}0,60(0,22) \\
0,56(0,47-0,66)\end{array}$ & $<0,001^{*}$ \\
\hline $\begin{array}{l}\text { Plaquetas } \\
\left(\mathrm{mil}^{\prime} \mathrm{mm}^{3}\right)\end{array}$ & $\begin{array}{c}244,97(53,63) \\
251,00(214,00-275,00)\end{array}$ & $\begin{array}{c}261,05(56,51) \\
264,00(220,00-307,00)\end{array}$ & $0,002^{*}$ \\
\hline $\begin{array}{l}\text { Potássio soro } \\
\text { (mEq/L) }\end{array}$ & $\begin{array}{c}4,44(0,45) \\
4,40(4,10-4,80)\end{array}$ & $\begin{array}{c}4,62(0,39) \\
4,60(4,40-4,80)\end{array}$ & $0,070^{*}$ \\
\hline $\begin{array}{l}\text { Sódio soro } \\
\text { (mEq/L) }\end{array}$ & $\begin{array}{c}141,17(9,49) \\
141,00(139-144)\end{array}$ & $\begin{array}{c}146,92(11,87) \\
142,00(141,00-146,00)\end{array}$ & $<0,001^{* *}$ \\
\hline $\begin{array}{l}\text { TP } \\
(\%)\end{array}$ & $\begin{array}{c}84,92(10,06) \\
84,50(77,75-93,50)\end{array}$ & $\begin{array}{c}84,89(9,38) \\
84,00(77,00-92,00)\end{array}$ & $0,922^{*}$ \\
\hline $\begin{array}{l}\text { TTPA } \\
\text { (segundos) }\end{array}$ & $\begin{array}{c}38,91(3,82) \\
38,20(36,20-41,12) \\
\end{array}$ & $\begin{array}{c}36,66(4,34) \\
36,20(34,30-39,60) \\
\end{array}$ & $<0,001^{* *}$ \\
\hline \multicolumn{4}{|c|}{$\begin{array}{l}\text { Nota: } \mathrm{PQ}=\text { Circuito Parque; } \mathrm{COHb} \% \text { : \% carboxihemoglobina no sangue; TGP: A transaminase } \\
\text { glutâmico pirúvica; TGO: transaminase glutâmico oxalacética; CPK: creatinaquinase; DHL: } \\
\text { desidrogenase lática; TP: tempo de trombina; INR: Índice Internacional Normalizado do TP; } \\
\text { TTPA: Tempo de tromboplastina parcial ativada. Valores expressos em Média } \pm \text { Desvio padrão e }\end{array}$} \\
\hline
\end{tabular}


Tabela 4 - Resultado dos marcadores sanguíneos (Circuito em Parque), Pré e

Pós-corrida às sextas-feiras $(\mathrm{N}=34)$.

\begin{tabular}{|c|c|c|c|}
\hline Variáveis & $\begin{array}{c}\text { PQ pré, 6⿳a feira } \\
\text { Media ( } \pm \text { DP) } \\
\text { Mediana (IIQ) }\end{array}$ & $\begin{array}{c}\text { PQ pós, 6a feira } \\
\text { Media ( } \pm \text { DP) } \\
\text { Mediana (IIQ) } \\
\end{array}$ & Valor $p$ \\
\hline $\begin{array}{l}\text { COHb } \\
(\%)\end{array}$ & $\begin{array}{c}0,05(0,04) \\
0,05(0,05-0,05)\end{array}$ & $\begin{array}{c}0,05(0,00) \\
0,05(0,05-0,05)\end{array}$ & $1,000^{* *}$ \\
\hline $\begin{array}{l}\text { CPK } \\
(\mathrm{U} / \mathrm{L})\end{array}$ & $\begin{array}{c}336,25(207,37) \\
342,00(150,00-421,00)\end{array}$ & $\begin{array}{c}408,41(234,28) \\
350,00(223,50-557,50)\end{array}$ & $<0,001^{\star *}$ \\
\hline $\begin{array}{l}\text { DHL } \\
\text { (U/L) }\end{array}$ & $\begin{array}{c}190,24(43,00) \\
187,50(174,00-210,00)\end{array}$ & $\begin{array}{c}223,35(38,10) \\
223,00(198,00-246,00)\end{array}$ & $<0,001^{* *}$ \\
\hline $\begin{array}{l}\text { Eritrócitos } \\
\text { (milhões/mm³) }\end{array}$ & $\begin{array}{c}5,20(0,30) \\
5,12(4,97-5,42) \\
\end{array}$ & $\begin{array}{c}5,24(0,34) \\
5,14(4,95-5,56) \\
\end{array}$ & $0,311^{*}$ \\
\hline $\begin{array}{l}\text { Hemoglobina } \\
(\mathrm{g} / \mathrm{dL})\end{array}$ & $\begin{array}{c}14,94(0,72) \\
14,90(14,40-15,40)\end{array}$ & $\begin{array}{c}15,03(0,86) \\
15,00(14,47-15,60)\end{array}$ & $0,651^{*}$ \\
\hline $\begin{array}{l}\text { Hematócrito } \\
(\%)\end{array}$ & $\begin{array}{c}45,10(1,99) \\
45,40(43,60-46,40)\end{array}$ & $\begin{array}{c}44,71(2,29) \\
44,35(42,92-46,42)\end{array}$ & $0,243^{*}$ \\
\hline $\begin{array}{l}\text { Leucócitos } \\
\left(\mathrm{mil} / \mathrm{mm}^{3}\right)\end{array}$ & $\begin{array}{c}6,34(1,22) \\
6,28(5,47-7,08)\end{array}$ & $\begin{array}{c}7,61(2,22) \\
7,31(6,03-8,58)\end{array}$ & $<0,001^{\star *}$ \\
\hline $\begin{array}{l}\text { Neutrófilos } \\
\left(\mathrm{mil} / \mathrm{mm}^{3}\right)\end{array}$ & $\begin{array}{c}3,49(1,03) \\
3,39(2,85-3,78)\end{array}$ & $\begin{array}{c}4,43(1,49) \\
4,05(3,32-5,28)\end{array}$ & $<0,001^{* *}$ \\
\hline $\begin{array}{l}\text { Linfócitos } \\
\left(\mathrm{mil} / \mathrm{mm}^{3}\right)\end{array}$ & $\begin{array}{c}1,92(0,44) \\
1,91(1,55-2,19)\end{array}$ & $\begin{array}{c}2,24(0,83) \\
2,12(1,59-2,58)\end{array}$ & $0,004^{*}$ \\
\hline $\begin{array}{l}\text { Monócitos } \\
\left(\mathrm{mil} / \mathrm{mm}^{3}\right)\end{array}$ & $\begin{array}{c}0,66(0,21) \\
0,60(0,54-0,70)\end{array}$ & $\begin{array}{c}0,69(0,30) \\
0,63(0,51-0,83)\end{array}$ & $0,262^{*}$ \\
\hline $\begin{array}{l}\text { Plaquetas } \\
\left(\mathrm{mil}^{3} / \mathrm{mm}^{3}\right)\end{array}$ & $\begin{array}{c}241,69(50,06) \\
245,00(210,00-270,00)\end{array}$ & $\begin{array}{c}262,47(68,55) \\
260,50(214,50-294,50)\end{array}$ & $0,043^{*}$ \\
\hline $\begin{array}{l}\text { Potássio soro } \\
\text { (mEq/L) }\end{array}$ & $\begin{array}{c}4,53(0,57) \\
4,40(4,30-4,70) \\
\end{array}$ & $\begin{array}{c}4,46(0,30) \\
4,40(4,30-4,62) \\
\end{array}$ & $0,699^{*}$ \\
\hline $\begin{array}{l}\text { Sódio soro } \\
\text { (mEq/L) }\end{array}$ & $\begin{array}{c}146,71(16,85) \\
142,00(141,00-144,00)\end{array}$ & $\begin{array}{c}142,29(2,45) \\
142(140,00-143,25)\end{array}$ & $0,737^{\star \star}$ \\
\hline $\begin{array}{l}\text { TP } \\
(\%)\end{array}$ & $\begin{array}{c}82,46(12,18) \\
87,00(73,00-90,00)\end{array}$ & $\begin{array}{c}83,08(12,62) \\
85,00(71,75-92,25) \\
\end{array}$ & $0,861^{*}$ \\
\hline $\begin{array}{l}\text { TTPA } \\
\text { (segundos) }\end{array}$ & $\begin{array}{c}39,85(4,91) \\
39,50(35,60-44,10)\end{array}$ & $\begin{array}{c}38,01(3,77) \\
38,20(35,27-40,32)\end{array}$ & $0,009^{* *}$ \\
\hline
\end{tabular}

Nota: $\mathrm{PQ}=$ Circuito Parque; $\mathrm{COHb} \%: \%$ carboxihemoglobina no sangue; TGP: A transaminase glutâmico pirúvica; TGO: transaminase glutâmico oxalacética; CPK: creatinaquinase; DHL: desidrogenase lática; TP: tempo de trombina; INR: Índice Internacional Normalizado do TP;

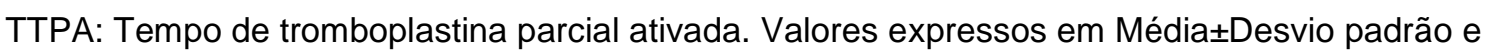
mediana e Intervalo Interquartil; * Teste $t{ }^{* *}$ Wilcoxon Signed Rank Test. 
Tabela 5 - Resultado dos marcadores sanguíneos (Circuito Vias Públicas), Pré

e Pós-corrida às segundas-feiras $(\mathrm{N}=39)$.

\begin{tabular}{|c|c|c|c|}
\hline Variável & $\begin{array}{l}\text { VP pré, } 2^{\text {a }} \text { feira } \\
\text { Media ( } \pm \text { DP) } \\
\text { Mediana (IIQ) }\end{array}$ & $\begin{array}{l}\text { VP pós, } 2^{\text {a }} \text { feira } \\
\text { Media ( } \pm \text { DP) } \\
\text { Mediana (IIQ) }\end{array}$ & Valor $p$ \\
\hline $\begin{array}{l}\text { COHb } \\
(\%)\end{array}$ & $\begin{array}{c}0,28(0,87) \\
0,05(0,05-4,20) \\
\end{array}$ & $\begin{array}{c}0,13(0,53) \\
0,05(0,05-3,40) \\
\end{array}$ & $0,125^{\star *}$ \\
\hline $\begin{array}{l}\text { CPK } \\
\text { (U/L) }\end{array}$ & $\begin{array}{c}213,08(135,64) \\
159,00(120,50-282,50)\end{array}$ & $\begin{array}{c}265,51(134,88) \\
212,00(166,50-340,00)\end{array}$ & $<0,001^{\star *}$ \\
\hline $\begin{array}{l}\mathrm{DHL} \\
(\mathrm{U} / \mathrm{L})\end{array}$ & $\begin{array}{c}193,77(59,55) \\
192,00(167,50-211,50)\end{array}$ & $\begin{array}{c}218,60(59,03) \\
216,00(190,00-233,00)\end{array}$ & $<0,001^{* *}$ \\
\hline $\begin{array}{l}\text { Eritrócitos } \\
\text { (milhões/mm³) }\end{array}$ & $\begin{array}{c}5,37(0,34) \\
5,30(5,11-5,66) \\
\end{array}$ & $\begin{array}{c}5,35(0,33) \\
5,34(5,11-5,56) \\
\end{array}$ & $0,354^{*}$ \\
\hline $\begin{array}{l}\text { Hemoglobina } \\
(\mathrm{g} / \mathrm{dL})\end{array}$ & $\begin{array}{c}15,38(0,73) \\
15,50(14,90-15,80)\end{array}$ & $\begin{array}{c}15,42(0,79) \\
15,45(14,92-16,00)\end{array}$ & $0,813^{*}$ \\
\hline $\begin{array}{l}\text { Hematócrito } \\
(\%)\end{array}$ & $\begin{array}{c}46,32(2,11) \\
46,70(44,30-47,90)\end{array}$ & $\begin{array}{c}45,48(2,03) \\
45,75(44,02-46,95) \\
\end{array}$ & $<0,001^{\star *}$ \\
\hline $\begin{array}{l}\text { Leucócitos } \\
\left(\mathrm{mil}^{\prime} / \mathrm{mm}^{3}\right)\end{array}$ & $\begin{array}{c}6,93(1,87) \\
6,38(5,52-7,86)\end{array}$ & $\begin{array}{c}7,34(2,20) \\
6,91(5,75-8,65)\end{array}$ & $0,111^{*}$ \\
\hline $\begin{array}{l}\text { Neutrófilos } \\
\left(\mathrm{mil} / \mathrm{mm}^{3}\right)\end{array}$ & $\begin{array}{c}3,85(1,56) \\
3,57(2,69-4,56)\end{array}$ & $\begin{array}{c}4,29(1,54) \\
3,76(3,16-5,64) \\
\end{array}$ & $0,003^{*}$ \\
\hline $\begin{array}{l}\text { Linfócitos } \\
\left(\mathrm{mil} / \mathrm{mm}^{3}\right)\end{array}$ & $\begin{array}{c}2,03(0,42) \\
1,96(1,73-2,33)\end{array}$ & $\begin{array}{c}2,12(0,81) \\
2,04(1,61-2,48) \\
\end{array}$ & $0,454^{*}$ \\
\hline $\begin{array}{l}\text { Monócitos } \\
\left(\mathrm{mil} / \mathrm{mm}^{3}\right)\end{array}$ & $\begin{array}{c}0,71(0,17) \\
0,75(0,54-0,86)\end{array}$ & $\begin{array}{c}0,66(0,26) \\
0,60(0,50-0,72)\end{array}$ & $0,125^{*}$ \\
\hline $\begin{array}{l}\text { Plaquetas } \\
\left(\mathrm{mil}^{\prime} / \mathrm{mm}^{3}\right)\end{array}$ & $\begin{array}{c}243,21(50,66) \\
232,00(206,00-269,00)\end{array}$ & $\begin{array}{c}257,26(62,35) \\
244,50(211,75-301,75)\end{array}$ & $0,031^{*}$ \\
\hline $\begin{array}{l}\text { Potássio soro } \\
(\mathrm{mEq} / \mathrm{L})\end{array}$ & $\begin{array}{c}4,64(0,51) \\
4,60(4,30-4,80)\end{array}$ & $\begin{array}{c}4,63(0,40) \\
4,55(4,30-4,90)\end{array}$ & $0,974^{*}$ \\
\hline $\begin{array}{l}\text { Sódio soro } \\
\text { (mEq/L) }\end{array}$ & $\begin{array}{c}144,05(11,11) \\
141,00(139,00-144,00)\end{array}$ & $\begin{array}{c}144,50(5,72) \\
142,50(141,00-146,00)\end{array}$ & $0,128^{\star *}$ \\
\hline $\begin{array}{l}\text { TP } \\
(\%)\end{array}$ & $\begin{array}{c}84,97(11,18) \\
85,50(77,00-94,50)\end{array}$ & $\begin{array}{c}82,71(10,08) \\
86,00(75,00-90,00)\end{array}$ & $0,102^{*}$ \\
\hline $\begin{array}{l}\text { TTPA } \\
\text { (segundos) }\end{array}$ & $\begin{array}{c}39,45(3,61) \\
39,35(37,00-41,35) \\
\end{array}$ & $\begin{array}{c}37,96(4,65) \\
38,05(34,47-40,57) \\
\end{array}$ & $0,090^{\star \star}$ \\
\hline
\end{tabular}

Nota: $\mathrm{PQ}=$ Circuito Parque; $\mathrm{COHb} \%: \%$ carboxihemoglobina no sangue; TGP: A transaminase glutâmico pirúvica; TGO: transaminase glutâmico oxalacética; CPK: creatinaquinase; DHL: desidrogenase lática; TP: tempo de trombina; INR: Índice Internacional Normalizado do TP;

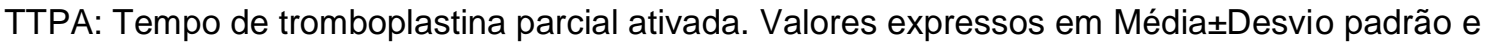
mediana e Intervalo Interquartil; * Teste t ${ }^{* *}$ Wilcoxon SignedRank Test. 
Tabela 6 - Resultado dos marcadores sanguíneos (Circuito Vias Públicas), Pré

e Pós-corrida às sextas-feiras $(\mathrm{N}=34)$.

\begin{tabular}{|c|c|c|c|}
\hline Variáveis & $\begin{array}{l}\text { VP pré, 6 } \text { a feira } \\
\text { Media ( } \pm \text { DP) } \\
\text { Mediana (IIQ) }\end{array}$ & $\begin{array}{l}\text { VP pós, 6aㅡ feira } \\
\text { Media ( } \pm \text { DP) } \\
\text { Mediana (IIQ) }\end{array}$ & Valor $p$ \\
\hline $\begin{array}{l}\text { COHb } \\
(\%)\end{array}$ & $\begin{array}{c}0,05(0,00) \\
0,05(0,05-0,05)\end{array}$ & $\begin{array}{c}0,07(0,13) \\
0,05(0,05-0,05)\end{array}$ & $1,000^{* \star}$ \\
\hline $\begin{array}{l}\text { CPK } \\
\text { (U/L) }\end{array}$ & $\begin{array}{c}315,81(198,58) \\
244,00(177,00-385,25)\end{array}$ & $\begin{array}{c}370,21(212,85) \\
301,00(225,50-444,50)\end{array}$ & $<0,001^{* *}$ \\
\hline $\begin{array}{l}\mathrm{DHL} \\
(\mathrm{U} / \mathrm{L})\end{array}$ & $\begin{array}{c}197,51(46,07) \\
203,00(180,00-210,00)\end{array}$ & $\begin{array}{c}220,82(57,37) \\
211,00(198,00-225,00)\end{array}$ & $<0,001^{* *}$ \\
\hline $\begin{array}{l}\text { Eritrócitos } \\
\left(\text { milhões } / \mathrm{mm}^{3}\right)\end{array}$ & $\begin{array}{c}5,16(0,25) \\
5,15(5,01-5,40)\end{array}$ & $\begin{array}{c}5,10(0,24) \\
5,08(4,96-5,27)\end{array}$ & $0,003^{*}$ \\
\hline $\begin{array}{l}\text { Hemoglobina } \\
\text { (g/dL) }\end{array}$ & $\begin{array}{c}14,77(0,65) \\
14,80(1,40-15,00) \\
\end{array}$ & $\begin{array}{c}14,59(0,68) \\
14,45(14,10-15,12)\end{array}$ & $0,008^{*}$ \\
\hline $\begin{array}{l}\text { Hematócrito } \\
(\%)\end{array}$ & $\begin{array}{c}44,90(1,97) \\
44,60(43,80-46,60)\end{array}$ & $\begin{array}{c}43,62(1,86) \\
43,45(42,60-44,90)\end{array}$ & $<0,001^{* \star}$ \\
\hline $\begin{array}{l}\text { Leucócitos } \\
\left(\mathrm{mil}^{\prime} \mathrm{mm}^{3}\right)\end{array}$ & $\begin{array}{c}6,14(1,15) \\
6,05(5,27-6,79) \\
\end{array}$ & $\begin{array}{c}6,98(2,26) \\
6,53(5,26-7,76)\end{array}$ & $0,008^{*}$ \\
\hline $\begin{array}{l}\text { Neutrófilos } \\
\left(\mathrm{mil} / \mathrm{mm}^{3}\right)\end{array}$ & $\begin{array}{c}3,32(1,05) \\
3,27(2,46-4,10)\end{array}$ & $\begin{array}{c}4,04(1,64) \\
3,82(2,87-4,79) \\
\end{array}$ & $0,004^{*}$ \\
\hline $\begin{array}{l}\text { Linfócitos } \\
\left(\mathrm{mil} / \mathrm{mm}^{3}\right)\end{array}$ & $\begin{array}{c}1,81(0,46) \\
1,88(1,64-2,01)\end{array}$ & $\begin{array}{c}2,05(0,70) \\
1,84(1,60-2,49)\end{array}$ & $0,007^{*}$ \\
\hline $\begin{array}{l}\text { Monócitos } \\
\left(\mathrm{mil} / \mathrm{mm}^{3}\right)\end{array}$ & $\begin{array}{c}0,67(0,17) \\
0,67(0,55-0,76) \\
\end{array}$ & $\begin{array}{c}0,65(0,18) \\
0,61(0,54-0,78) \\
\end{array}$ & $0,053^{*}$ \\
\hline $\begin{array}{l}\text { Plaquetas } \\
\left(\mathrm{mil} / \mathrm{mm}^{3}\right)\end{array}$ & $\begin{array}{c}244,90(49,32) \\
246,00(212,00-291,00)\end{array}$ & $\begin{array}{c}251,70(53,13) \\
246,50(214,75-286,25) \\
\end{array}$ & $0,093^{*}$ \\
\hline $\begin{array}{l}\text { Potássio soro } \\
\text { (mEq/L) }\end{array}$ & $\begin{array}{c}4,57(0,59) \\
4,40(4,30-4,70)\end{array}$ & $\begin{array}{c}4,39(0,32) \\
4,40(4,20-4,70)\end{array}$ & $0,343^{*}$ \\
\hline $\begin{array}{l}\text { Sódio soro } \\
(\mathrm{mEq} / \mathrm{L})\end{array}$ & $\begin{array}{c}147,02(16,14) \\
142,00(141,00-144,00)\end{array}$ & $\begin{array}{c}142,00(1,80) \\
142,00(141,00-143,00)\end{array}$ & $0,761^{* *}$ \\
\hline $\begin{array}{l}\text { TP } \\
(\%)\end{array}$ & $\begin{array}{c}85,30(11,89) \\
89,00(76,00-95,00)\end{array}$ & $\begin{array}{c}82,58(11,19) \\
82,50(73,50-90,00)\end{array}$ & $0,187^{*}$ \\
\hline $\begin{array}{l}\text { TTPA } \\
\text { (segundos) }\end{array}$ & $\begin{array}{c}39,41(4,85) \\
40,10(36,70-42,50)\end{array}$ & $\begin{array}{c}38,38(4,14) \\
37,80(35,30-40,95)\end{array}$ & $0,031^{* *}$ \\
\hline
\end{tabular}

Nota: $\mathrm{PQ}=$ Circuito Parque; $\mathrm{COHb} \%: \%$ carboxihemoglobina no sangue; TGP: $\mathrm{A}$ transaminase glutâmico pirúvica; TGO: transaminase glutâmico oxalacética; CPK: creatinaquinase; DHL: desidrogenase lática; TP: tempo de trombina; INR: Índice Internacional Normalizado do TP; TTPA: Tempo de tromboplastina parcial ativada. Valores expressos em Média \pm Desvio padrão e mediana e Intervalo Interquartil; * Teste $t{ }^{* *}$ Wilcoxon Signed Rank Test. 


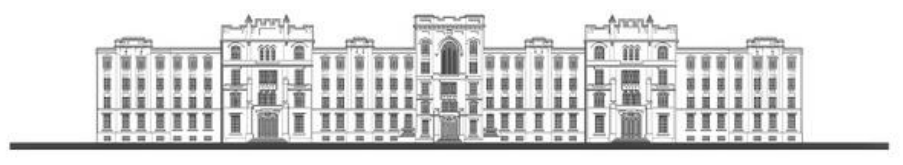

As tabelas 3 e 4 mostram os resultados obtidos nas avaliações pré e pósexercício das segundas e sextas-feiras do $P Q$. Os dados revelam aumento significativo das variáveis CPK, DHL, Neutrófilos, Plaquetas, e diminuição do TTPA, após as corridas, sódio sérico e diminuição do hematócrito e do TTPA após o exercício $(\mathrm{p}<0,005)$. Já nas sextas-feiras, houve aumento de CPK, DHL, Neutrófilos, Monócitos, Linfócitos, plaquetas e diminuição do TTPA após as corridas.

Nas Tabelas 5 e 6 são apresentados os resultados das avaliações pré e pós-exercício no circuito VP. Pode ser observada elevação da CPK, DHL, Plaquetas e Neutrófilos e diminuição do Hematócrito.

Os dados dos dois circuitos revelam diferenças no comportamento de alguns marcadores entre os dias da semana.

Em nenhuma das análises houve aumento significativo da carboxihemoglobina. 


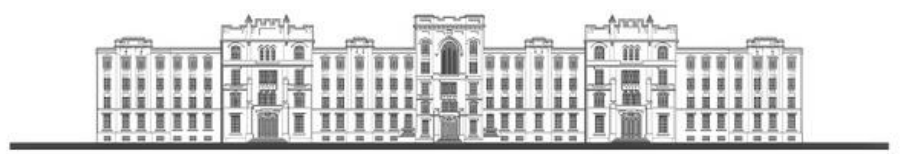

$\mathrm{Na}$ Tabela 7 são apresentados os dados das análises de regressão multivariada de alguns marcadores sanguíneos avaliados. Houve variação dos marcadores sanguíneos analisados após o exercício, mas sem associação com circuito.

Tabela 7 - Efeito da realização de exercício e do local em marcadores sanguíneos. Modelo de regressão linear com efeito misto $(\mathrm{N}=39)$.

\begin{tabular}{|c|c|c|c|c|}
\hline Marcador & $\begin{array}{l}\text { Variáveis de Efeito } \\
\text { (\&) }\end{array}$ & $\begin{array}{c}\text { Coeficiente } \\
\text { de Regressão }\end{array}$ & $\begin{array}{c}\text { Erro } \\
\text { Padrão }\end{array}$ & Valor $p$ \\
\hline Plaquetas $\left(\mathrm{mil} / \mathrm{mm}^{3}\right)^{\star \star}$ & Exercício & 17,8384 & 4,9650 & 0,0001 \\
\hline Hematócrito $(\%)^{\star \star \star}$ & Exercício & $-0,3330$ & 0,2496 & 0,0003 \\
\hline CPK $(U / L) * *$ & Exercício & 0,2680 & 0,0405 & 0,0001 \\
\hline DHL (U/L) ** & Exercício & 16,630 & 8,1082 & 0,0001 \\
\hline Neutrófilos $\left(\mathrm{mil} / \mathrm{mm}^{3}\right)^{* *}$ & Exercício & 0,1696 & 0,0268 & 0,0001 \\
\hline
\end{tabular}

Nota: *Modelo de regressão linear com efeito misto, ajustado para IMC; ** Log: Dados de análise com transformação logarítmica dos valores; ${ }^{* * *}$ Dados de análise com transformação em raiz quadrada dos valores; \&: Efeito do exercício tendo como referência o repouso pré-corrida. 


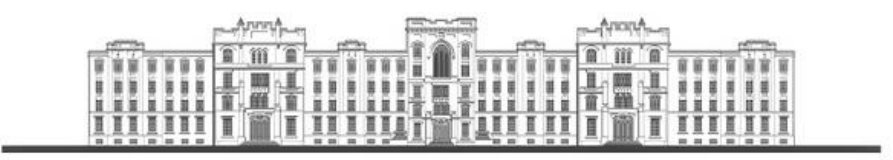

\section{IV.3 - Resultados da análise da Proteína CC16 nos circuitos}

Abaixo, apresentamos a sequência de resultados das análises da proteína CC16 nos circuitos PQ e VP, separando os resultados por dia da semana em que a corrida foi executada e unindo os dois dias.

Tabela 8 - Resultado das análises da proteína CC16 corrigida pela creatinina urinária $(\mu \mathrm{g} / \mathrm{g})(\mathrm{N}=39)$.

\begin{tabular}{llccc}
\hline Circuito & Dia da semana & $\begin{array}{c}\text { Pré-corrida } \\
\text { Mediana (IQR) }\end{array}$ & $\begin{array}{c}\text { Pós-corrida } \\
\text { Mediana (IQR) }\end{array}$ & Valor $\mathbf{p}^{*}$ \\
\hline \multirow{2}{*}{ PQ } & Segundas & $5,47(2,31-8,44)$ & $25,99(17,44-72,40)$ & $<0,001$ \\
& Sextas & $6,27(1,96-13,67)$ & $20,58(10,77-40,73)$ & $<0,001$ \\
& Segundas + Sextas & $6,19(2,10-9,93)$ & $22,60(13,01-47,36)$ & $<0,001$ \\
\hline VP & Segundas & $9,40(4,11-17,26)$ & $18,30(9,35-27,56)$ & $<0,001$ \\
& Sextas & $8,39(2,44-12,68)$ & $22,64(13,17-30,75)$ & $<0,001$ \\
& Segundas + Sextas & $9,31(3,27-13,97)$ & $19,44(11,10-30,22)$ & $<0,001$ \\
\hline
\end{tabular}

Nota: Os valores em ng/g, resultado da divisão do resultado da Proteína CC16 pelo resultado da creatinina, expressos como mediana e intervalo interquartil (IQR); $P Q=$ Parque; $V P=$ Vias Públicas. * Wilcoxon Signed- Rank Test.

A Tabela 8 mostra os resultados da análise da proteína CC16, por pré e pós-exercício, por dias da semana e com resultados de segunda e sexta-feira juntos. 


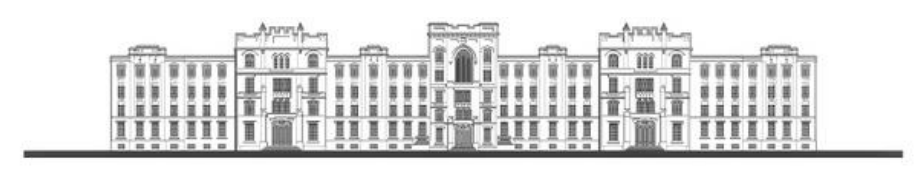

Tabela 9 - Avaliação do efeito* da realização de exercício e do local (Parque x Via Pública) no marcador pulmonar- proteína CC16 corrigida pela creatinina urinária $(\mathrm{N}=39)$.

\begin{tabular}{|c|c|c|c|c|}
\hline Marcador & $\begin{array}{c}\text { Variáveis de Efeito } \\
\text { (\&) }\end{array}$ & $\begin{array}{l}\text { Coeficiente de } \\
\text { Regressão }\end{array}$ & Erro Padrão & Valor $p$ \\
\hline \multirow{3}{*}{$\begin{array}{l}\text { Proteína CC16 } \\
(\mu \mathrm{g} / \mathrm{g})^{\star *}\end{array}$} & Exercício & 1,6511 & 0,1753 & $<0,0001$ \\
\hline & Circuito VP & 0,2400 & 0,1553 & 0,8138 \\
\hline & $\begin{array}{l}\text { Interação Local e } \\
\text { Exercício }\end{array}$ & $-0,4437$ & 0,2238 & 0,0485 \\
\hline
\end{tabular}
com transformação logarítmica dos valores; \&: Efeito do exercício tendo como referência o repouso pré-corrida e o efeito circuito do VP tendo como referência circuito $P Q$.

A análise multivariada (Tabela 9) revelou que o efeito do exercício no aumento da proteína CC16, foi de 5,21 vezes com relação ao repouso no circuito PQ [exponencial $(1,6511)]$, superior ao aumento observado após a corrida no circuito VP, que foi de 4,52 vezes [exponencial $(1,6511+0,2400+(-0,4437)]$, ou seja, a proteína aumentou após o exercício, porém, apresentou aumento mais significativo após a corrida realizada em ambiente com concentrações menores de $\mathrm{MP}_{2,5}$.

O gráfico 1 mostra o perfil individual de aumento da proteína CC16 corrigida pela creatinina do pré para o pós-corrida em ambos os circuitos, e o gráfico 2 mostra o comportamento da proteína CC16 corrigida pela creatinina do grupo todo no pré e pós-corrida em ambos os circuitos. 


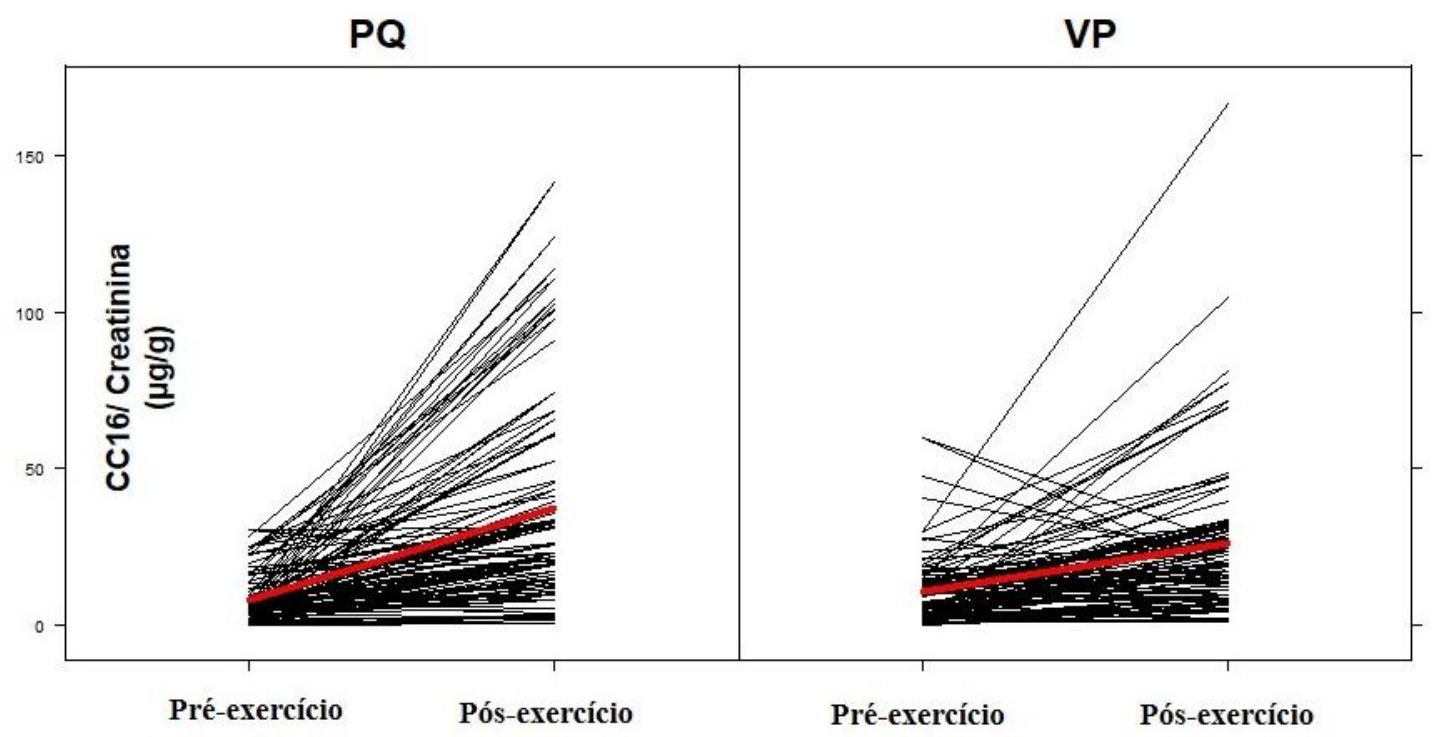

Gráfico 1 - Gráfico de perfil individual e perfil do grupo no aumento da proteína CC16 corrigida pela Creatinina nos indivíduos em ambos os circuitos.

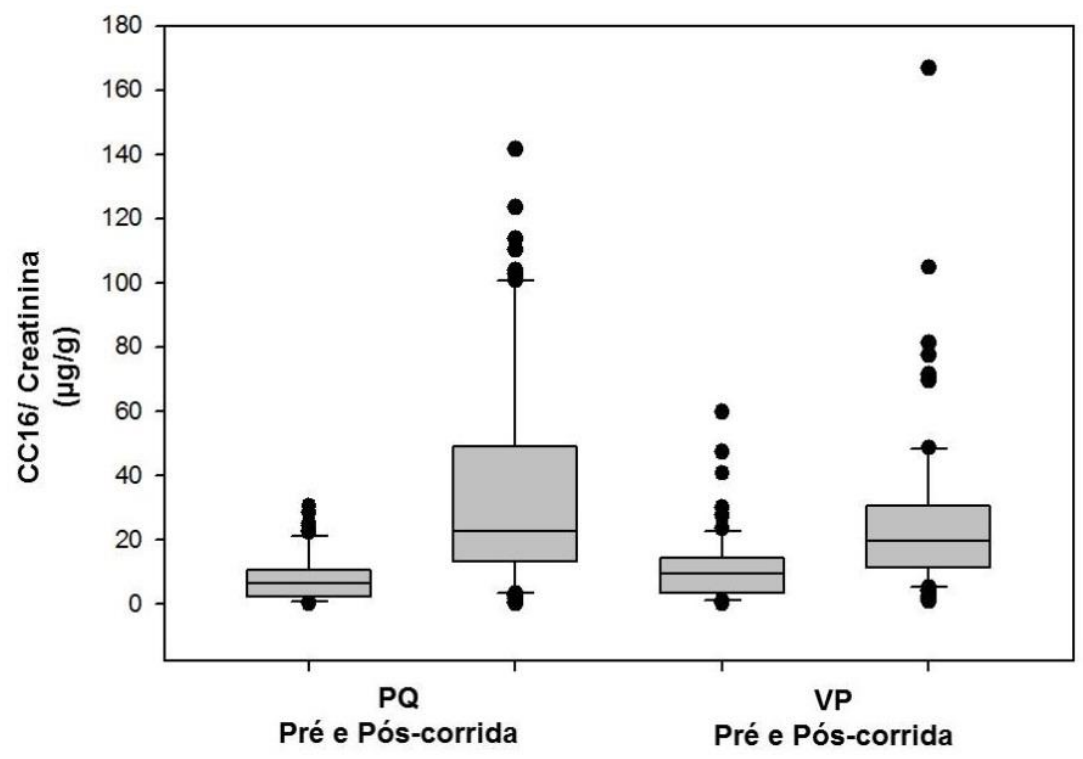

Gráfico 2 - Box plot dos valores da proteína CC16 corrigida pela creatinina antes e após a corrida nos circuitos. 


\section{IV.4. - Resultados dos marcadores de Função Renal nos circuitos}

Nas tabelas 10,11, 12 e 13 temos os resultados da análise de marcadores para avaliação da função renal.

Tabela 10 - Resultado dos marcadores renais por circuito (Circuito Parque), Pré

e Pós-corrida às segundas-feiras $(\mathrm{N}=39)$.

\begin{tabular}{|c|c|c|c|}
\hline Variáveis & $\begin{array}{c}\text { PQ pré, } 2^{a} \text { feira } \\
\text { Media ( } \pm \text { DP) } \\
\text { Mediana (IIQ) }\end{array}$ & $\begin{array}{c}\text { PQ pós, 2a feira } \\
\text { Media ( } \pm \text { DP) } \\
\text { Mediana (IIQ) }\end{array}$ & Valor $p$ \\
\hline $\begin{array}{l}\text { Creatinina } \\
(\mathrm{mg} / \mathrm{dL})\end{array}$ & $\begin{array}{c}0,86(0,16) \\
0,90(0,80-1,00)\end{array}$ & $\begin{array}{c}0,97(0,18) \\
1,00(0,90-1,10)\end{array}$ & $<0,001^{\star *}$ \\
\hline $\begin{array}{l}\text { Creatinina urina } \\
\text { (g/L) }\end{array}$ & $\begin{array}{c}1,45(0,70) \\
1,29(0,92-1,89)\end{array}$ & $\begin{array}{c}1,84(1,08) \\
1,68(1,14-2,17) \\
\end{array}$ & $0,057^{* *}$ \\
\hline $\begin{array}{l}\text { Microalbuminuria } \\
\text { (mg/L) }\end{array}$ & $\begin{array}{c}9,97(26,36) \\
3,20(0-8,20) \\
\end{array}$ & $\begin{array}{c}89,32(166,39) \\
20,4(6,60-111,6)\end{array}$ & $<0,001^{* *}$ \\
\hline $\begin{array}{l}\text { Potássio urina } \\
\text { (mEq/L) }\end{array}$ & $\begin{array}{c}54,71(30,17) \\
48,00(32,00-70,00)\end{array}$ & $\begin{array}{c}66,71(27,07) \\
66,00(46,00-84,00)\end{array}$ & $0,070^{*}$ \\
\hline $\begin{array}{l}\text { Sódio urina } \\
\text { (mEq/L) }\end{array}$ & $\begin{array}{c}152,05(52,03) \\
158,00(111,00-191,00)\end{array}$ & $\begin{array}{c}116,12(50,54) \\
103,000(77,00-157,00)\end{array}$ & $<0,001^{* *}$ \\
\hline $\begin{array}{l}\text { KIM-1 } \\
\text { (ng/ml) }\end{array}$ & $\begin{array}{c}0,44(0,38) \\
0,31(0,18-0,56)\end{array}$ & $\begin{array}{c}1,24(1,81) \\
0,82(0,47-1,39) \\
\end{array}$ & $0,009^{*}$ \\
\hline $\begin{array}{l}\text { Cistatina C } \\
\text { (ng/ml) }\end{array}$ & $\begin{array}{c}159,63(178,93) \\
97,16(19,09-243,88)\end{array}$ & $\begin{array}{c}442,64(505,55) \\
298,41(167,30-459,26)\end{array}$ & $<0,001^{\star *}$ \\
\hline $\begin{array}{l}\text { Ngal soro } \\
\text { (ng/ml) }\end{array}$ & $\begin{array}{c}131,00(83,49) \\
115,22(63,99-178,32)\end{array}$ & $\begin{array}{c}160,52(81,67) \\
146,58(110,56-194,12)\end{array}$ & $0,035^{\star \star}$ \\
\hline $\begin{array}{l}\text { Ngal urina } \\
\text { (ng/ml) }\end{array}$ & $\begin{array}{c}72,70(64,04) \\
56,50(24,08-110,00) \\
\end{array}$ & $\begin{array}{c}137,28(95,00) \\
101,20(85,00-191,22) \\
\end{array}$ & $0,018^{\star \star}$ \\
\hline $\begin{array}{l}\text { FENa } \\
(\%)\end{array}$ & $\begin{array}{c}0,79(0,44) \\
0,79(0,36-1,03) \\
\end{array}$ & $\begin{array}{c}0,53(0,36) \\
0,41(0,26-0,82) \\
\end{array}$ & $0,003^{* *}$ \\
\hline $\begin{array}{l}\text { CKD-epi } \\
\left(\mathrm{ml} / \mathrm{min} / 1,73 \mathrm{~m}^{2}\right)\end{array}$ & $\begin{array}{c}122,00(14,00) \\
123,40(109,40-130,00)\end{array}$ & $\begin{array}{c}111,00(19,25) \\
109,00(97,00-124,00)\end{array}$ & $<0,001^{*}$ \\
\hline $\begin{array}{l}\text { MDRD } \\
\left(\mathrm{mL} / \mathrm{min} / 1,73 \mathrm{~m}^{2}\right)\end{array}$ & $\begin{array}{c}122,50(26,00) \\
115,50(103,40-132,40)\end{array}$ & $\begin{array}{c}110,24(28,60) \\
102,30(92,00-116,15)\end{array}$ & $<0,001^{*}$ \\
\hline
\end{tabular}

Nota: FENa: Fração de excreção de Sódio; eFG CKD-EPI: Estimativa da Taxa de Filtração Glomerular pela fórmula Chronic Kidney Disease Epidemiology; * Teste $t$ ** Wilcoxon Signed Rank Test. 
Tabela 11 - Resultado dos marcadores renais por circuito (Circuito Parque), Pré

e Pós-corrida às sextas-feiras $(\mathrm{N}=34)$.

\begin{tabular}{|c|c|c|c|}
\hline Variáveis & $\begin{array}{c}\text { PQ pré, 6a feira } \\
\text { Media ( } \pm \text { DP) } \\
\text { Mediana (IIQ) }\end{array}$ & $\begin{array}{c}\text { PQ pós, 6a feira } \\
\text { Media ( } \pm \text { DP) } \\
\text { Mediana (IIQ) }\end{array}$ & Valor $p$ \\
\hline $\begin{array}{l}\text { Creatinina } \\
\text { (mg/dL) }\end{array}$ & $\begin{array}{c}0,87(0,15) \\
0,90(0,80-1,00)\end{array}$ & $\begin{array}{c}0,97(0,12) \\
1,00(0,90-1,10)\end{array}$ & $<0,001^{\star \star}$ \\
\hline $\begin{array}{l}\text { Creatinina urina } \\
(\mathrm{g} / \mathrm{L})\end{array}$ & $\begin{array}{c}1,73(0,83) \\
1,55(1,14-2,19)\end{array}$ & $\begin{array}{c}1,74(0,84) \\
1,47(1,14-2,27)\end{array}$ & $0,499^{\star \star}$ \\
\hline $\begin{array}{l}\text { Microalbuminuria } \\
(\mathrm{mg} / \mathrm{L})\end{array}$ & $\begin{array}{c}3,35(3,87) \\
1,80(0,00-5,37)\end{array}$ & $\begin{array}{c}44,67(64,11) \\
13,55(8,00-82,60)\end{array}$ & $<0,001^{* *}$ \\
\hline $\begin{array}{l}\text { Potássio urina } \\
\text { (mEg/L) }\end{array}$ & $\begin{array}{c}66,07(47,22) \\
58,00(40,00-79,00)\end{array}$ & $\begin{array}{c}82,64(37,20) \\
79,00(54,75-105,00)\end{array}$ & $<0,001^{* *}$ \\
\hline $\begin{array}{l}\text { Sódio urina } \\
(\mathrm{mEq} / \mathrm{L})\end{array}$ & $\begin{array}{c}178,25(49,65) \\
175,00(145,00-211,00)\end{array}$ & $\begin{array}{c}130,88(58,89) \\
140,50(82,00-160,25)\end{array}$ & $<0,001^{* *}$ \\
\hline $\begin{array}{l}\text { KIM-1 } \\
(\mathrm{ng} / \mathrm{ml})\end{array}$ & $\begin{array}{c}0,68(0,67) \\
0,44(0,22-0,99)\end{array}$ & $\begin{array}{c}0,82(0,53) \\
0,70(0,48-1,20)\end{array}$ & $0,151^{*}$ \\
\hline $\begin{array}{l}\text { Cistatina C } \\
(\mathrm{ng} / \mathrm{ml})\end{array}$ & $\begin{array}{c}197,46(167,32) \\
167,13(71,76-341,39)\end{array}$ & $\begin{array}{c}289,57(252,81) \\
232,49(147,64-335,77)\end{array}$ & $0,054^{* *}$ \\
\hline $\begin{array}{l}\text { Ngal soro } \\
(\mathrm{ng} / \mathrm{ml})\end{array}$ & $\begin{array}{c}126,49(82,13) \\
105,19(78,05-160,29)\end{array}$ & $\begin{array}{c}148,01(78,80) \\
120,52(91,88-194,38)\end{array}$ & $<0,001^{* *}$ \\
\hline $\begin{array}{l}\text { Ngal urina } \\
\text { (ng/ml) }\end{array}$ & $\begin{array}{c}130,45(194,90) \\
71,00(51,90-98,03)\end{array}$ & $\begin{array}{c}179,07(132,00) \\
142,36(71,00-268,00)\end{array}$ & $0,039^{* *}$ \\
\hline $\begin{array}{l}\text { FENa } \\
(\%)\end{array}$ & $\begin{array}{c}0,78(0,48) \\
0,71(0,42-0,97)\end{array}$ & $\begin{array}{c}0,61(0,39) \\
0,55(0,29-0,86)\end{array}$ & $0,043^{* *}$ \\
\hline $\begin{array}{l}\text { CKD-epi } \\
\left(\mathrm{ml} / \mathrm{min} / 1,73 \mathrm{~m}^{2}\right)\end{array}$ & $\begin{array}{c}123,00(17,38) \\
123,40(109,40-130,00)\end{array}$ & $\begin{array}{c}112,29(14,23) \\
109,00(98,00-123,40)\end{array}$ & $<0,001^{*}$ \\
\hline $\begin{array}{l}\text { MDRD } \\
\left(\mathrm{mL} / \mathrm{min} / 1,73 \mathrm{~m}^{2}\right)\end{array}$ & $\begin{array}{c}127,20(50,60) \\
116,00(103,40-132,40)\end{array}$ & $\begin{array}{c}108,01(17,00) \\
102,30(92,70-115,50)\end{array}$ & $<0,001^{*}$ \\
\hline
\end{tabular}

Nota: FENa: Fração de excreção de Sódio; eFG CKD-EPI: Estimativa da Taxa de Filtração Glomerular pela fórmula Chronic Kidney Disease Epidemiology; ${ }^{*}$ Teste $t{ }^{* *}$ Wilcoxon Signed Rank Test. 
Tabela 12 - Resultado dos marcadores renais por circuito (Circuito Via Pública),

Pré e Pós-corrida às segundas-feiras $(\mathrm{N}=39)$.

\begin{tabular}{|c|c|c|c|}
\hline Variáveis & $\begin{array}{l}\text { VP pré, } 2^{\text {a }} \text { feira } \\
\text { Media ( } \pm \text { DP) } \\
\text { Mediana (IIQ) }\end{array}$ & $\begin{array}{l}\text { VP pós, } 2^{\text {a }} \text { feira } \\
\text { Media ( } \pm \text { DP) } \\
\text { Mediana (IIQ) }\end{array}$ & Valor $p$ \\
\hline $\begin{array}{l}\text { Creatinina } \\
(\mathrm{mg} / \mathrm{dL})\end{array}$ & $\begin{array}{c}0,86(0,11) \\
0,90(0,80-0,90)\end{array}$ & $\begin{array}{c}0,99(0,12) \\
1,00(0,90-1,10)\end{array}$ & $<0,001^{* *}$ \\
\hline $\begin{array}{l}\text { Creatinina urina } \\
(\mathrm{g} / \mathrm{L})\end{array}$ & $\begin{array}{c}1,33(0,80) \\
1,12(0,80-1,72) \\
\end{array}$ & $\begin{array}{c}1,41(0,95) \\
1,30(0,76-1,86)\end{array}$ & $0,942^{* *}$ \\
\hline $\begin{array}{l}\text { Microalbuminuria } \\
\text { (mg/L) }\end{array}$ & $\begin{array}{c}5,61(10,40) \\
0,80(0,00-5,20)\end{array}$ & $\begin{array}{c}26,57(40,06) \\
10,20(3,50-40,00)\end{array}$ & $<0,001^{\star \star}$ \\
\hline $\begin{array}{l}\text { Potássio urina } \\
\text { (mEq/L) }\end{array}$ & $\begin{array}{c}49,00(22,29) \\
48,0(32,00-61,00)\end{array}$ & $\begin{array}{c}59,48(24,23) \\
56,00(38,00-80,00)\end{array}$ & $0,041^{*}$ \\
\hline $\begin{array}{l}\text { Sódio urina } \\
\text { (mEq/L) }\end{array}$ & $\begin{array}{c}171,79(46,26) \\
167,00(149,00-202,00)\end{array}$ & $\begin{array}{c}149,82(67,05) \\
156,00(95,00-202,00)\end{array}$ & $0,035^{\star *}$ \\
\hline $\begin{array}{l}\mathrm{KIM}-1 \\
\text { (ng/ml) }\end{array}$ & $\begin{array}{c}0,50(0,60) \\
0,35(0,12-0,65)\end{array}$ & $\begin{array}{c}0,93(1,13) \\
0,65(0,23-1,14)\end{array}$ & $0,002^{*}$ \\
\hline $\begin{array}{l}\text { Cistatina C } \\
(\mathrm{ng} / \mathrm{ml})\end{array}$ & $\begin{array}{c}185,05(197,63) \\
136,64(25,39-272,41)\end{array}$ & $\begin{array}{c}268,63(274,58) \\
199,60(119,28-337,70)\end{array}$ & $0,049^{* *}$ \\
\hline $\begin{array}{l}\text { Ngal soro } \\
(\mathrm{ng} / \mathrm{ml})\end{array}$ & $\begin{array}{c}140,07(73,71) \\
119,28(74,65-199,93) \\
\end{array}$ & $\begin{array}{c}142,78(71,29) \\
121,81(87,92-182,74) \\
\end{array}$ & $0,823^{* *}$ \\
\hline $\begin{array}{l}\text { Ngal urina } \\
\text { (ng/ml) }\end{array}$ & $\begin{array}{c}109,00(80,00) \\
75,00(48,19-137,12)\end{array}$ & $\begin{array}{c}150,44(91,00) \\
149,00(91,04-204,00)\end{array}$ & $0,212^{* *}$ \\
\hline $\begin{array}{l}\text { FENa } \\
(\%)\end{array}$ & $\begin{array}{c}1,02(0,68) \\
0,93(0,59-1,20) \\
\end{array}$ & $\begin{array}{c}0,95(0,56) \\
0,95(0,59-1,14) \\
\end{array}$ & $0,994^{* *}$ \\
\hline $\begin{array}{l}\text { CKD-epi } \\
\left(\mathrm{ml} / \mathrm{min} / 1,73 \mathrm{~m}^{2}\right)\end{array}$ & $\begin{array}{c}124,01(12,00) \\
123,40(123,40-130,00)\end{array}$ & $\begin{array}{c}110,00(15,00) \\
109,00(97,00-123,40)\end{array}$ & $<0,001^{*}$ \\
\hline $\begin{array}{l}\text { MDRD } \\
\left(\mathrm{mL} / \mathrm{min} / 1,73 \mathrm{~m}^{2}\right)\end{array}$ & $\begin{array}{c}124,47(22,00) \\
116,00(116,00-132,40)\end{array}$ & $\begin{array}{c}105,25(19,00) \\
102,30(92,00-116,00)\end{array}$ & $<0,001^{*}$ \\
\hline
\end{tabular}

Nota: FENa: Fração de excreção de Sódio; eFG CKD-EPI: Estimativa da Taxa de Filtração

Glomerular pela fórmula Chronic Kidney Disease Epidemiology; * Teste $t{ }^{* *}$ Wilcoxon Signed

Rank Test. 
Tabela 13 - Resultado dos marcadores renais por circuito (Circuito Via Pública),

Pré e Pós-corrida às sextas-feiras $(\mathrm{N}=34)$.

\begin{tabular}{|c|c|c|c|}
\hline Variáveis & $\begin{array}{l}\text { VP pré, 6 } \text { a feira } \text { Media ( } \pm \text { DP) } \\
\text { Mediana (IIQ) }\end{array}$ & $\begin{array}{l}\text { VP pós, 6a feira } \\
\text { Media ( } \pm \text { DP) } \\
\text { Mediana (IIQ) }\end{array}$ & Valor $p$ \\
\hline $\begin{array}{l}\text { Creatinina } \\
(\mathrm{mg} / \mathrm{dL})\end{array}$ & $\begin{array}{c}0,86(0,14) \\
0,80(0,80-0,90)\end{array}$ & $\begin{array}{c}0,95(0,10) \\
0,95(0,90-1,00)\end{array}$ & $<0,001^{* *}$ \\
\hline $\begin{array}{l}\text { Creatinina urina } \\
\text { (g/L) }\end{array}$ & $\begin{array}{c}1,55(0,70) \\
1,56(0,97-1,87) \\
\end{array}$ & $\begin{array}{c}1,40(0,60) \\
1,26(0,91-1,84)\end{array}$ & $0,069^{* *}$ \\
\hline $\begin{array}{l}\text { Microalbuminuria } \\
\text { (mg/L) }\end{array}$ & $\begin{array}{c}6,37(21,17) \\
1,10(0,00-4,40)\end{array}$ & $\begin{array}{c}40,36(85,10) \\
9,75(3,62-35,17)\end{array}$ & $<0,001^{* *}$ \\
\hline $\begin{array}{l}\text { Potássio urina } \\
\text { (mEq/L) }\end{array}$ & $\begin{array}{c}55,35(28,51) \\
46,00(35,00-80,00)\end{array}$ & $\begin{array}{c}68,02(28,57) \\
63,00(44,50-90,75)\end{array}$ & $<0,001^{* *}$ \\
\hline $\begin{array}{l}\text { Sódio urina } \\
\text { (mEq/L) }\end{array}$ & $\begin{array}{c}172,43(61,36) \\
185,00(132,00-221,00)\end{array}$ & $\begin{array}{c}156,41(52,45) \\
164,00(120,75-194,25)\end{array}$ & $0,081^{* *}$ \\
\hline $\begin{array}{l}\mathrm{KIM}-1 \\
\text { (ng/ml) }\end{array}$ & $\begin{array}{c}0,50(0,42) \\
0,30(0,22-0,75)\end{array}$ & $\begin{array}{c}0,81(0,63) \\
0,61(0,38-1,06)\end{array}$ & $<0,001^{*}$ \\
\hline $\begin{array}{l}\text { Cistatina C } \\
\text { (ng/mL) }\end{array}$ & $\begin{array}{c}186,82(157,46) \\
143,12(75,43-247,89)\end{array}$ & $\begin{array}{c}237,06(150,35) \\
197,50(150,47-314,32)\end{array}$ & $0,148^{* *}$ \\
\hline $\begin{array}{l}\text { Ngal soro } \\
\text { (ng/ml) }\end{array}$ & $\begin{array}{c}129,23(130,16) \\
109,25(84,96-140,02)\end{array}$ & $\begin{array}{c}131,85(64,11) \\
138,19(78,92-165,86)\end{array}$ & $0,168^{\star \star}$ \\
\hline $\begin{array}{l}\text { Ngal urina } \\
\text { (ng/ml) }\end{array}$ & $\begin{array}{c}90,00(95,00) \\
63,00(43,34-86,00)\end{array}$ & $\begin{array}{c}129,44(75,34) \\
112,00(85,37-173,00)\end{array}$ & $0,113^{\star *}$ \\
\hline $\begin{array}{l}\text { FENa } \\
(\%)\end{array}$ & $\begin{array}{c}0,78(0,44) \\
0,71(0,42-1,04) \\
\end{array}$ & $\begin{array}{c}0,84(0,36) \\
0,78(0,52-1,01) \\
\end{array}$ & $0,898^{\star \star}$ \\
\hline $\begin{array}{l}\text { CKD-epi } \\
\left(\mathrm{ml} / \mathrm{min} / 1,73 \mathrm{~m}^{2}\right)\end{array}$ & $\begin{array}{c}123,37(15,47) \\
130,00(123,40-130,00)\end{array}$ & $\begin{array}{c}115,00(12,24) \\
116,00(109,00-123,40)\end{array}$ & $0,007^{*}$ \\
\hline $\begin{array}{l}\text { MDRD } \\
\left(\mathrm{mL} / \mathrm{min} / 1,73 \mathrm{~m}^{2}\right)\end{array}$ & $\begin{array}{c}126,40(33,47) \\
132,40(116,00-132,40)\end{array}$ & $\begin{array}{c}109,34(15,00) \\
109,00(102,30-116,00)\end{array}$ & $<0,001^{*}$ \\
\hline
\end{tabular}

Nota: FENa: Fração de excreção de Sódio; eFG CKD-EPI: Estimativa da Taxa de Filtração

Glomerular pela fórmula Chronic Kidney Disease Epidemiology; * Teste $t{ }^{* *}$ Wilcoxon Signed

Rank Test. 


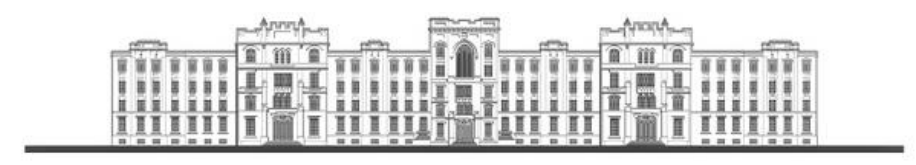

Após a corrida no circuito em PQ (tabelas 10 e 11) podemos observar que os resultados indicam aumento significativo dos marcadores após a corrida, exceto do potássio e da creatinina urinários, e mostra a redução da FENa e da filtração renal após o exercício. Já o circuito VP (tabelas 12 e 13) os resultados evidenciam comportamento das variáveis semelhante ao observado no circuito Parque com exceção da FENa e da NGAL que apresentaram variação significativa.

Abaixo, a tabela 14 mostra que, na análise de regressão multivariada, os resultados indicam alteração dos marcadores após o exercício. Não foi observada associação com circuito e com dia da semana, exceto, para a FENa, que apresentou menor redução no circuito $V P$, com relação ao circuito $P Q$, ao final da corrida. Houve aumento da Creatinina, da microalbuminúria, da Ngal e da KIM-1, e redução da Taxa de Filtração Glomerular, associados apenas à corrida. 


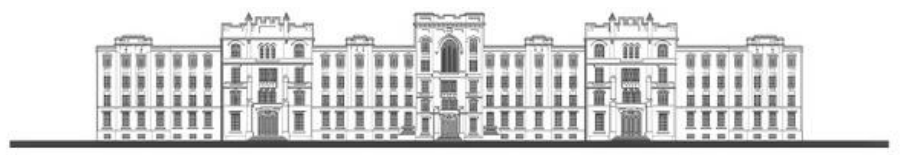

Tabela 14 - Efeito* da realização de exercício e em diferentes ambientes (Parque x Via Pública) em marcadores da função renal.

\begin{tabular}{|c|c|c|c|c|}
\hline Marcadores & Variáveis de Efeito & $\begin{array}{l}\text { Coeficiente de } \\
\text { Regressão }\end{array}$ & Erro Padrão & Valor $p$ \\
\hline $\begin{array}{l}\text { Creatinina** }_{(\mathrm{mg} / \mathrm{dL})} \\
\end{array}$ & Repouso x Exercício & 0,0889 & 0,01682 & $<0,0001$ \\
\hline \multirow{3}{*}{$\begin{array}{l}\mathrm{FENa}^{\star \star} \\
(\%)\end{array}$} & Repouso x Exercício & -03781 & 0,0951 & 0,0086 \\
\hline & $P Q \times V P$ & 0,1261 & 0,0937 & $<0,0001$ \\
\hline & Exercício $\times$ Circuito & 0,4012 & 0,1349 & 0,0032 \\
\hline $\begin{array}{l}\text { CKD-epi } \\
\left(\mathrm{ml} / \mathrm{min} / \mathbf{1}, \mathbf{7 3 m ^ { 2 } )}\right.\end{array}$ & Repouso x Exercício & $-10,7615$ & 1,7811 & $<0,0001$ \\
\hline 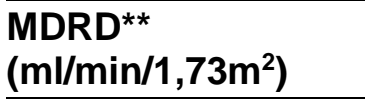 & Repouso x Exercício & $-16,4354$ & 2,7879 & $<0,0001$ \\
\hline $\begin{array}{l}\text { Microalbuminúria* } \\
\text { (mg/L) }\end{array}$ & $\begin{array}{l}\text { Repouso x Exercício } \\
P Q \times V P\end{array}$ & $\begin{array}{r}1,6813 \\
-0,4034\end{array}$ & $\begin{array}{l}0,1290 \\
0,1290\end{array}$ & $\begin{array}{c}<0,0001 \\
0,002\end{array}$ \\
\hline $\begin{array}{l}\mathrm{KIM}-1^{* *} \\
(\mathrm{ng} / \mathrm{ml})\end{array}$ & $\begin{array}{l}\text { Repouso x Exercício } \\
P Q \text { x VP }\end{array}$ & $\begin{array}{c}0,5598 \\
-0,1427 \\
\end{array}$ & $\begin{array}{l}0,0743 \\
0,0743 \\
\end{array}$ & $\begin{array}{c}<0,0001 \\
0,0559 \\
\end{array}$ \\
\hline $\begin{array}{l}\mathrm{NgalU}{ }^{\star \star} \\
(\mathrm{ng} / \mathrm{ml})\end{array}$ & Repouso x Exercício & 0,5724 & 0,1206 & $<0,0001$ \\
\hline
\end{tabular}

Nota: *Modelo de regressão linear com efeito misto, ajustado para IMC; ${ }^{* \star}$ Log: Dados de análise com transformação logarítmica dos valores. 


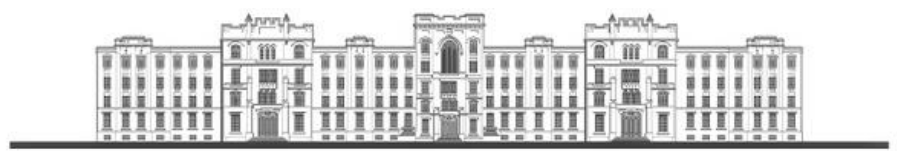

\section{DISCUSSÃO}

Os dados do presente estudo revelaram que a maioria dos marcadores sanguíneos e os marcadores de função renal sofreram alterações significativas após a realização de exercícios físicos com intensidade moderada/alta, não sendo observado diferenças entre circuitos com diferentes concentrações de poluentes, exceto para a FENa.

A proteína CC16, marcador de toxicidade pulmonar, aumentou após os exercícios, sendo a elevação foi maior no circuito $P Q$, onde as concentrações de $\mathrm{MP}_{2,5}$ foram, em média, três vezes menores do que no circuito localizado em vias públicas. Não houve influência significativa do dia da semana (segunda ou sextafeira), em que a corrida foi realizada, nos marcadores estudados.

\section{V.1 - Marcadores Sanguíneos}

Foi observada uma diminuição significativa na contagem de eritrócitos, no hematócrito e na hemoglobina após o exercício, sem diferenças entre os circuitos. Seaton et al. (57), avaliando indivíduos idosos no Reino Unido, encontrou associação negativa entre exposição a poluentes e a hemoglobina, e sugere como mecanismos hemodiluição por influxo de fluído para a circulação ou possível sequestro periférico de hemácias por alteração endotelial com adesão das mesmas em decorrência de reação com moléculas de adesão como ICAM-1 (81). Estudo recente (33) envolvendo 19 atletas, entre 21-27 anos de idade, observou redução do hematócrito após exposição a poluição e exercícios físicos, como observado no presente estudo, mas não de hemoglobina.

O aumento dos leucócitos, de forma mais consistente os neutrófilos, e secundariamente, os monócitos, também foi observado após exposição a 


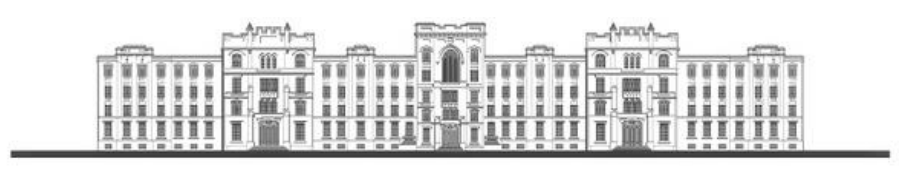

poluentes em estudos experimentais com animais (85) e humanos (81). Entretanto, não foi observado em outros estudos $(25,82)$. Provavelmente diferenças nos momentos da coleta, intensidade do exercício, variação do influxo de leucócito da circulação sistêmica para o pulmão podem estar na raíz das diferenças. Mas, interessante estudo (83) com homens que saíram de uma cidade poluída no Japão e foram de navio para a Antártida e depois retornaram à cidade observou uma redução dos leucócitos e de citocinas inflamatórias a partir dos primeiros dias e durante o trajeto da viagem marítima e elevação quando retornaram ao Japão.

Sua elevação também tem sido observada em estudos como associada à realização de exercícios físicos $(84,85)$ e após exposição a poluição do ar e exercícios $(28,33,86)$. Estudo que avaliou os efeitos de atividade de bicicleta, por 20 minutos, ao longo de uma estrada com elevada concentração de poluentes, comparado à 20 minutos de exercício em sala com ar filtrado (87). Entretanto, o estudo que comparou efeitos de viagens/locomoções por diferentes meios de transporte e exposição à poluição do ar - carro, ônibus, bicicleta e caminhadas- não observou associação da exposição com alterações agudas em marcadores inflamatório e de coagulação do sangue (25). Estudo de base populacional, realizado nos Estados Unidos da América do Norte, com pessoas com idades entre 20-89 anos, revelou associação positiva entre a exposição em longo prazo a MP e a elevação de leucócitos (86). Em nosso estudo, embora elaboramos desenho para avaliação de efeitos agudos, pré e pós exercícios, não se pode descartar efeito crônico, uma vez que os indivíduos avaliados já vinham se exercitando em vias públicas há seis meses. 


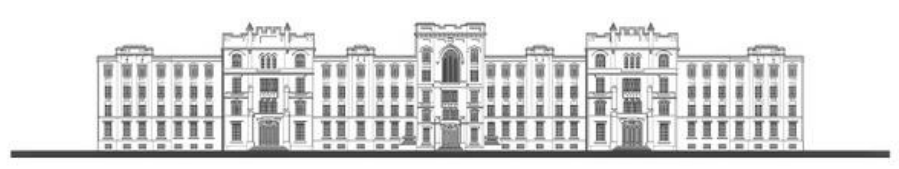

O encurtamento do tempo de coagulação e o aumento das plaquetas, associado a maior risco de eventos tromboembólicos, também foram encontrados em estudos associados, tanto à poluição do ar (87), como ao exercício (88).

Vários estudos mostram que o exercício agudo provoca um aumento transitório do número de plaquetas $(88,89)$. Outros estudos mostram que existe alteração da contagem de plaquetas após exposição à poluição.

Estudo conduzido por Kargarfard et al. publicado em 2015, mostrou que após o exercício em um ambiente poluído, foi registrado um aumento significativo na contagem de plaquetas em adultos saudáveis (33).

Três mecanismos têm sido sugeridos para explicar a inflamação sistêmica associada à inalação de poluentes. O primeiro decorre de stress oxidativo, seguido de inflamação pulmonar e a liberação de mediadores para a circulação sistêmica onde agem em diversos órgãos; o segundo decorre de alteração do sistema nervoso autonômico, que além de induzir à redução da variabilidade frequência cardíaca está associado à inflamação; e o terceiro decorrente da translocação de partículas ultrafinas do pulmão para a circulação sistêmica onde provocam stress oxidativo e inflamação em diversos órgãos e sistemas, principalmente no sistema circulatório $(1,3,81)$.

O aumento dos níveis de CPK e DHL encontrados após a realização dos exercícios pode sinalizar lesão muscular causada pela corrida. Estudos anteriores $(90,91)$ mostraram altos níveis de CPK e DHL em atletas após atividade física intensa. Estas enzimas são biomarcadores de disfunção e morte celular, especialmente os miócitos, e pode sinalizar neste contexto lesão aguda ou lesão muscular repetida (92). 


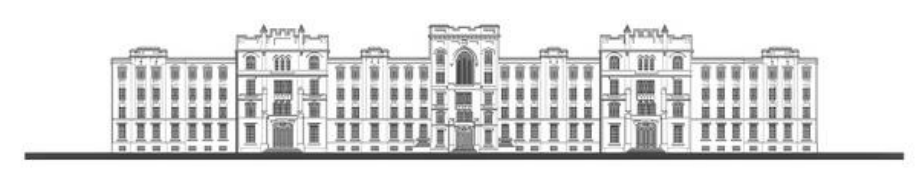

Os mecanismos pelos quais marcadores sanguíneos se alteram após o exercício são bem documentados $(78,79,84,85,92)$. O exercício físico com elevada intensidade induz inflamação após o trauma. O objetivo da ativação desse processo inflamatório, que é local e sistêmico, é uma tentativa de restabelecer a homeostasia orgânica após o exercício. A resposta aguda consiste de ações integradas entre leucócitos, citocinas, proteínas de fase aguda, hormônios e outras moléculas sinalizadoras que controlam a resposta tanto a uma sessão de exercícios, como também direcionam as adaptações decorrentes do treinamento $(23,24,78,89,93,94)$. De forma geral, uma única sessão de exercício físico intenso induz um estado pró-inflamatório, representado por leucocitose transitória, em decorrência de neutrofilia, monocitose e linfocitose, seguida de supressão parcial da imunidade celular. Também são documentados aumentos nas concentrações séricas de CPK e DHL, proteína C-reativa e moléculas de adesão celular, além do aumento na secreção de cortisol e citocinas (95).

\section{V.2 - Proteína CC16}

Com relação ao comportamento da proteína CC16 após o exercício, existem resultados controversos. Corroborando com nossos resultados, a elevação da proteína CC16 após a realização de exercícios também foi observada em diversos outros estudos (96-98). Provavelmente esse aumento esteja relacionado à desidratação do epitélio respiratório durante episódios de hiperventilação e aumento da permeabilidade epitelial. Os achados sobre o comportamento da proteína CC16 concentram-se em estudos onde exercício e poluição foram fatores independentes na avaliação. Em um estudo publicado em 


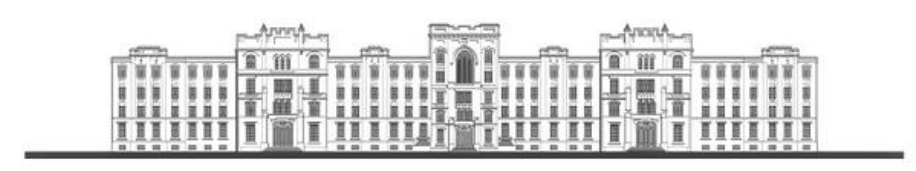

2001 (98), 14 indivíduos jovens e saudáveis foram avaliados em duas situações, sendo uma em simulação de combate a incêndio (como controle sem exercício) e em outra situação, onde participaram de corrida em esteira por 60 minutos (chegando à frequência cardíaca máxima). Sangue e escarro foram coletados antes e 1 hora após o exercício, sendo realizada a mesma coleta antes e depois da simulação de combate a incêndio. Um aumento foi observado nos níveis séricos de proteína CC16 após o exercício, mas não houve diferença entre os resultados obtidos após a realização de atividade física realizada com presença de poluentes. Bolger et al., (96) avaliou 21 jovens, atletas, incluindo 10 indivíduos com histórico de broncoespasmo induzido pelo exercício, onde realizou testes de exercícios de 8 minutos, um dia em ambiente seco e frio e o outro em ambiente quente e úmido. Os resultados mostraram um aumento na proteína CC16 urinária em todos os indivíduos após o exercício, mas este aumento foi menor após a inalação de ar quente e úmido.

Em outro estudo, 22 pacientes com asma e 18 indivíduos saudáveis realizaram teste com exercício em esteira (60). Os pesquisadores avaliaram a temperatura no ar exalado e óxido nítrico exalado após o exercício e proteína CC16 na urina. O aumento nos níveis urinários de CC16 ocorreu com um pico registrado após 30 minutos $(p<0,001)$ com progressiva diminuição dos níveis, embora após 60 minutos ainda eram superiores aos níveis basais da proteína verificados antes do exercício. Nenhuma diferença foi observada entre os indivíduos asmáticos e controles saudáveis, sugerindo os autores que se deva a uma resposta fisiológica e não uma resposta fisiopatológica.

Outros estudos mostram resultados diferentes. Em um estudo conduzido por Brauner et al. (64), que submeteu indivíduos adultos saudáveis ao exercício 


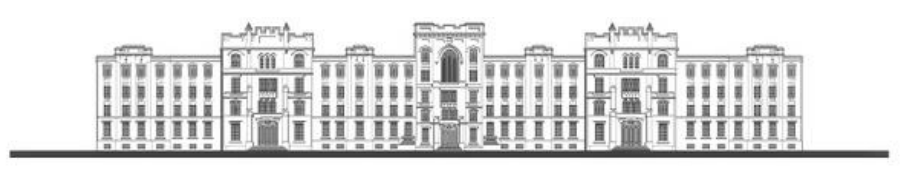

submáximo com bicicleta, em câmara com e sem ar poluído, não foi encontrada associação significativa entre a proteína CC16 e a exposição a poluentes e/ou exercício, muito embora as concentrações de material particulado fino $\left(9,7 \mu \mathrm{g} / \mathrm{m}^{3}\right)$ tenham sido duas a sete vezes inferiores aos observados no presente estudo, nos circuitos $P Q$ e VP, respectivamente.

O aumento da proteína CC16, pode também ter ocorrido também em razão da exposição à $\mathrm{MP}_{2,5}$ cujas concentrações superaram os valores limites recomendados pela OMS (12). A exposição à poluição do ar sozinha parece aumentar a concentração urinária de proteína CC16, mesmo sem associação com a realização de atividade física. Em um estudo realizado em três cidades europeias (Amsterdã, Erfurt e Helsínque) um grupo de pesquisadores observou o comportamento das concentrações urinárias de CC16 através de coletas quinzenais de urina, durante 6 meses, em indivíduos com doença coronariana. Eles também avaliaram as concentrações diárias de $\mathrm{MP}_{2,5}$ e $\mathrm{MP}_{10}$. Em Helsínque, a concentração de proteína CC16 na urina aumentou 20,2\% para cada aumento de $10 \mu \mathrm{g} / \mathrm{m}^{3}$ na concentração de $\mathrm{MP}_{2,5}$ (62). Outro estudo, envolvendo 825 adolescentes de ambos os sexos (99) encontrou uma associação entre a exposição aguda a MP 10 e aumento de proteína $\mathrm{CC} 16$ sérica, mas não encontrou nenhuma associação com a exposição crônica.

Estudo conduzido por Zhao et al. (100) comparou os níveis de proteína CC16 de policiais e trânsito e cidadãos não expostos à poluição e não encontrou associação entre exposição à poluentes e aumento da proteína, enquanto que Guarnieri et al. (101) relatou resultado exatamente oposto, ou seja, encontrou associação entre exposição à poluição do ar e aumento nos níveis de proteína CC16 em policiais de rua na cidade de Pádua, na Itália. 


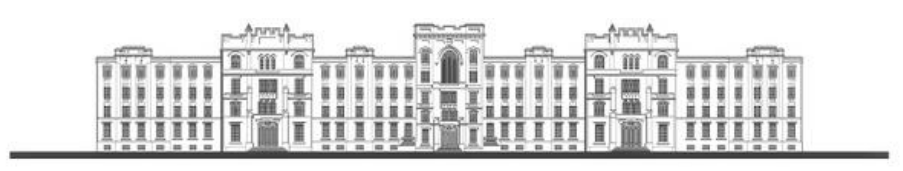

Um outro estudo recentemente publicado (102) avaliou a associação entre a exposição à poluição ambiental e a prevalência de doenças respiratórias em 48 idosos, com ar filtrado no domicílio durante quatro semanas. O estudo monitorou todas as casas, durante 24 horas (o nível interno de $\mathrm{MP}_{2,5}$ foi medido no quarto e na sala de cada casa em uma base semanal) e não encontrou associação entre exposição à MP e aumento da proteína CC16.

Estas descobertas podem ajudar a explicar os resultados do nosso estudo, em que a maior elevação aconteceu no circuito de $P Q$. $O$ circuito $P Q$ está localizado em uma área florestal, com presença de animais, pássaros e com uma grande variedade de árvores, flores e fungos (líquens). É provável que a carga inalada de bioaerossóis tenha sido elevada o suficiente para irritar as vias aéreas dos indivíduos e provocar um novo aumento na produção de proteína CC16, durante exercício realizado dentro deste circuito, embora a concentração do $\mathrm{MP}_{2,5}$ do mesmo ter sido 3 vezes menor do que a registada no circuito VP. Outro estudo publicado em 2015 (103) observou a relação entre a exposição a bioaerossóis e sintomas relacionados com o trabalho, a função pulmonar e biomarcadores de inflamação das vias aéreas em trabalhadores de compostagem. Neste estudo, eles descobriram uma associação entre a presença de esporos de actinomyces e alterações na função pulmonar, mas não encontraram nenhuma relação entre a exposição e aumento de proteínas inflamatórias pulmonares. Em outro estudo foi encontrado resultado oposto (104), ou seja, foi encontrada uma associação entre a exposição à bioaerossóis trabalhadores coletores de lixo e de saneamento e elevação das maiores concentrações de CC16. 


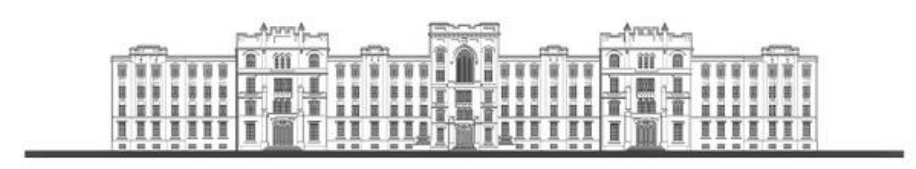

Como a proteína CC16 não foi medida no lavado nasal em nosso estudo, não sabemos se o aumento ocorreu por resposta de produção aumentada da proteína pelos pulmões em resposta à agressão do epitélio, ou se esse aumento está relacionado apenas ao aumento da permeabilidade.

\section{V.3 - Função Renal}

O esforço físico realizado durante os exercícios é uma causa conhecida da modificação da fisiologia renal. O exercício físico de intensidade moderada à intensa pode produzir alterações hemodinâmicas e lesão muscular, e em casos extremos levar à lesão renal aguda. Por outro lado, também é bem documentado o benefício do exercício físico sobre parâmetros renais e que por consequência atenuam doença hipertensiva $(109,110)$.

As alterações em marcadores renais são um tema bastante discutido e parece não restar controvérsias sobre o comportamento da Cistatina $\mathrm{C}$ e Creatinina após o exercício físico (105-108), além de novos marcadores sugeridos como mais sensíveis para detecção precoce de injúria renal aguda $(38,69,73-75,77,109)$.

Um estudo conduzido por Junglee et al. (38), mostrou aumento nos níveis de Ngal plasmática e urinária após exercício físico, e os autores atribuem tal resultado à hipótese de que o aumento da produção de Ngal pelos túbulos proximais e também pelo efeito de olíguria, sejam induzidas pelo exercício, não caracterizando, portanto, lesão renal, mas alteração por desidratação e aumento da concentração urinária. Já no estudo conduzido por Lippi et al. (73) foi encontrada associação entre exercício e aumento da creatinina sérica e da Ngal 


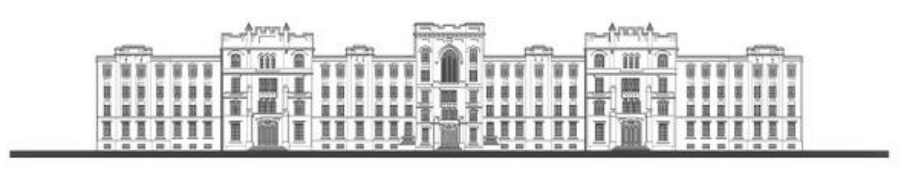

sérica, mas não foi encontrada associação entre exercício e aumento da Ngal urinária.

A alteração de marcadores de função e da estrutura renal após exposição aos poluentes é um tema pouco estudado. Isquemia e toxicidade são considerados os principais fatores fisiopatológicos que conduzem ao desenvolvimento de IRA. Além disso, outros estudos $(110,111)$ tem relatado que a exposição ambiental a produtos químicos durante a vida cotidiana pode ter consequências adversas na função renal podendo contribuir para lesão renal progressiva ao longo da vida. Outro estudo (112), mostrou aumento em marcadores de lesão renal em ratos expostos à poluição depois de receberem uma dose intraperitoneal de cisplatina. Esses resultados evidenciam que indivíduos com doenças renais podem estar em maior risco quando expostos à poluição.

Estudo conduzido por Lue et al. (46), verificou que a taxa de filtração glomerular em indivíduos que viviam próximos às rodovias de grande circulação de veículos era menor do que a verificada em indivíduos que moravam às distâncias maiores dessas rodovias. Um estudo conduzido com cortadores de cana saudáveis, expostos à níveis altos de $\mathrm{MP}_{2,5}$ e a esforço físico em sobrecarga, durante o corte de cana-de-açúcar queimada (49) mostrou diminuição aguda e significativa na taxa de filtração glomerular e um aumento da Creatinina ao final do turno de trabalho, que em $30 \%$ deles eram compatíveis com IRA.

Estudo conduzido na Nicarágua com 200 adolescentes (113) sugere que os achados indicam injúria renal nessa população antes mesmo de exposição ocupacional à poluentes. Isso se deu devido ao crescimento de casos de doença 


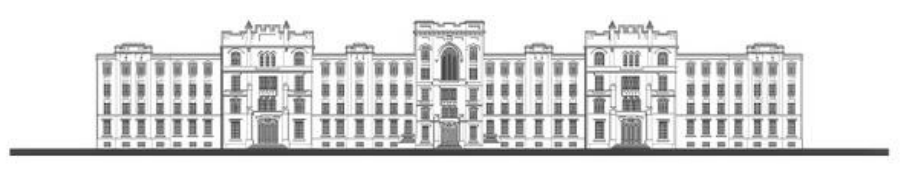

renal aguda diagnosticada em adultos jovens, e o interesse da pesquisa foi levantar se haviam sinais de início dessa alteração ainda na adolescência, entre jovens que ainda não trabalham.

Outro estudo conduzido no mesmo país (48) apresenta resultados que são consistentes com a hipótese de que stress ocupacional e stress térmico do trabalho de cortadores de cana, podem ser associados com o desenvolvimento de doença renal, e que a presença de marcadores de lesão tubular (NGAL, interleucina 18, N-acetil- $\beta$-d-glucosaminidase (NAG), e albumina, além de taxa de filtração glomerular (EGFR)) aumentados nesses indivíduos pode ocorrer em decorrência de lesão tubular repetida.

Em outro estudo (114), a albumina urinária e a creatinina foram medidas entre os membros do Estudo multiétnico de aterosclerose em três visitas durante 2000-2004 em cidades dos Estados Unidos. Foi avaliada a possibilidade de relação entre a excreção de albumina urinária (um marcador subclínico da função microvascular que prevê eventos cardiovasculares), com exposição de partículas ambiente. Os resultados mostraram que para cada incremento de 10 $\mu \mathrm{g} / \mathrm{m}^{3}$ em exposição de $\mathrm{PM}_{10}$ foi associada com uma probabilidade de desenvolver microalbuminúria em 3-4 anos.

A KIM-1 é um marcador pouco estudado, e é sabido que é um marcador indetectável em tecido renal normal. Poucos ensaios clínicos e pesquisas tem mostrado sua relação com intoxicação por poluentes. Um estudo conduzido na Bélgica (115) avaliou a relação entre exposição à cadmio e aumento em marcadores de lesão renal. Os resultados mostraram que os níveis KIM-1 estão positivamente correlacionados com as concentrações de cádmio numa 


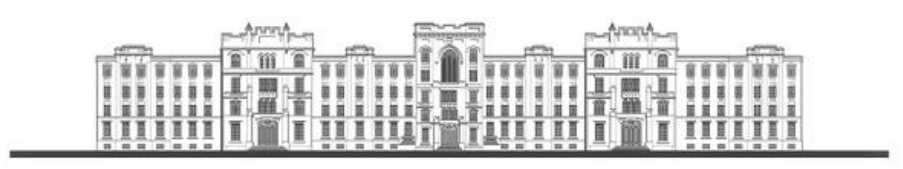

população idosa após exposição a longo prazo e em baixas doses ao cádmio, e que os marcadores clássicos (uréia, microalbuminúria, Alfa 1-microglobulina, beta 2-microglobulina e nitrogênio uréico sérico) não apresentam associação.

A não observância de diferenças nos efeitos da realização de atividade física, em ambientes com diferentes níveis de poluição do ar, na maioria dos marcadores avaliados no presente estudo, pode ser decorrer de vários fatores: um primeiro pode ser o fato de que, o efeito da corrida é de tal magnitude, que supera em muito o efeito da exposição, não permitindo a discriminação dos efeitos entres os dois fatores; um segundo fator é de que os valores de material particulado, apesar de diferirem, eram elevados em ambos os circuitos, dificultando a observância de diferenças nos efeitos; um terceiro fato pode deverse ao fato dos indivíduos estarem em treinamento há cerca de seis meses, quando o estudo foi realizado; e um quarto pode decorrer do período para "lavagem" entre as trocas de corridas entre os circuitos, de 72 horas (6” feira para $2^{\underline{a}}$ feira), ter sido excessivamente curto.

Nenhum estudo, até o momento, estudou a relação entre atividade física e exposição à poluentes sobre marcadores de função renal em adultos jovens. Os resultados do presente estudo são fortemente sugestivos de que a realização de corrida de intensidade moderada a alta ao ar livre pode exercer efeito em marcadores sanguíneos, na toxicidade pulmonar, e principalmente em marcadores de função renal, cujas consequências necessitam de estudos complementares para melhor adequar a pratica de exercícios, cada vez mais frequente e necessária. 


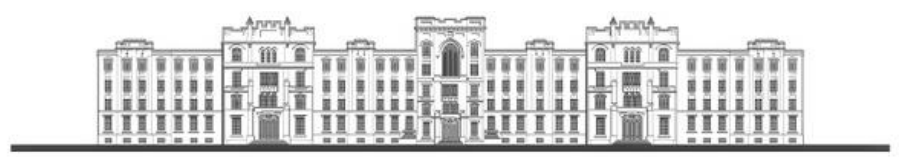

\section{LIMITAÇÕES DO ESTUDO}

Uma das limitações do nosso estudo foi o fato de as medições qualitativas e quantitativas de partículas orgânicas presentes nos ambientes em que os exercícios foram realizados não terem sido realizadas, isto é, a diferença na concentração de bioaerossóis entre os circuitos não foi confirmada. Quanto às amostras de urina, pode ter havido um intervalo diferente entre o fim da corrida e o início da coleta entre os indivíduos. Todos os indivíduos foram treinados e orientados sobre os métodos de coleta dessas amostras, mas esta não foi cronometrada. Esta diferença não foi maior do que 5 minutos entre o fim da corrida e o início da coleta, pois todas foram registradas nos formulários individuais de avaliação, ato este que precedeu todas as coletas de sangue realizadas.

Dado que nosso estudo foi realizado em condições reais, não foi possível identificar a associação de um único fator com os efeitos observados. Além disso, não foi possível determinar os mecanismos subjacentes aos efeitos na saúde observada após exposição à poluição atmosférica. A importância clínica destes resultados deve ser avaliada em estudos longitudinais. 


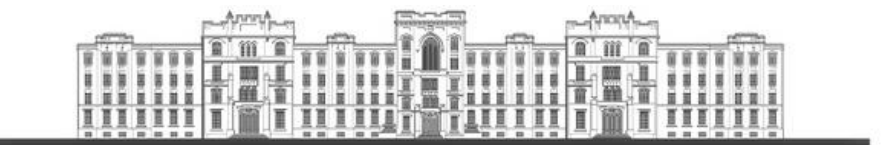

\section{CONCLUSÕES}

Os resultados revelaram que indivíduos jovens e hígidos submetidos à realização de atividade física de moderada a intensa, ao ar livre, com concentrações médias até elevadas de poluentes, apresentaram efeitos decorrentes da toxicidade nas células epiteliais das vias aéreas inferiores, redução da filtração glomerular e alterações em marcadores de danos renais. 


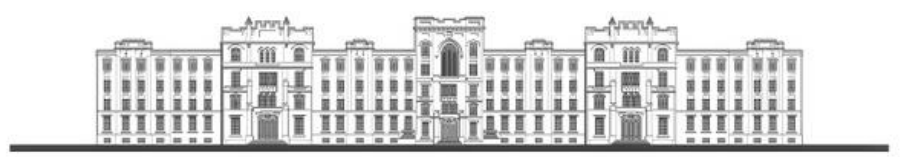

\section{REFERÊNCIAS BIBLIOGRÁFICAS}

1. Brook RD, Franklin B, Cascio W, Hong Y, Howard G, Lipsett M, et al. Air pollution and cardiovascular disease: a statement for healthcare professionals from the Expert Panel on Population and Prevention Science of the American Heart Association. Circulation. 2004;109(21):2655-71.

2. Rivero DH, Soares SR, Lorenzi-Filho G, Saiki M, Godleski JJ, Antonangelo $\mathrm{L}$, et al. Acute cardiopulmonary alterations induced by fine particulate matter of Sao Paulo, Brazil. Toxicol Sci. 2005;85(2):898-905.

3. Brook RD, Rajagopalan S, Pope CA, 3rd, Brook JR, Bhatnagar A, DiezRoux AV, et al. Particulate matter air pollution and cardiovascular disease: An update to the scientific statement from the American Heart Association. Circulation. 2010;121(21):2331-78.

4. World Health Organization. Reducing global health risks through mitigation of short-lived climate pollutants. Geneva, Switzerland. 2015.

5. World Health Organization. Air quality guidelines for particulate matter, ozone, nitrogen dioxide and sulfur dioxide. WHO Press. 2005.

6. De Sario M, Katsouyanni K, Michelozzi P. Climate change, extreme weather events, air pollution and respiratory health in Europe. Eur Respir J. $2013 ; 42(3): 826-43$.

7. Mirsaeidi M, Motahari H, Taghizadeh Khamesi M, Sharifi A, Campos M, Schraufnagel DE. Climate Change and Respiratory Infections. Ann Am Thorac Soc. $2016 ; 13(8): 1223-30$.

8. Gold DR, Samet JM. Air pollution, climate, and heart disease. Circulation. 2013;128(21):e411-4. 


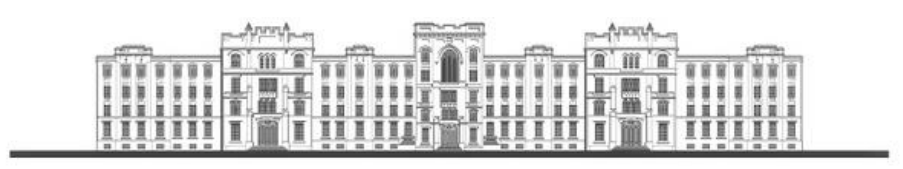

9. von Klot S, Mittleman MA, Dockery DW, Heier M, Meisinger C, Hormann A, et al. Intensity of physical exertion and triggering of myocardial infarction: a case-crossover study. Eur Heart J. 2008;29(15):1881-8.

10. McCreanor J, Cullinan P, Nieuwenhuijsen MJ, Stewart-Evans J, Malliarou E, Jarup L, et al. Respiratory effects of exposure to diesel traffic in persons with asthma. N Engl J Med. 2007;357(23):2348-58.

11. Sheffield PE, Landrigan PJ. Global climate change and children's health: threats and strategies for prevention. Environ Health Perspect. 2011;119(3):2918.

12. World Health Organization. Mortality from ambient air pollution. Global Health Observatory $(\mathrm{GHO})$ data.

13. Bartra J, Mullol J, del Cuvillo A, Davila I, Ferrer M, Jauregui I, et al. Air pollution and allergens. J Investig Allergol Clin Immunol. 2007;17 Suppl 2:3-8.

14. Schwartz J. Air pollution and hospital admissions for the elderly in Detroit, Michigan. Am J Respir Crit Care Med. 1994;150(3):648-55.

15. Dennekamp M, Carey M. Air quality and chronic disease: why action on climate change is also good for health. N S W Public Health Bull. 2010;21(56):115-21.

16. Burnett RT, Dales RE, Raizenne ME, Krewski D, Summers PW, Roberts GR, et al. Effects of low ambient levels of ozone and sulfates on the frequency of respiratory admissions to Ontario hospitals. Environ Res. 1994;65(2):172-94.

17. Arbex MA, de Souza Conceicao GM, Cendon SP, Arbex FF, Lopes AC, Moyses EP, et al. Urban air pollution and chronic obstructive pulmonary diseaserelated emergency department visits. $J$ Epidemiol Community Health. 2009;63(10):777-83. 


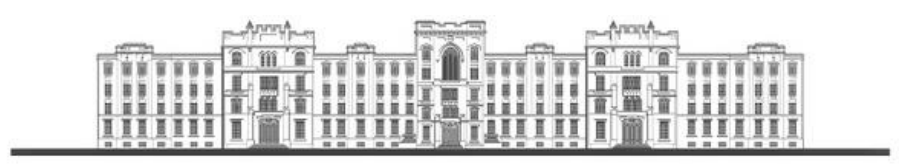

18. Simoni M, Baldacci S, Maio S, Cerrai S, Sarno G, Viegi G. Adverse effects of outdoor pollution in the elderly. J Thorac Dis. 2015;7(1):34-45.

19. Bentayeb M, Simoni M, Baiz N, Norback D, Baldacci S, Maio S, et al. Adverse respiratory effects of outdoor air pollution in the elderly. Int $\mathrm{J}$ Tuberc Lung Dis. 2012;16(9):1149-61.

20. Neupane B, Jerrett M, Burnett RT, Marrie T, Arain A, Loeb M. Long-term exposure to ambient air pollution and risk of hospitalization with communityacquired pneumonia in older adults. Am J Respir Crit Care Med. 2010;181(1):4753.

21. Brook RD. Cardiovascular effects of air pollution. Clin Sci (Lond). 2008;115(6):175-87.

22. Lim SS, Vos T, Flaxman AD, Danaei G, Shibuya K, Adair-Rohani H, et al. A comparative risk assessment of burden of disease and injury attributable to 67 risk factors and risk factor clusters in 21 regions, 1990-2010: a systematic analysis for the Global Burden of Disease Study 2010. Lancet. 2012;380(9859):2224-60.

23. Handschin C, Spiegelman BM. The role of exercise and PGC1alpha in inflammation and chronic disease. Nature. 2008;454(7203):463-9.

24. O'Donovan G, Blazevich AJ, Boreham C, Cooper AR, Crank H, Ekelund $U$, et al. The ABC of Physical Activity for Health: a consensus statement from the British Association of Sport and Exercise Sciences. J Sports Sci. 2010;28(6):57391.

25. Zuurbier M, Hoek G, Oldenwening M, Meliefste K, Krop E, van den Hazel $\mathrm{P}$, et al. In-traffic air pollution exposure and $\mathrm{CC} 16$, blood coagulation, and 


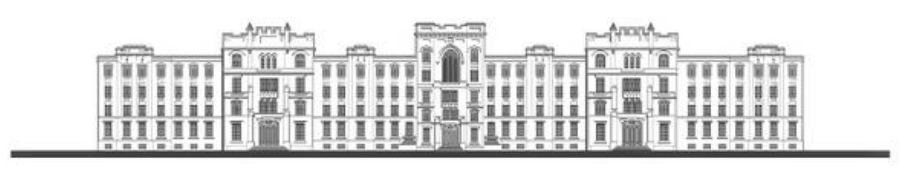

inflammation markers in healthy adults. Environ Health Perspect. 2011;119(10):1384-9.

26. Rundell KW. Effect of air pollution on athlete health and performance. $\mathrm{Br} \mathrm{J}$ Sports Med. 2012;46(6):407-12.

27. Daigle CC, Chalupa DC, Gibb FR, Morrow PE, Oberdorster G, Utell MJ, et al. Ultrafine particle deposition in humans during rest and exercise. Inhal Toxicol. 2003;15(6):539-52.

28. Giles LV, Koehle MS. The health effects of exercising in air pollution. Sports Med. 2014;44(2):223-49.

29. Giorgini P, Rubenfire M, Bard RL, Jackson EA, Ferri C, Brook RD. Air Pollution and Exercise: A REVIEW OF THE CARDIOVASCULAR IMPLICATIONS FOR HEALTH CARE PROFESSIONALS. J Cardiopulm Rehabil Prev. 2016;36(2):84-95.

30. de Hartog JJ, Boogaard H, Nijland H. Do the Health Benefits of Cycling Outweigh the Risks? Environ Health Perspect. 2010;118(8)::1109-16.

31. CETESB - Companhia Ambiental do Estado de São Paulo. Qualidade do ar no estado de São Paulo em 2014. 2014.

32. Tainio M, de Nazelle AJ, Gotschi T, Kahlmeier S, Rojas-Rueda D, Nieuwenhuijsen MJ, et al. Can air pollution negate the health benefits of cycling and walking? Prev Med. 2016;87:233-6.

33. Kargarfard M, Shariat A, Shaw BS, Shaw I, Lam ET, Kheiri A, et al. Effects of polluted air on cardiovascular and hematological parameters after progressive maximal aerobic exercise. Lung. 2015;193(2):275-81.

34. Samet JM, Graff D, Berntsen J, Ghio AJ, Huang YC, Devlin RB. A comparison of studies on the effects of controlled exposure to fine, coarse and 


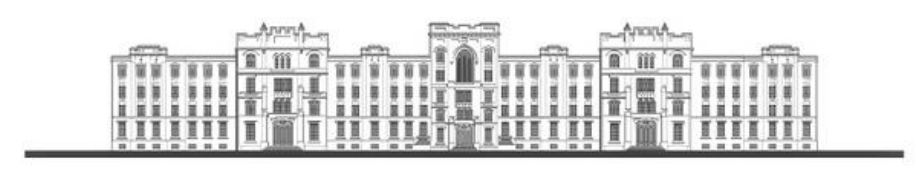

ultrafine ambient particulate matter from a single location. Inhal Toxicol. 2007;19 Suppl 1:29-32.

35. Langrish JP, Mills NL, Chan JK, Leseman DL, Aitken RJ, Fokkens PH, et al. Beneficial cardiovascular effects of reducing exposure to particulate air pollution with a simple facemask. Part Fibre Toxicol. 2009;6:8.

36. Charlton JR, Portilla D, Okusa MD. A basic science view of acute kidney injury biomarkers. Nephrol Dial Transplant. 2014;29(7):1301-11.

37. Herget-Rosenthal S, van Wijk JA, Brocker-Preuss M, Bokenkamp A. Increased urinary cystatin $\mathrm{C}$ reflects structural and functional renal tubular impairment independent of glomerular filtration rate. Clin Biochem. 2007;40(1314):946-51 .

38. Junglee NA, Di Felice U, Dolci A, Fortes MB, Jibani MM, Lemmey AB, et al. Exercising in a hot environment with muscle damage: effects on acute kidney injury biomarkers and kidney function. Am $\mathrm{J}$ Physiol Renal Physiol. 2013;305(6):F813-20.

39. Bangert K, Heslet L, Ghiglione M, O. UL. NGAL is significantly increased in urine and plasma in acute renal failure. Intensive Care Med. 2006;32 (Suppl.1): S10.

40. Medic B, Rovcanin B, Vujovic KS, Obradovic D, Duric D, Prostran M. Evaluation of Novel Biomarkers of Acute Kidney Injury: The Possibilities and Limitations. Curr Med Chem. 2016;23(19):1981-97.

41. Peres LA, Cunha Junior AD, Schafer AJ, Silva AL, Gaspar AD, Scarpari DF, et al. Biomarkers of acute kidney injury. J Bras Nefrol. 2013;35(3):229-36.

42. Kwon SH, Park MY, Jeon JS. KIM-1 expression predicts renal outcomes in IgA nephropathy. Clin Exp Nephrol. 2013;17:359-64. 


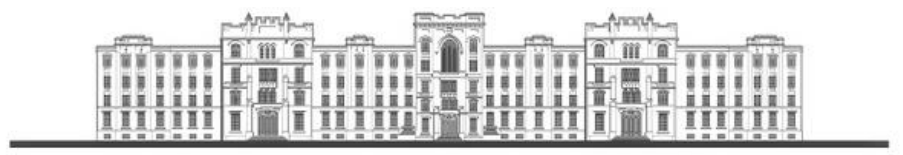

43. Tesch GH. Review: Serum and urine biomarkers of kidney disease: A pathophysiological perspective. Nephrology (Carlton). 2010;15(6):609-16.

44. Urbschat A, Obermuller N, Haferkamp A. Biomarkers of kidney injury. Biomarkers. 2011;16 Suppl 1:S22-30.

45. Abella V, Scotece M, Conde J, Gomez R, Lois A, Pino J, et al. The potential of lipocalin-2/NGAL as biomarker for inflammatory and metabolic diseases. Biomarkers. 2015;20(8):565-71.

46. Lue SH, Wellenius GA, Wilker EH, Mostofsky E, Mittleman MA. Residential proximity to major roadways and renal function. J Epidemiol Community Health. 2013;67(8):629-34.

47. Wesseling C, Aragon A, Gonzalez M, Weiss I, Glaser J, Bobadilla NA, et al. Kidney function in sugarcane cutters in Nicaragua--A longitudinal study of workers at risk of Mesoamerican nephropathy. Environ Res. 2016;147:125-32.

48. Laws RL, Brooks DR, Amador JJ, Weiner DE, Kaufman JS, RamirezRubio O, et al. Biomarkers of Kidney Injury Among Nicaraguan Sugarcane Workers. Am J Kidney Dis. 2016;67(2):209-17.

49. Paula Santos U, Zanetta DM, Terra-Filho M, Burdmann EA. Burnt sugarcane harvesting is associated with acute renal dysfunction. Kidney Int. $2015 ; 87(4): 792-9$.

50. Orth SR, Ogata H, Ritz E. Smoking and the kidney. Nephrol Dial Transplant. 2000;15(10):1509-11.

51. Orth SR. Effects of smoking on systemic and intrarenal hemodynamics: influence on renal function. J Am Soc Nephrol. 2004;15 Suppl 1:S58-63. 


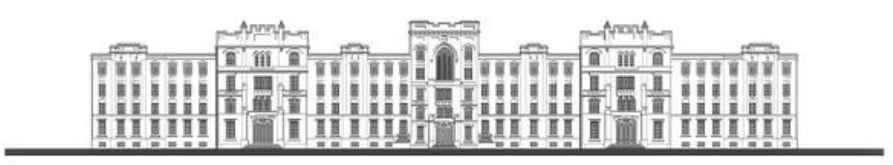

52. Boor P, Casper S, Celec P, Hurbankova M, Beno M, Heidland A, et al. Renal, vascular and cardiac fibrosis in rats exposed to passive smoking and industrial dust fibre amosite. J Cell Mol Med. 2009;13(11-12):4484-91.

53. Wu HJ, Chen KT, Shee BW, Chang HC, Huang YJ, Yang RS. Effects of $24 \mathrm{~h}$ ultra-marathon on biochemical and hematological parameters. World journal of gastroenterology. 2004;10(18):2711-4 .

54. Schwartz J. Air pollution and blood markers of cardiovascular risk. Environ Health Perspect. 2001;109 Suppl 3:405-9.

55. Peters A, Doring A, Wichmann HE, Koenig W. Increased plasma viscosity during an air pollution episode: a link to mortality? Lancet. 1997;349(9065):15827.

56. Seaton A, MacNee W, Donaldson K, Godden D. Particulate air pollution and acute health effects. Lancet. 1995;345(8943):176-8.

57. Seaton A, Soutar A, Crawford V, Elton R, McNerlan S, Cherrie J, et al. Particulate air pollution and the blood. Thorax. 1999;54(11):1027-32.

58. Andersson L, Lundberg PA, Barregard L. Methodological aspects on measurement of Clara cell protein in urine as a biomarker for airway toxicity, compared with serum levels. J Appl Toxicol. 2007;27(1):60-6.

59. Broeckaert F, Clippe A, Knoops B, Hermans C, Bernard A. Clara cell secretory protein (CC16): features as a peripheral lung biomarker. Ann N Y Acad Sci. 2000;923:68-77.

60. Tufvesson E, Svensson H, Ankerst J, Bjermer L. Increase of club cell (Clara) protein (CC16) in plasma and urine after exercise challenge in asthmatics and healthy controls, and correlations to exhaled breath temperature and exhaled nitric oxide. Respir Med. 2013;107(11):1675-81. 


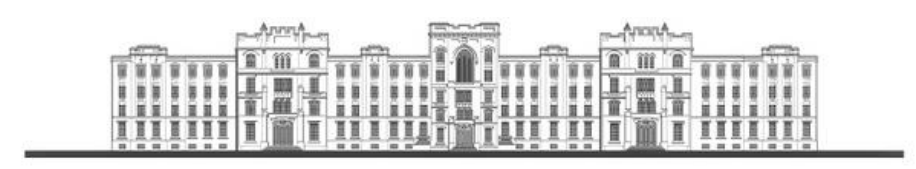

61. Bresolin N L, Bandeira M F S. Atualidades em Nefrologia. Sarvier. 2010:105-9.

62. Timonen KL, Hoek G, Heinrich J, Bernard A, Brunekreef B, de Hartog J, et al. Daily variation in fine and ultrafine particulate air pollution and urinary concentrations of lung Clara cell protein CC16. Occup Environ Med. 2004;61(11):908-14.

63. Gomes EC, Stone V, Florida-James G. Impact of heat and pollution on oxidative stress and CC16 secretion after $8 \mathrm{~km}$ run. Eur J Appl Physiol. $2011 ; 111(9): 2089-97$.

64. Brauner EV, Mortensen J, Moller P, Bernard A, Vinzents P, Wahlin P, et al. Effects of ambient air particulate exposure on blood-gas barrier permeability and lung function. Inhal Toxicol. 2009;21(1):38-47.

65. Collaborators. GMaCoD. Global, regional, and national age-sex specific all-cause and cause-specific mortality for 240 causes of death, 1990-2013: a systematic analysis for the Global Burden of Disease Study 2013. Lancet. 2015.;385.:117-71.

66. Lau L, Al-Ismaili Z, Harel-Sterling M, Pizzi M, Caldwell JS, Piccioni M, et al. Serum cystatin $\mathrm{C}$ for acute kidney injury evaluation in children treated with aminoglycosides. Pediatr Nephrol. 2016.

67. Uchida K, Gotoh A. Measurement of cystatin-C and creatinine in urine. Clin Chim Acta. 2002;323(1-2):121-8.

68. Page MK, Bukki J, Luppa P, Neumeier D. Clinical value of cystatin C determination. Clin Chim Acta. 2000;297(1-2):67-72.

69. Waghmare P, Goswami K. Microalbuminuria: A Mere Marker or An Ominous Sign? J Assoc Physicians India. 2016;64(3):61-5. 


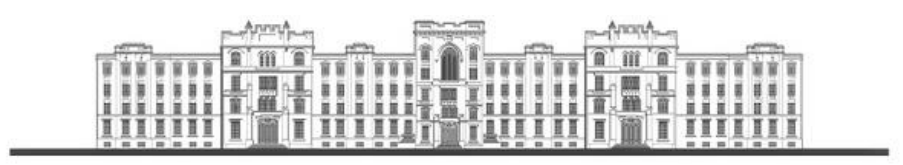

70. Priya VH, Padhy PK, Sastry AS. A study on microalbuminuria in newly diagnosed hypertensive patients. J Assoc Physicians India. 2016;64(1):114.

71. H. A. Biomarcadores na Nefrologia. Sociedade Brasileira de Nefrologia. 2011.

72. Levey AS, Coresh J, Greene T, Stevens LA, Zhang YL, Hendriksen S, et al. Using standardized serum creatinine values in the modification of diet in renal disease study equation for estimating glomerular filtration rate. Ann Intern Med. 2006;145(4):247-54.

73. Lippi G, Sanchis-Gomar F, Salvagno GL, Aloe R, Schena F, Guidi GC. Variation of serum and urinary neutrophil gelatinase associated lipocalin (NGAL) after strenuous physical exercise. Clin Chem Lab Med. 2012;50(9):1585-9.

74. Wasilewska A, Taranta-Janusz K, Debek W, Zoch-Zwierz W, KuroczyckaSaniutycz E. KIM-1 and NGAL: new markers of obstructive nephropathy. Pediatr Nephrol. 2011;26(4):579-86.

75. Waikar SS, Sabbisetti V, Arnlov J, Carlsson AC, Coresh J, Feldman HI, et al. Relationship of proximal tubular injury to chronic kidney disease as assessed by urinary kidney injury molecule-1 in five cohort studies. Nephrol Dial Transplant. 2016;31(9):1460-70.

76. van de Vrie M, Deegens JK, van der Vlag J, Hilbrands LB. Effect of longterm storage of urine samples on measurement of kidney injury molecule 1 (KIM1) and neutrophil gelatinase-associated lipocalin (NGAL). Am J Kidney Dis. 2014;63(4):573-6.

77. Shao X, Tian L, Xu W, Zhang Z, Wang C, Qi C, et al. Diagnostic value of urinary kidney injury molecule 1 for acute kidney injury: a meta-analysis. PLoS One. 2014;9(1):e84131. 


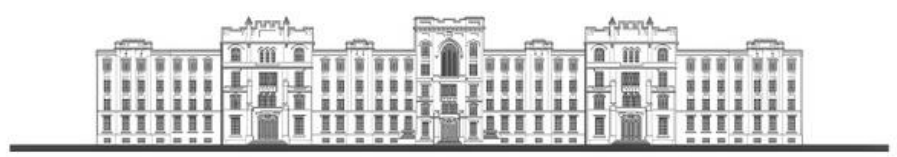

78. Haskell WL, Lee IM, Pate RR, Powell KE, Blair SN, Franklin BA, et al. Physical activity and public health: updated recommendation for adults from the American College of Sports Medicine and the American Heart Association. Circulation. 2007;116(9):1081-93.

79. Ainsworth BE, Haskell WL, Herrmann SD, Meckes N, Bassett DR, Jr., Tudor-Locke C, et al. 2011 Compendium of Physical Activities: a second update of codes and MET values. Med Sci Sports Exerc. 2011;43(8):1575-81.

80. Pinheiro J, Bates D, Debroy S, Sarkar D, Team RC. Linear and Nonlinear Mixed Effects Models. R package version 3.1-110. 2013.

81. Salvi S, Blomberg A, Rudell B, Kelly F, Sandstrom T, Holgate ST, et al. Acute inflammatory responses in the airways and peripheral blood after shortterm exposure to diesel exhaust in healthy human volunteers. Am J Respir Crit Care Med. 1999;159(3):702-9.

82. Krishnan RM, Sullivan JH, Carlsten C, Wilkerson HW, Beyer RP, Bammler T, et al. A randomized cross-over study of inhalation of diesel exhaust, hematological indices, and endothelial markers in humans. Part Fibre Toxicol. $2013 ; 10: 7$

83. Sakai M, Sato Y, Sato S, Ihara S, Onizuka M, Sakakibara Y, et al. Effect of relocating to areas of reduced atmospheric particulate matter levels on the human circulating leukocyte count. J Appl Physiol (1985). 2004;97(5):1774-80.

84. Fallon KE, Sivyer G, Sivyer K, Dare A. The biochemistry of runners in a 1600 km ultramarathon. Br J Sports Med. 1999;33(4):264-9.

85. Gleeson M. Biochemical and immunological markers of over-training. Journal of sports science \& medicine. 2002;1(2):31-41. 


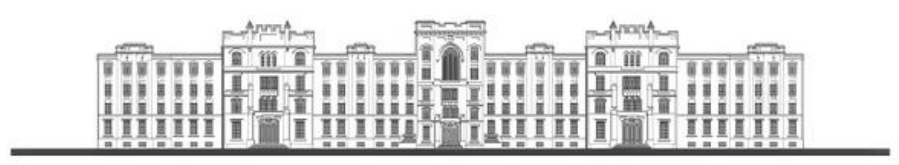

86. Oliveira RS, Barros Neto TL, Braga AL, Raso V, Pereira LA, Morette SR, et al. Impact of acute exposure to air pollution on the cardiorespiratory performance of military firemen. Braz J Med Biol Res. 2006;39(12):1643-9.

87. Davidson S B, G PD. Time course of blood volume change with carbono monoxide inhalation and its contribution to the overall cardiovascular response. Arch Toxicol,. 1988;61(4):306-13.

88. Niemela M, Kangastupa $\mathrm{P}$, Niemela $\mathrm{O}$, Bloigu $R$, Juvonen T. Individual responses in biomarkers of health after marathon and half-marathon running: is age a factor in troponin changes? Scand J Clin Lab Invest. 2016;76(7):575-80.

89. Heber S, Volf I. Effects of Physical (In)activity on Platelet Function. Biomed Res Int. 2015;2015:165078.

90. Ferreira HR, Ferreira PG, Loures JP, Fernandes Filho J, Fernandes LC, Buck HS, et al. Acute Oxidative Effect and Muscle Damage after a Maximum 4 Min Test in High Performance Athletes. PLoS One. 2016;11(4):e0153709.

91. Wiecek M, Maciejczyk M, Szymura J, Szygula Z. Effect of maximalintensity exercise on systemic nitro-oxidative stress in men and women. Redox Rep. 2016:1-7.

92. Brancaccio P, Lippi G, Maffulli N. Biochemical markers of muscular damage. Clin Chem Lab Med. 2010;48(6):757-67.

93. Pettersson J, Hindorf U, Persson P, Bengtsson T, Malmqvist U, Werkstrom $\mathrm{V}$, et al. Muscular exercise can cause highly pathological liver function tests in healthy men. Br J Clin Pharmacol. 2008;65(2):253-9.

94. Wagner CT, Kroll MH, Chow TW, Hellums JD, Schafer AI. Epinephrine and shear stress synergistically induce platelet aggregation via a mechanism that partially bypasses VWF-GP IB interactions. Biorheology. 1996;33(3):209-29. 


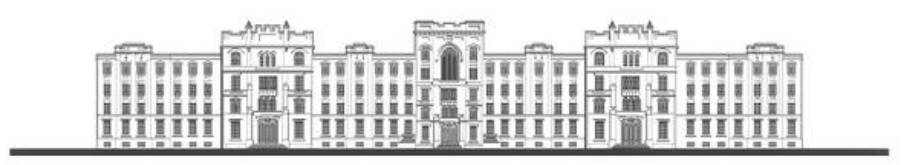

95. Schneider CM, Dennehy CA, Rodearmel SJ, Hayward JR. Effects of physical activity on creatine phosphokinase and the isoenzyme creatine kinaseMB. Ann Emerg Med. 1995;25(4):520-4.

96. Bolger C, Tufvesson E, Anderson SD, Devereux G, Ayres JG, Bjermer L, et al. Effect of inspired air conditions on exercise-induced bronchoconstriction and urinary CC16 levels in athletes. J Appl Physiol (1985). 2011;111(4):1059-65. 97. Bolger C, Tufvesson E, Sue-Chu M, Devereux G, Ayres JG, Bjermer L, et al. Hyperpnea-induced bronchoconstriction and urinary CC16 levels in athletes. Med Sci Sports Exerc. 2011;43(7):1207-13.

98. Nanson CJ, Burgess JL, Robin M, Bernard AM. Exercise alters serum pneumoprotein concentrations. Respir Physiol. 2001;127(2-3):259-65.

99. Provost EB, Chaumont A, Kicinski M, Cox B, Fierens F, Bernard A, et al. Serum levels of club cell secretory protein (Clara) and short- and long-term exposure to particulate air pollution in adolescents. Environ Int. 2014;68:66-70. 100. Zhao J, Bo L, Gong C, Cheng P, Kan H, Xie Y, et al. Preliminary study to explore gene-PM2.5 interactive effects on respiratory system in traffic policemen. Int J Occup Med Environ Health. 2015;28(6):971-83.

101. Guarnieri G, Lodde V, Ferrazzoni S, Bordini A, Venturini R, Zaninotto M, et al. [Acute effects of environmental pollution on the urban vigilants airways]. $G$ Ital Med Lav Ergon. 2007;29(3 Suppl):838-40.

102. Karottki DG, Spilak M, Frederiksen M, Jovanovic Andersen Z, Madsen AM, Ketzel $\mathrm{M}$, et al. Indoor and outdoor exposure to ultrafine, fine and microbiologically derived particulate matter related to cardiovascular and respiratory effects in a panel of elderly urban citizens. Int $\mathrm{J}$ Environ Res Public Health. 2015;12(2):1667-86. 


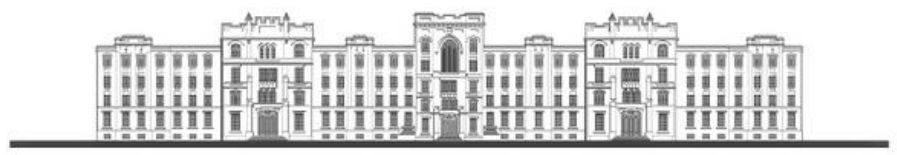

103. Heldal KK, Madso L, Eduard W. Airway inflammation among compost workers exposed to actinomycetes spores. Ann Agric Environ Med. 2015;22(2):253-8.

104. Steiner D, Jeggli S, Tschopp A, Bernard A, Oppliger A, Hilfiker S, et al. Clara cell protein and surfactant protein B in garbage collectors and in wastewater workers exposed to bioaerosols. Int Arch Occup Environ Health. 2005;78(3):18997.

105. Hargrove WO, Jr., Wise LJ, Jr. A laboratory study of urinary changes following exercise. Bull Tulane Univ Med Fac. 1957;17(1):9-18.

106. Hobson W. Urinary output of creatine and creatinine associated with physical exercise, and its relationship to carbohydrate metabolism. Biochem J. 1939;33(9):1425-31.

107. Miyai T, Ogata M. Changes in the concentrations of urinary proteins after physical exercise. Acta Med Okayama. 1990;44(5):263-6.

108. Rougier G, Babin JP, Dupuy G. [Study in man of the blood and urinary effects of intense muscular exercise on certain elements of protein metabolism]. Pathol Biol (Paris). 1975;23(1):35-43.

109. Schrezenmeier EV, Barasch J, Budde K, Westhoff T, Schmidt-Ott KM. Biomarkers in acute kidney injury - pathophysiological basis and clinical performance. Acta Physiol (Oxf). 2016.

110. Nemmar A, Al-Salam S, Zia S, Yasin J, Al Husseni I, Ali BH. Diesel exhaust particles in the lung aggravate experimental acute renal failure. Toxicol Sci. 2010;113(1):267-77.

111. Kataria A, Trasande L, Trachtman $\mathrm{H}$. The effects of environmental chemicals on renal function. Nat Rev Nephrol. 2015;11(10):610-25. 


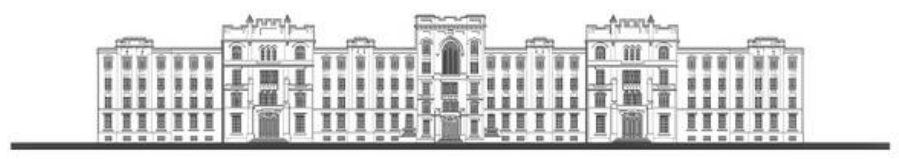

112. Ali BH, Al Za'abi M, Shalaby A, Manoj P, Waly MI, Yasin J, et al. The effect of thymoquinone treatment on the combined renal and pulmonary toxicity of cisplatin and diesel exhaust particles. Exp Biol Med (Maywood). 2015;240(12):1698-707.

113. Ramirez-Rubio O, Amador JJ, Kaufman JS, Weiner DE, Parikh CR, Khan $\mathrm{U}$, et al. Urine biomarkers of kidney injury among adolescents in Nicaragua, a region affected by an epidemic of chronic kidney disease of unknown aetiology. Nephrol Dial Transplant. 2016;31(3):424-32.

114. O'Neill MS, Diez-Roux AV, Auchincloss AH, Franklin TG, Jacobs DR, Jr., Astor $\mathrm{BC}$, et al. Airborne particulate matter exposure and urinary albumin excretion: the Multi-Ethnic Study of Atherosclerosis. Occup Environ Med. 2008;65(8):534-40.

115. Pennemans V, De Winter LM, Munters E, Nawrot TS, Van Kerkhove E, Rigo JM, et al. The association between urinary kidney injury molecule 1 and urinary cadmium in elderly during long-term, low-dose cadmium exposure: a pilot study. Environ Health. 2011;10:77. 


\section{ANEXOS}

\section{Anexo 1 - Parecer da Comissão Científica}

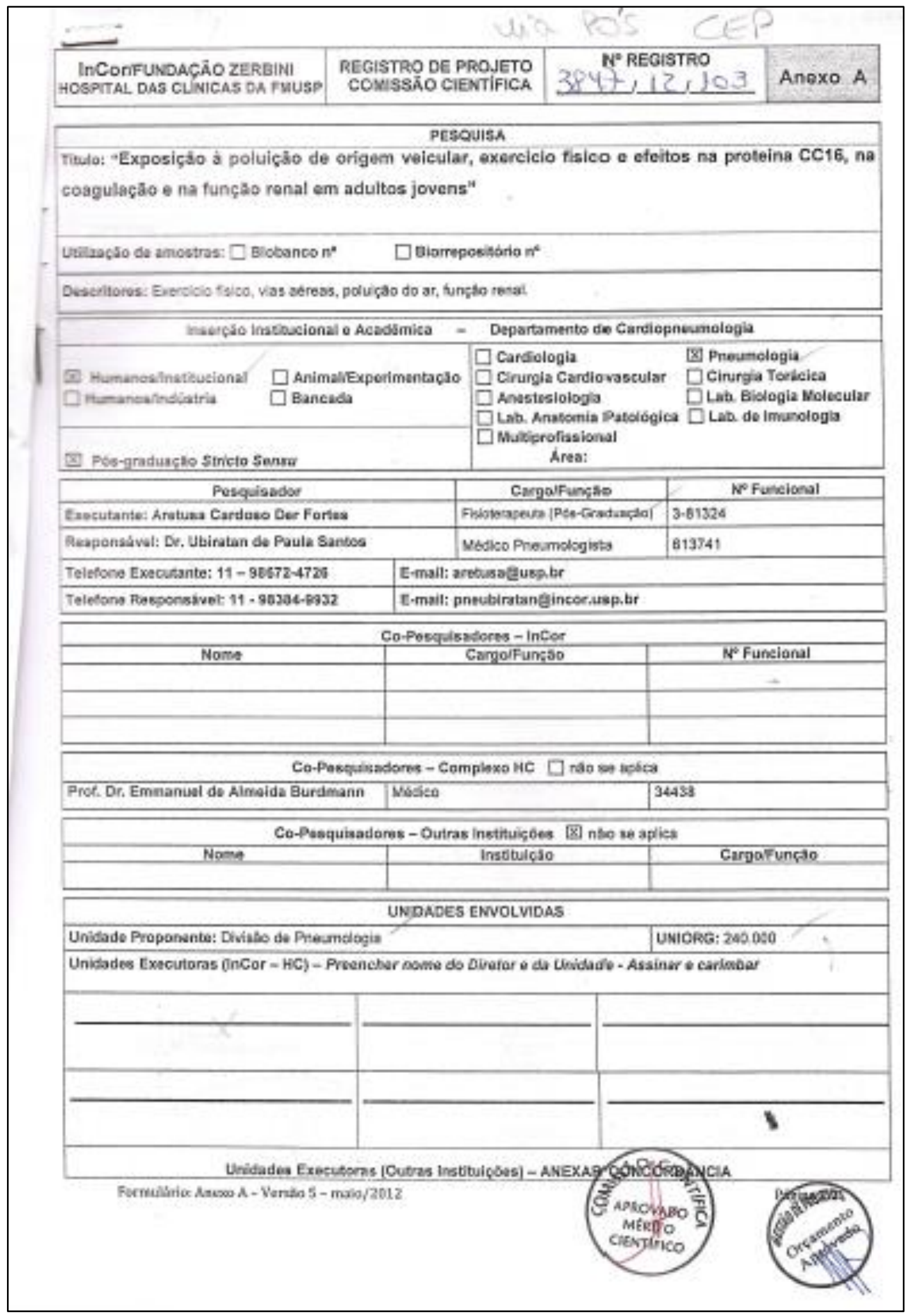




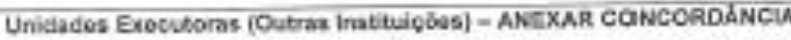

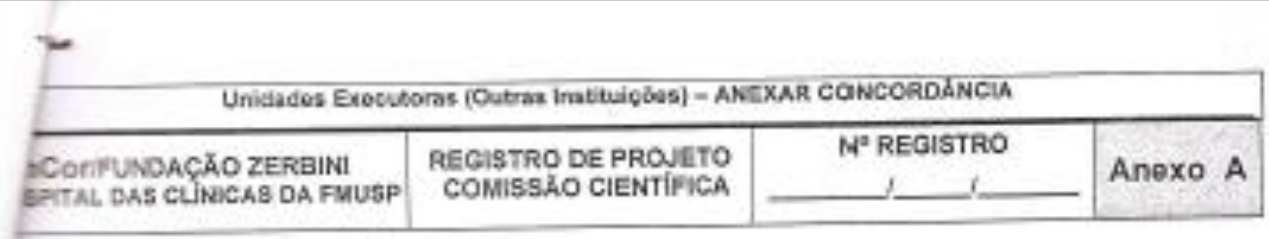

\begin{tabular}{|c|c|c|}
\hline 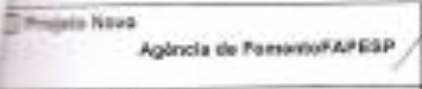 & $\begin{array}{l}\text { Agencis: Fipeip } \\
\text { Presens we: }\end{array}$ & Welar sostivada: \\
\hline 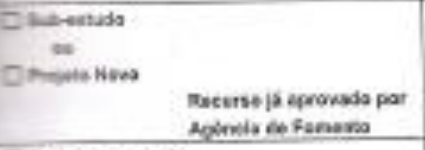 & 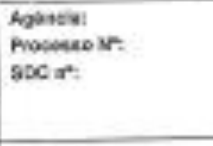 & 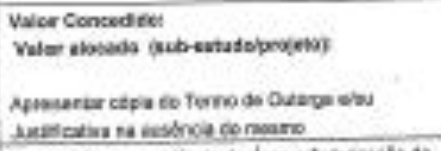 \\
\hline 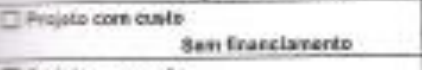 & Whar I & 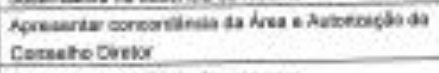 \\
\hline 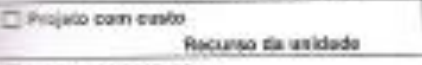 & Walsen & 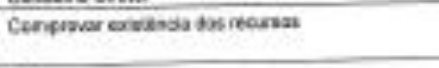 \\
\hline 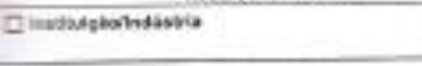 & Provanuear: & 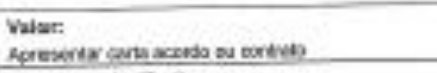 \\
\hline C Frowe tee ceata & & Roresaive denVlexila \\
\hline
\end{tabular}

TERMO DE COMPROMISSO

- Oechar fer a intaestutura necessina incuindo área fisics e prefscianais capactados.

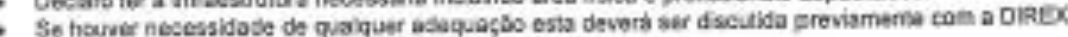

- Currieuluw Laties atual crado nes dismos 30 des.

- A "Tasa de Publ capla de Aftigo" devers ser comamplada pela Reserva Teterice cosso haja aprovagâs do projeto pela FAFESP.

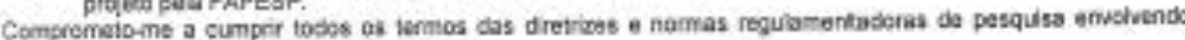
veres humanges dartre os quais destacamos.

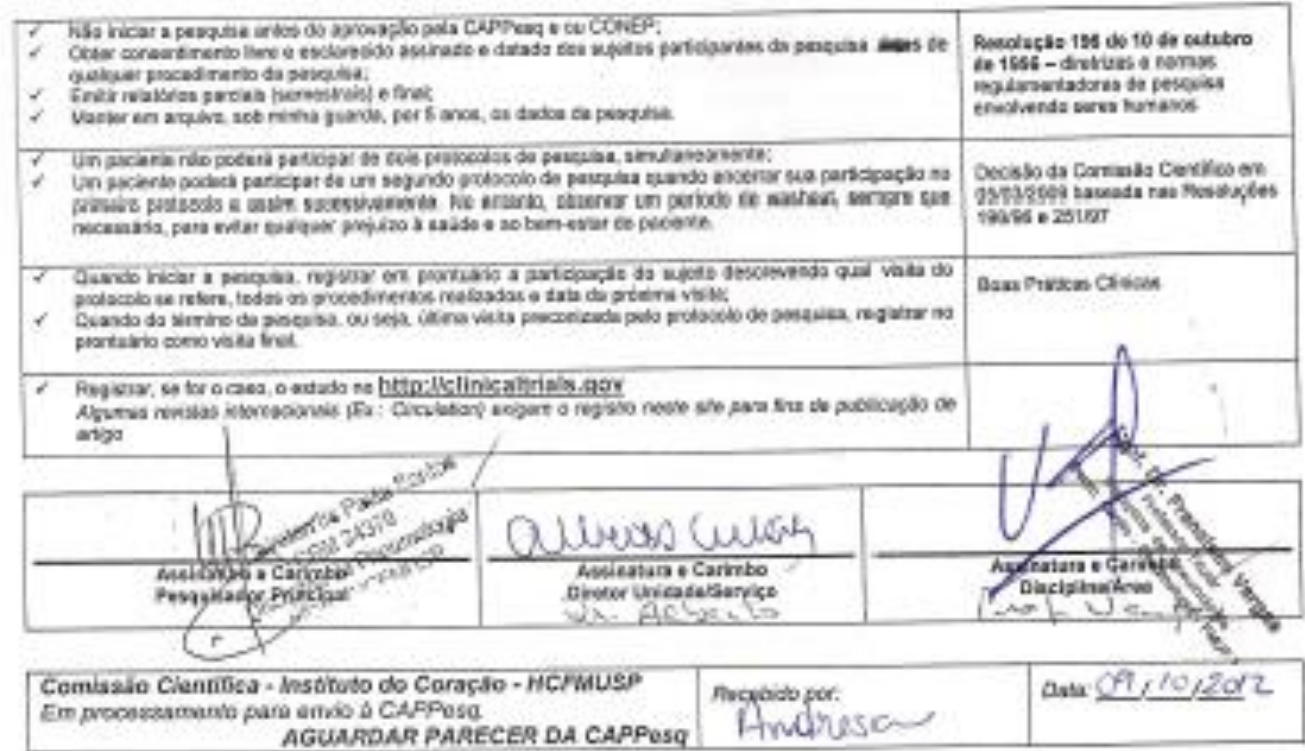




\section{ANÁLISE ORÇAMENTÁRIA DE PROJETOS}

Data de Recebimenta: 05/10/2012 16:11

$50 \mathrm{C}$ ndo mencionads

Unidade: Divisto de Pneumologis

Uniorr: 240.000

Trudo: Exposicito o poluicito de origem weicular, exerdio fisioo e efeitos na proveina CC16, na coagulactio e na

funcaso sonial em aduitos jovens.

Fesquisador Responsgvel: Dr, Utiratan de Paula Samtos

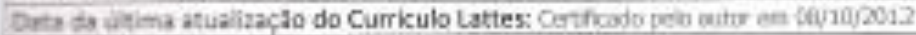

Feasusador Executante: Aretusa Cardose Der Fortes

Praso de Execusto do Projeto: 24 meses

Somsa da Financiamento: FAPESP

Situaça: Solicitedo ( ) Cancedido ( ) A solictar $\{\mathrm{X}\}$

Whor Tota: $25111,571,53$

Valor Alocado parz este projeto: 105 111671,53

\section{DBJETIVOS}

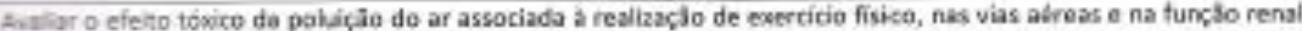
St adukos jovens do sexo mascuino. $O$ estuda visa tambdnt avaliar a inflamaçio das vias aéreas, funçăa renal e a nucciacto encre marcadores de alteracodes resciratórias e reazis.

\section{METOOOLOGIA}

arricipartis do estudo 40 indwiduos que, por pelo menos 4 wazes na semana durarte 1 hora por dia, pratiquern corride de rua. Eles seräo dividibos em dois grupos aleatócios e correrío per dois circultos de $7 \mathrm{~km}$ diferentes.

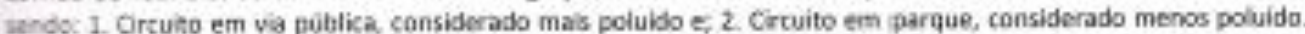
Serao realizados exames pre e pas cerrida, sendo: 1. Exame fisico IPA, FC, Saturaça de exigenis e CO exaladol; 2. Coleta de sangue para analse (hemograma completo com contagem de plaquetas, TP, TPA, Cotatina C, Creatinina, Sodio e Potassio, CPK, OHL, TGO+TGP, Carboxhemodobinak 3. Coleta de urina para andise (Creatinina, Sodio e Potassio, Urina tipo k, Proteinas de celulas clara Cc16. Microslbuminüra, Marcadores do bsalo tubular renal KIM-1 e Nyal| Tambem serajo feitas as medidas de poluentes e de varibveis tlimaticas durante as corridas atraves da ralizactio de mediçes continuas de material particulado ( $\mathrm{PM}_{2}$ al, do temperatura e da curidade relatha do ar. Os dois grupos correrto por ambos os circuitos totaforando 320 exames.

D̈BSERVACÓES

Fiojeto solicita apoio FAPES com materiais de consums, permacente e serviço de terceiras, condizentes.

Nowve necessdade de esclarecimentos por pacte do Responshuel? NSo (X) Sim f

Em caso afirmativo, anesaf relatória a parte.

\begin{tabular}{|c|c|c|}
\hline \multicolumn{3}{|c|}{ STATUS } \\
\hline $\begin{array}{l}\text { Aorpvade poe: } \\
\text { disus }\end{array}$ & $\begin{array}{l}\text { Datk: } \\
09 / 10 / 2012\end{array}$ & 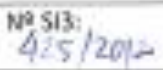 \\
\hline
\end{tabular}

Relatoria de Questionamento ao Pesquistover 
Anexo 2 - Aprovação do Comitê de Ética.

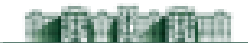 \\ MEDICINA \\ TSP \\ COMITÊ DE ÉTICA EM PESQUISA}

\section{APROVAÇÃO}

- Comitê de Ética em Pesquisa da Faculdade de Medicina da Universidade de São Paulo, em sessão de 28/11/2012, APROVOU o Protocolo de Pesquisa no 391/12 intitulado: "EXPOSIÇão À POLUIÇÃO DE ORIGEM VEICULAR, EXERCíCIO FÍSICO E EFEITOS NA PROTÉ́Na CC16, NA COAGULAÇÃo E NA FUNÇÃo RENAL EM ADULTos JOVENS." apresentado pela COMISSÃo CIENTífiCA DO INCOR.

Cabe ao pesquisador elaborar e apresentar ao CEPFMUSP, os relatórios parciais e final sobre a pesquisa (Resolução do Conselho Nacional de Saúde $n^{\circ} 196$, de 10/10/1996, inciso IX.2, letra "c").

Pesquisador (a) Responsável: Ubiratan de Paula Santos

Pesquisador (a) Executante: Aretusa Cardoso Der Fortes

CEP-FMUSP, 29 de Novembro de 2012.

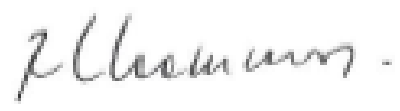

Prof. Dr. Roger Chammas Coordenador Comitê de Ética em Pesquisa 
Anexo 3 - Termo de Consentimento Livre e Esclarecido

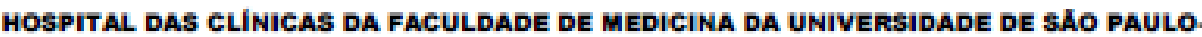
HCFMUSP

TERMO DE CONSENTIMENTO UVRE E ESCLARECIDO

DADOS DE IDENTIFICAÇÅ DO SUJETTO DA PESQUISA OU RESPONSÁVEL LEGAL

1. NONE

DOCUNENTO DEIDENTIDADE No: SEXO: M $\square$ F

DATA NASCIMENTO:

ENDEREÇO:

BAIRRO:

CEP:

$N^{2}$.

2. RESPONSAVEL LEGAL:

NATUREZA (grau de parentesco, tutor, curador etc.)

DOCUMENTO DEIDENTIDADE N" :

DATA NASCIMENTO: _ _ _ _ _

ENDEREÇO

BAIRRO: TELEFONES:

CIDADE:

CEP:

TELEFONES: ( CIDADE

DADOS SOBRE A PESQUISA

1. TITULO DO PROTOCOLO DE PESOUISA: "Exposiçäo a polulçäo de origem veicular, exercicio flaico $\theta$ efeltos na proteina CC16, na coagulaç30 $\theta$ na funçaso renal em adultos jovens".

PESQUISADOR RESPONSAVEL: Dr. Ubiratan de Paula Sartos

CARGO/FUNCAO: Reeponsavel pelos ambulatorlos de Cessaça de Tabaglsmo $\theta$ de Doenças Respiratorlas Ocupacionals e Amblentals da Divis 30 de Pneumologla do instituto do Coraçåo (inCor).

INSCRIÇÅ CRM N: 34379

UNIDADE DO HCFMUSP: Divlaso de Pneumologla - InCor HCFMUSP

2. AVALAÇ̊ DO RISCO DA PESQUISA:

$\begin{array}{ll}\text { RISCO MINIMO } X & \text { RISCO MEDIO } \\ \text { RISCO BAIXO } \square & \text { RISCO MAIOR } \square\end{array}$

3. DURACุÅO DA PESQUISA: 36 meses.

HOSPITAL DAS CLINICAS DA FACULDADE DE MEDICINA DA UNIVERSIDADE DE SAO PAULO-HCFMUSP

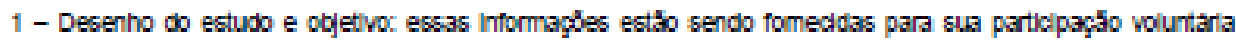
neste estudo, que visa avaliar 06 efeitos agudos da poluç̧5̆o sobre a sua respiraçăo e o seu funcionamento dos 
rins. Voce e outros 39 partcipantes serălo submetidos a avallaçles antes e apos 36 comid3s de 45 minutos que voce realiza habltuaimente as segundas e sextas-felras. Estas avallaçbes ajudard̆o a avallar o efeito da realzaçấ do seu exercicio na presença de ar poluido;

2 - Voce sera submetido, antes e apos $\mathbf{x}$ comidas que serăo realizadzs 2 vezes em cada clrcutto (sendo um circulto no parque do Horto Florestal e outro nas avenidas proximas ao Campo de Marte) a coleta de amostras de sangue (cerca de $20 \mathrm{ml}$ ) e de urina e meddas da sua pressfo arterial e de sua frequencla cardlaca:

3 - A coleta de urna sera simples em 3 reciplentes pequenos e a coleta de sangue sera felta atraves de uma agulina que sera introduzda em uma vela de seu antebraço direlto ou esquerdo. A medida de pressto arterlal sera feita com um aparehno medidor de pressfo e a medida da frequencla cardlaca atraves de um frequencimetro;

4-O único desconforto esperado e o da punçăo de sua vela para retirada do sangue;

5 - Os resultados dos exames realzados serâo correlaclonados com as concentraçbles de poluentes que serăo medidas durante a cornda e servirâo para avaliar possivel efelto dos poluentes na sua capacidade de exercicio e nos seus slstemas resplratorio e renal. Essas informaçdes poderdo melhor orientar no futuro locals mals adequados para a pratica de exercicio fisico.

6 - Garantla de acesso: en qualquer etapa do estudo, voce tera acesso aos pronssionals responsavels pela pesqulsa para esclarecimento de eventuals dúmdas. O princlpal Investigador e o Dr. Ubiratan de Paula Sartos que pode ser encontrado no endereço Av. Dr. Eneas de Agular Carvalho, bioco 2, $8^{\circ}$ andar no telefone 2661-5191. Em casso de consideraçăo ou dúvida sobre a etica da pesquisa, entre em contato com o Comite de Ética em Pesquisa (CEP) - A. Dr. Amaldo, 455, $1^{\circ}$ andar - Instituto Oscar Freire - e-mal: capoesonahonet.uso.bc

7 - E garantda a liberdade da retirada de consentimento a qualquer momento e debar de participar do estudo, sem qualquer prejulzo a cortinuidade de seu tratamento na institulç5̆o;

8 - Direlto de corfidencialdade - As Informaçbes obtid3s serăo analsad3s em conjunto com outros pacientes, nấ sendo dlvulgada a identifcaçăo de nenhum paclente:

9 - Todo particlpante tem o drelto de ser mantdo ahuallzado sobre $\propto s$ resultados parclals da pesquisa ou de resultados que sejam do conhecimento dos pesquisadores;

10 - Despesas e compensaçbes: năo ha despesas pessoals para o participante em qualquer fase do estudo, Inciưndo exames e consultas. Tambem năo ha compensaçăo fnancelra relacionada a sua participaçăo. Se existir qualquer despesa aclcional, ela sera absorvida pelo orçamento da pesquisa.

11 - Por fim, e fimado o compromisso do pesquisador de utllzar os dados e o material coletado somente para esta pesquisa. 


\section{HOSPITAL DAS CLINICAS DA FACULDADE DE MEDICINA DA UNIVERSIDADE} DE SAOO PAULO-HCFMUSP

Acredito ter sido sufficientemente Informado a respetto das informaçles que I ou que foram Idas para mim, descrevendo o estudo "Exposiçă a polulçă de origem veicular, exercicio fisico $\theta$ efeltos na proteina CC16, na coagulaç:so e na funç:ăo renal em adultos jowens".

Eu discutil com o Dr. Ubiratan de Paula Santos sobre a minha decisáo em participar nesse estudo. Ficaram claros para mim quals sato os propositos do estudo, os procedmentos a serem realzados, seus descorfortos e niscos, 36 garantas de confldencialdade e de esclaredmentos permanentes. Ficou claro tambem que minha particlpaçá e isenta de despesas e que terho garantla do acesso a tratamento hospltalar quando necessario. Concordo voluntarlamente em particlpar deste estudo e poderel retirar o meu consentimento a quaiquer momento, antes ou durante o mesmo, sem penaldades ou prejulzo ou perda de quaiquer beneficio que eu possa ter adquirido, ou no meu atendimento neste Serviço.

Assinatura do paclenteirepresentante legal

Data

Deciaro que ootive de forma aproprlada e volurtarla o Consentimento Luve e Esclarecido deste paclente ou representante legal para a participaça neste estudo.

Dr. Ublratan de Paula Santos

Pesqulsador responsavel

\section{Aretusa Cardoso}

Peequlaador executante 
Anexo 4 - Ficha de registro individual e controle de coletas.

1 - Ficha de registro individual

Cód:

\section{Dados gerais}

Nome:

Contato:

Nome da Mãe:

Data nascimento:

RG:

Tabagismo: Nảo ( ) Sim ( )

Peso: kg Altura: $\mathrm{cm}$

Sexo: masculino

PA: $\mathrm{mmHg}$

FC: bpm

\section{Avaliações - SEMANA 1}

$1^{3}$ Avaliaçäo - Data:

Circuito:

Vias públicas ( )

Horto ( )

Avaliacão Pré-Corrida - horário de inicio:

PA1: $\mathrm{mmHg}$

PA2: $\mathrm{mmHg}$

FC1: bpm

FC2: bpm

Co exalado: PPM

$\mathrm{COHb}$ :

Avaliação Pós-Corrida - horário de início:

PA1: $\mathrm{mmHg}$

FC1 bpm

Co exalado:
PA2: $\mathrm{mmHg}$

FC2: bpm

$\mathrm{COHb}$ : 
Annent

$2^{a}$ Avaliação - Data:

Circuito:

Vias públicas (

Horto ( )

Avaliacão Pré-Corrida - horário de início:

PA1:

$\mathrm{mmHg}$

FC1: bpm

Co exalado: PPM

Avaliação Pós-Corrida - horário de início:

PA1:

$\mathrm{mmHg}$

FC1:

bpm

Co exalado:
PA2

$\mathrm{FC} 2$ $\mathrm{mmHg}$

PPM

$\mathrm{COHb}$ bpm
$\mathrm{FC} 2$ bpm

$\mathrm{COHb}$ :

PA2: $\mathrm{mmHg}$ 